\title{
On topic
}

\section{ACCM CLINICAL PRACTICE PARAMETERS FOR \\ HEMODYNAMIC SUPPORT OF PEDIATRIC AND NEONATAL SEPTIC SHOCK}

Revision Committee:

ACCM Liaison Timothy S Yeh, Ed Conway, Bruce Greenwald

LWW/SCCM Liaison Lynn Retford, Sarah Kraus

Taskforce Chairperson Joseph A. Carcillo

Clinical Signs and Hemodynamic Variables to Direct Treatment of Shock/Goals/Therapeutic Endpoints John Lin Lin_Jo@kids.wustl.edu (subgroup chair)

Alan L Davis aland3@gmail.com

Niranjan Kissoon nkissoon@cw.bc.ca

Martha C. Kutko martha_kutko@hotmail.com

Suchitra Ranjit suchitraranjit@yahoo.co.in

Mark Hall, Mark.Hall@nationwidechildrens.org

Allan Doctor doctor_a@kids.wustl.edu

Timothy Cornell ttcornel@med.umich.edu

Jacki Weingarten jweingar@montefiore.org

\section{Intravascular Access}

Tim Yeh tyeh@barnabashealth.org (subgroup chair)

Yong Yun Han yhan@cmh.edu

Heidi Flori hflori@mail.cho.org

\section{Fluid therapy/Fluid Resuscitation}

Alan L. Davis aland3@gmail.com (subgroup chair)

Michele Mariscalco mmariscalco@kumc.edu

Allan Doctor doctor_a@kids.wustl.edu

Simon Nadel s.nadel@imperial.ac.uk

Jeanine Graf jmgraf@texaschildrens.org

Suchitra Ranjit suchitraranjit@yahoo.co.in

Mark Peters mark.peters@ucl.ac.uk

Hector Wong hector.wong@cchmc.org

\section{Mechanical Ventilation/Airway \& Breathing}

Bonnie Stojadinovic bstojadi@mcw.edu (subgroup chair)

Alan Duncan alan.duncan@ health.wa.gov.au

Mark Hall, Mark.Hall@ nationwidechildrens.org

Jacki Weingarten jweingar@montefiore.org

Ira Cheifetz ira.cheifetz@duke.edu

Sedation for Invasive Procedures or Intubation

Regina Okhuysen-Cawley rokhuyse@mdanderson.org (subgroup chair)

Mark Peters mark.peters@ucl.ac.uk

Fola Odetola fodetola@med.umich.edu

Invasive and Non-Invasive Hemodynamic Monitoring

Rajesh K. Aneja anejar@upmc.edu (subgroup chair)

Renuka Mehta remehta@gru.edu

Eduardo Schnizler eduardoschnitzler@gmail.com

Howard Jeffries howard.jeffries@ seattlechildrens.org 
Lynn Hernan lynnhernan@gmail.com

Aaron Zuckerberg bbfan33@ comcast.net

Suchitra Ranjit suchitraranjit@yahoo.co.in

Inotropes/Hemodynamic Support

Monica Relvas mrelvas@aol.com

Ana Lia Graciano alg2341@gmail.com

Saraswati Kache skache@stanford.edu

Jose Irazuzta irazuzta@aol.com

Rajesh K. Aneja anejar@upmc.edu

Alexander Kon kon.sandiego@gmail.com

Elizabeth Iselin elizabeth.iselin.md@gmail.com

Karen Choong choongk@mcmaster.ca

\section{Vasodilators/Hemodynamic Support and PPHN Therapies}

Peter Skippen pskippen@cw.bc.ca (subgroup chair)

Marc-Andre Dugas marc-andre.dugas@mail.chuq.qc.ca

Howard Jeffries howard.jeffries@seattlechildrens.org

Andreas Deymann adeymann@iupui.edu

Karin Reuter-Rice karin.reuter-rice@duke.edu

Joe Brierley brierj@gosh.nhs.uk

Sara Skache Skache@stanford.edu

Arno Zaritskyzarital@peds.ufl.edu

\section{Vasopressors/Hemodynamic Support}

Ranna Rozenfeld rrozenfeld@northwestern.edu (subgroup chair)

Jon Feldman jon.feldman@kp.org

Allan de Caen allan.decaen@albertahealthservices.ca

Eduardo Schnitzler eschnitzle@cas.austral.edu.ar

Glucose, Calcium, Thyroid, and Hydrocortisone Replacement

Andreas Deymann adeymann@iupui.edu (subgroup chair)

Adalberto Torres, Jr. atorres@nemours.org

Eric Williams eawillia@texaschildrens.org

Kristine Parbuoni kristine.rapan@gmail.com

\section{Extracorporeal Therapies}

Trung Nguyen tcnguyen@ @exaschildrens.org (subgroup chair)

Peter Skippen pskippen@cw.bc.ca

Timothy Cornell ttcornel@med.umich.edu

Timothy Maul maultm@upmc.edu

Graeme Maclaren gmaclaren@iinet.net.au

James Fortenberry james.fortenberry@ choa.org

\section{Bundle Development Taskforce}

Eric Williams(chair) eawillia@texaschildrens.org (subgroup chair)

Scott L. Weiss WeissS@email.chop.edu

Julie C. Fitzgerald FITZGERALDJ@email.chop.edu

Bruce Greenwald bmgreen@med.cornell.edu

Monica Relvas mrelvas@aol.com

Chhavi Katyal ckatyal@montefiore.org

Edward Conway econway@ chpnet.org

Halden Scott halden.scott@ childrenscolorado.org

Fran Balamuth balamuthf@email.chop.edu

Raina Paulrpaul@wakehealth.edu

Elise van der Jagt Elise_Van_der_Jagt@URMC.Rochester.edu 
Background: The American College of Critical Care Medicine (ACCM) provided 2002 and 2007 guidelines for hemodynamic support of newborn and pediatric septic shock.

Objective: Provide the 2014 update of the 2007 ACCM Clinical Guidelines for Hemodynamic Support of Neonates and Children with Septic Shock.

Participants: Society of Critical Care Medicine (SCCM) members were identified from general solicitation at SCCM Educational and Scientific Symposia (2006-2014).

Methods: The PUBMED/MEDLINE/EMBASE literature (2006-14) was searched by the SCCM librarian using the keywords: sepsis, septicemia, septic shock, endotoxemia, persistent pulmonary hypertension, nitric oxide, ECMO, and ACCM Guidelines in the newborn and pediatric age groups. Using a modified Delphi method and the GRADE system, recommendations were developed with > 90\% consensus.

Results: The 2002 and 2007 guidelines were widely disseminated, translated into Spanish and Portuguese, and incorporated into SCCM and AHA/PALS sanctioned recommendations. The review of new literature highlights two tertiary pediatric centers that implemented quality improvement initiatives to improve early septic shock recognition and first hour compliance to these guidelines. Improved compliance reduced hospital mortality from $4 \%$ to $2 \%$. Analysis of Global Sepsis Initiative data in resource rich developed and developing nations further showed improved hospital mortality with compliance to first hour and stabilization guideline recommendations.

Conclusions: The major new recommendation in the 2014 update is consideration of institution - specific use of 1) a Recognition Bundle containing a trigger tool for rapid identification of patients with septic shock, 2) a Resuscitation and Stabilization Bundle to help adherence to best practice principles, and 3) a Performance Bundle to identify and overcome perceived barriers to the pursuit of best practice principles. 
In 1998 the Institute of Medicine called for establishment of best practice guidelines across medicine. In 2002 and 2007, the ACCM Clinical Practice Parameters for Hemodynamic Support of Pediatric and Neonatal Shock ${ }^{1,2}$ were published in part to replicate the reported outcomes associated with implementation of 'best clinical practices' (mortality rates of $0-5 \%$ in previously healthy ${ }^{3-5}$ and $10 \%$ in chronically ill children with septic shock ${ }^{5}$ ). Of note neonatal and pediatric severe sepsis outcomes were already improving prior to 2002 with the advent of neonatal and pediatric intensive care (reduction in mortality from $97 \%$ to $9 \%$ ), ${ }^{6-9}$ and were markedly better than in adults (9\% compared to $28 \%$ mortality). ${ }^{8}$ There are two purposes served by this 2014 update of these 2002/2007 Clinical Practice Parameters. First, this 2014 update examines and grades new studies performed to test the utility and efficacy of the 2007 updated recommendations. Second, this 2014 update examines and grades relevant new treatment and outcome studies to determine to what degree, if any, the 2007 guidelines should be modified.

METHODS Clinical investigators and clinicians affiliated with the Society of Critical Care Medicine who had special interest in hemodynamic support of pediatric patients with sepsis volunteered to be members of the update task force. Subcommittees were formed to review and grade the literature using the GRADE system. A strong recommendation received the 'number' grade 1 and a weak recommendation received the 'number' grade 2. The strength of the literature used to support these 'number' grade recommendations was given 'letter' grades with $\mathrm{A}=$ to multiple randomized controlled trials and at least one metanalysis, $\mathrm{B}=$ one randomized controlled trial, $\mathrm{C}=$ cohort, case control studies, and D expert opinion and case reports. There is common discordance between strength of recommendation and strength of literature providing impetus to study most all recommendations made.

The literature was accrued by the SCCM librarian in part by searching PUBMED/MEDLINE/EMBASE using the following keywords: sepsis, septicemia, septic shock, endotoxemia, persistent pulmonary hypertension, nitric oxide, and ECMO. The search was narrowed to identify studies specifically relevant to children and newborns. Best Practice Outcomes were identified and described clinical practice in these centers 
was used as a model. A modified Delphi method was used attaining $90 \%$ agreement in the recommendations made.

\section{RESULTS}

\section{Evolution of the 2002, 2007, and 2014 guidelines}

Many studies have tested the observations and recommendations of the 2002 and 2007 guidelines. The findings have been mixed in the 'resource poor setting' where there is not access to mechanical ventilators, intravenous infusion pumps, inotrope medications and intensive care monitoring. Wills and colleagues (NEJM, 2005) demonstrated near $100 \%$ survival when fluid resuscitation was provided to children with dengue shock in the first hour. ${ }^{10}$ In contrast, Maitland et al (NEJM 2011) found fluid boluses were harmful compared to maintenance intravenous fluid infusion and blood transfusion in severe malaria endemic sub-Saharan Africa. ${ }^{11}$ The Maitland study included a large population of children with severe malaria and anemia, and excluded cases with severe malnutrition or gastroenteritis; whereas, the Wills study only included a population of children with Dengue Shock, with capillary leak, hemoconcentration, and dehydration . Importantly, neither of these studies formally tested fluid bolus use as recommended in the 2002 and 2007 ACCM guidelines because boluses were given without attention to the presence of rales and hepatomegaly in the patients. The 2002 and 2007 ACCM guidelines specifically recommend against fluid boluses when rales or hepatomegaly are present, and instead recommend inotropic support for these patients. ${ }^{1,2}$ The basic tenet of fluid resuscitation proposed in the ACCM guidelines is that 'some do' and 'some do not' require fluid resuscitation. Hypovolemic shock patients require fluid boluses, whereas euvolemic and hyper-volemic patients do not. Severely anemic patients require blood transfusion, severely malnourished children require slow feeding, and patients with congestive heart failure or fluid overload require inotropes and diuretics, not fluid boluses.

Studies in the resource rich setting where mechanical ventilators, intravenous infusion pumps, inotrope medications and intensive care monitoring (allowing for recognition of severe anemia, hypoproteinemia, and fluid overload/congestive sates) are available, have uniformly favored use of the ACCM/PALS guidelines. Han 
and colleagues showed an association between early use of practice consistent with the 2002 guidelines in the community hospital and improved outcomes in newborns and children (mortality rate $8 \%$ vs 38\%; NNT $=3.3$ ). Every hour that went by without restoration of normal blood pressure for age and capillary refill $<3$ seconds was associated with a two-fold increase in adjusted mortality odds ratio. ${ }^{12}$ Ninis and colleagues similarly reported an association between delay in inotrope resuscitation and a 22.6-fold increased adjusted mortality odds ratio in meningococcal septic shock which led to the new guideline recommendation in 2007 that inotropes be started through peripheral infusion in children with fluid refractory septic shock until central access is attained. ${ }^{13}$ Codreiro et al tested this 2007 recommendation in a randomized trial and found that use of peripheral adrenaline infusion reduced mortality to $7 \%$ compared to $20 \%$ with use of peripheral dopamine infusion until central access was attained. ${ }^{14}$ de Oliveira reported in a randomized trial that use of the 2002 guidelines with continuous central venous oxygen saturation $\left(\mathrm{ScvO}_{2}\right)$ monitoring and therapy directed to maintenance of $\mathrm{ScvO}_{2}$ $>70 \%$, reduced mortality from $39 \%$ to $12 \%(\mathrm{NNT}=3.6)$ compared to therapy directed only to blood pressure and capillary refill. ${ }^{15}$ Sankar et al, has now corroborated this finding in a cohort study in a population of Indian children showing that directing therapy to $\mathrm{ScvO} 2$ was associated with improved outcome with a number needed to treat $=5 .{ }^{16}$ In a before and after study, Lin reported that implementation of the 2002 guidelines in a U.S. tertiary center achieved best practice outcome with a fluid refractory shock 28-day mortality of $3 \%$ and hospital mortality of $6 \%$ (3\% in previously healthy children; $9 \%$ in chronically ill children). ${ }^{17}$ This outcome matched the 'best practice outcomes' targeted by the 2002 guidelines. ${ }^{3-5}$, Similar to the experience of St. Mary's Hospital before 2002, ${ }^{4}$ Sophia Children's Hospital in Rotterdam also reported a reduction in mortality rate from purpura and severe sepsis from $20 \%$ to $1 \%$ after implementation of 2002 guideline-based therapy in the referral center, transport system and tertiary care settings. ${ }^{18}$ Both of these centers also used high flux continuous renal replacement therapy (CRRT) and fresh frozen plasma infusion directed to the goal of normal INR (prothrombin time). 
There is general consensus that these studies indirectly and directly support the utility and efficacy of implementation of the time-sensitive, goal-directed recommendations of the 2002 and 2007 ACCM/PALS guidelines in the 'resource rich' setting. In this regard, since 2007 there has been a major effort in the USA to test the first hour recommendations in pediatric academic centers in the American Academy of Pediatrics collaborative Septic Shock consortium which is dedicated to quality improvement in septic shock recognition and treatment. There have been four studies conducted in tertiary pediatric emergency departments that have examined adherence to ACCM/PALS guidelines for sepsis resuscitation in the first hour. ${ }^{19-22}$ Together, these studies demonstrated incomplete adherence to recommended goals for administration of IV fluids, antibiotics, and vasoactive agents. Subsequent quality-directed efforts from these studies showed improvement in both process metrics (e.g., decreased time to administration of intravenous fluids, antibiotics, and peripheral vasoactive agents) $)^{19-22}$ and outcome metrics, including hospital and PICU length of stay and mortality. ${ }^{20-22}$ Importantly, all quality improvement studies were predicated on rapid identification of patients with suspected septic shock to trigger rapid clinician evaluation and implementation of appropriate resuscitation efforts. Multiple elements have been incorporated into trigger tools with success by several institutions, ${ }^{23}$ however, there has been notable variation in the algorithms used at each institution, and none have sufficient evidence to fully endorse as a specific tool. Given the complexity of resource allocation and implementation, it appears reasonable that each institution could locally develop their trigger tool while further studies refine the derivation and validation of an optimally sensitive and specific sepsis trigger tool. ${ }^{24}$

From the best practice model standpoint, Paul et al implemented a hospital-wide quality improvement initiative to improve compliance with all five elements of the ACCM/PALS guidelines first hour recommendations; 1) recognition, 2) establishing intravenous access, 3) starting intravenous fluids and resuscitation as needed, 4) administering antibiotics, and 5) starting vasoactive agents if needed. ${ }^{22}$ Achievement of $100 \%$ compliance required a number of human interaction interventions including use of time clocks set to 
have time going from 0-60 minutes rather than 60-0 minutes, that resulted in an increase in number of cases between death occurrence $(\mathrm{p}<0.05)$ with an overall reduction in hospital mortality from $4.0 \%$ to $1.7 \%$.

Han et al analyzed the international Global Sepsis Initiative data base which included children from 'resource rich' settings in Europe, North America, and South America in order to derive 'three element' bundles associated with improved outcomes. ${ }^{25}$ The first hour/ emergency department three element bundle included 1) reversal of shock defined by normal blood pressure and capillary refill $<3$ seconds, 2) provision of antibiotics, and 3) provision of D10 containing intravenous fluid infusion. The stabilization / PICU three element bundle included 1) reversal of shock defined by maintaining normal MAP-CVP for age and ScVO2 > 70\%, 2) timely provision of the appropriate sensitive antibiotic and source control, and 3) maintenance of effective tidal volumes between $6-8 \mathrm{~mL} / \mathrm{kg}$ in children mechanically ventilated with ARDS. Reversal of shock was associated with use of the 2007 ACCM/PALS guidelines in both the resuscitation and stabilization bundles. ${ }^{2}$

\section{Major new recommendations in the 2014 update}

Due to the success of the 2002 and 2007 guidelines, ${ }^{1,2}$ the 2014 update compilation and discussion of the new literature were directed to the question of what changes, if any, should be implemented in the update. The members of the committee were asked whether there are clinical practices which the 'Best Outcome Practices' are using in 2014 which are not recommended in the 2002 and 2007 guidelines and should be recommended in the 2014 guidelines? The changes recommended were few. Most importantly, there was no change in emphasis between the 2002 guidelines and the 2014 update. The continued emphasis is directed to 1) first hour fluid resuscitation and inotrope therapy directed to goals of threshold heart rates, normal blood pressure, and capillary refill $\leq 2$ seconds with specific evalution after each bolus for signs of fluid overload, as well as first hour antibiotic administration; and 2) subsequent ICU hemodynamic support directed to goals of ScvO $\mathrm{O}_{2}>70 \%$ and cardiac index 3.3-6.0 L/min/ $\mathrm{m}^{2}$ with appropriate antibiotic coverage and source control. 
The major new recommendation in the 2014 update is that hemodynamic support of septic shock now be addressed at the institutional level rather than only at the practitioner level. The new guidelines recommend that each institution implement their own adopted or home-grown bundles that include the following

1) Recognition Bundle containing a trigger tool for rapid identification of patients with suspected septic shock at that institution,

2) Resuscitation and Stabilization Bundle to drive adherence to consensus best practice at that institution, and

3) Performance Bundle to monitor, improve, and sustain adherence to that best practice.

The new 2014 guidelines provide examples of each bundle (Figure 1) for consideration and review by each hospital's expert committee.

\section{LITERATURE AND BEST PRACTICE REVIEW}

\section{Developmental Differences in the Hemodynamic Response to Sepsis in Newborns, Children, and Adults}

The predominant cause of mortality in adult septic shock is vasomotor paralysis. ${ }^{26}$ Adults have myocardial dysfunction manifested as a decreased ejection fraction; however, cardiac output is usually maintained or increased by two mechanisms: tachycardia and ventricular dilation. Adults who do not develop this adaptive process to maintain cardiac output have a poor prognosis. ${ }^{27,28}$ Pediatric septic shock is typically associated with severe hypovolemia, and children frequently respond well to aggressive volume resuscitation; however, the hemodynamic response of fluid resuscitated children appears diverse compared to adults. Contrary to the adult experience, low cardiac output, not low systemic vascular resistance, is associated with mortality in pediatric septic shock. ${ }^{29-38}$ Attainment of the therapeutic goal of CI 3.3-6.0 L/min/m² may result in improved survival. ${ }^{30,38}$ Also contrary to adults, a reduction in oxygen delivery rather than a defect in oxygen extraction, is the major determinant of oxygen consumption in children. ${ }^{31}$ Attainment of the therapeutic goal of oxygen consumption $\left(\mathrm{VO}_{2}\right)>200 \mathrm{~mL} / \mathrm{min} / \mathrm{m}^{2}$ may also be associated with improved outcome. ${ }^{30}$ 
It was not until 1998 that investigators reported patient outcome when aggressive volume resuscitation $\left(60 \mathrm{~mL} / \mathrm{kg}\right.$ fluid in the first hour) and goal-directed therapies (goal $=$ CI $3.3-6.0 \mathrm{~L} / \mathrm{min} / \mathrm{m}^{2}$ and normal pulmonary capillary wedge pressure) were applied to children with septic shock. ${ }^{38}$ Ceneviva et al reported 50 children with fluid-refractory ( $\geq 60 \mathrm{ml} / \mathrm{kg}$ in the first hour), dopamine-resistant shock. ${ }^{38}$ The majority (58\%) showed a low cardiac output/high systemic vascular resistance state, and 22\% had low cardiac output and low vascular resistance. Hemodynamic states frequently progressed and changed over the first 48 hours. Persistent shock occurred in $33 \%$ of the patients. There was a significant decrease in cardiac function over time, requiring addition of inotropes and vasodilators. Although decreasing cardiac function accounted for the majority of patients with persistent shock, some showed a complete change from a low output state to a high output/low systemic vascular resistance state..$^{39-42}$ Inotropes, vasopressors, and vasodilators were directed to maintain normal CI and SVR in the patients. Mortality from fluid-refractory, dopamine-resistant septic shock in this study (18\%) was markedly reduced compared to mortality in the 1985 study $(58 \%),{ }^{30}$ in which aggressive fluid resuscitation was not used. More recently investigators in the UK confirmed these observations using Doppler ultrasound to measure cardiac output. ${ }^{43,44}$ They found that previously healthy children with community acquired sepsis often had a low cardiac output with a higher mortality rate, whereas cardiac output was high and mortality rate was low in septic shock related to catheter-associated blood stream infections. ${ }^{43}$

Neonatal septic shock can be complicated by the physiologic transition from fetal to neonatal circulation. In utero, $85 \%$ of fetal circulation bypasses the lungs through the patent ductus arteriosus and foramen ovale. This flow pattern is maintained by supra systemic pulmonary vascular resistance in the prenatal period. At birth, inhalation of oxygen triggers a cascade of biochemical events that ultimately result in reduction in pulmonary vascular resistance and artery pressure and transition from fetal to neonatal circulation with blood flow now being directed through the pulmonary circulation. Closure of the patent ductus arteriosus and foramen ovale (that can occur much later) complete this transition. Pulmonary vascular resistance and artery pressures can remain elevated and the ductus arteriosus can remain open for the first six weeks of life, while the 
foramen ovale may remain probe patent for years. Sepsis-induced acidosis and hypoxia can increase pulmonary vascular resistance and artery pressure and maintain patency of the ductus arteriosus, resulting in persistent pulmonary hypertension of the newborn (PPHN) and persistent fetal circulation (PFC). Neonatal septic shock with PPHN is associated with increased right ventricle work. Despite in utero conditioning, the thickened right ventricle may fail in the presence of systemic pulmonary artery pressures. Decompensated right ventricular failure can be clinically manifested by tricuspid regurgitation and hepatomegaly. Newborn animal models of Group B streptococcal and endotoxin shock have also documented reduced cardiac output, and increased pulmonary, mesenteric, and systemic vascular resistance. ${ }^{45-48}$ Therapies directed at reversal of right ventricle failure, through reduction of pulmonary artery pressures, are commonly needed in neonates with fluid refractory shock and PPHN.

The hemodynamic response in premature, very low birth weight infants with septic shock $(<32$ weeks gestation, <1000 gms) is least understood. Most hemodynamic information is derived only from echocardiographic evaluation and there are few septic shock studies in this population. Neonatology investigators often fold septic shock patients into 'RDS' and 'shock' studies rather than conduct septic shock studies alone. Hence, the available clinical evidence on the hemodynamic response in premature infants for the most part is in babies with respiratory distress syndrome or shock of undescribed etiology. In the first 24 hours after birth during the 'transitional phase', the neonatal heart must rapidly adjust to a high vascular resistance state compared to the low resistance placenta. Cardiac output and blood pressure may decrease when vascular resistance is increased. ${ }^{49}$ However, the literature indicates that premature infants with shock can respond to volume and inotropic therapies with improvements in stroke volume, contractility, and blood pressure..$^{50-63}$

Several other developmental considerations influence shock therapy in the premature infant. Relative initial deficiencies in the thyroid and parathyroid hormone axes have been reported and can result in the need for thyroid hormone and/or calcium replacement. ${ }^{64,65}$ Hydrocortisone has been examined in this population as well. Since 2002, randomized controlled trials showed that prophylactic use of hydrocortisone on day one of life 
reduced the incidence of hypotension in this population, ${ }^{66}$ and a seven-day course of hydrocortisone reduced the need for inotropes in very low birth weight (VLBW) infants with septic shock. ${ }^{67-69}$ Immature mechanisms of thermogenesis require attention to external warming. Reduced glycogen stores and muscle mass for gluconeogenesis require attention to maintenance of serum glucose concentration. Standard practices in resuscitation of preterm infants in septic shock employ a more graded approach to volume resuscitation and vasopressor therapy compared to resuscitation of term neonates and children. This more cautious approach is a response to anecdotal reports that preterm infants at risk for intraventricular hemorrhage (<30 weeks gestation) can develop hemorrhage after rapid shifts in blood pressure; however, some now question whether long-term neurologic outcomes are related to periventricular leukomalacia (a result of prolonged under perfusion) more than to intraventricular hemorrhage. Another complicating factor in very low birth weight infants is the persistence of the patent ductus arteriosus. This can occur because immature muscle is less able to constrict. The majority of infants with this condition are treated medically with indomethacin, or in some circumstances with surgical ligation. Rapid administration of fluid may further increase left to right shunting through the ductus with resultant pulmonary edema.

One single center randomized control trial reported improved outcome with use of daily 6-hour pentoxyfilline infusions in very premature infants with sepsis. ${ }^{70.71}$ This compound is both a vasodilator and an anti-inflammatory agent. A Cochrane analysis agrees that this promising therapy deserves evaluation in the multi-center trial setting. ${ }^{72}$

\section{What clinical signs and hemodynamic variables can be used to direct treatment of newborn and pediatric}

shock? Shock can be defined by clinical variables, hemodynamic variables, oxygen utilization variables, and/or cellular variables. However, after review of the literature, the committee continues to choose to define septic shock by clinical, hemodynamic, and oxygen utilization variables only.

Ideally, septic shock should be diagnosed by clinical signs, which include hypothermia or hyperthermia, altered mental status, and peripheral vasodilation (warm shock) or vasoconstriction with capillary refill $>2$ 
seconds (cold shock) before hypotension occurs. Threshold heart rates associated with increased mortality in critically ill (not necessarily septic) infants are a HR < 90 b.p.m. or $>160$ b.p.m, and in children are a HR $<70$ b.p.m. or > 150 b.p.m. ${ }^{73}$ Emergency department therapies should be directed towards restoring normal mental status, threshold heart rates, peripheral perfusion (capillary refill $<3$ seconds), palpable distal pulses, and blood pressure for age. ${ }^{12}$ Orr and colleagues reported that specific hemodynamic abnormalities in the emergency department were associated with progressive increase in mortality $(\%)$ : eucardia $(1 \%)<$ tachycardia/bradycardia $(3 \%)<$ hypotension with capillary refill less than 3 seconds $(5 \%)<$ normotension with capillary refill longer than 3 seconds $(7 \%)<$ hypotension with capillary refill longer than 3 seconds (33\%). Reversal of these hemodynamic abnormalities using ACCM/PALS recommended therapy was associated with a $40 \%$ reduction in mortality odds ratio regardless of the stage of hemodynamic abnormality at the time of presentation. ${ }^{74}$

In both neonates and children, shock should be further evaluated and resuscitation treatment guided by hemodynamic variables including perfusion pressure (mean arterial pressure minus central venous pressure or MAP-CVP) and cardiac output (CO). Invasive blood pressure monitoring provides more accurate reflection of vasomotor state. Shock has historically been divided into warm and cold based on clinical examination, inferring vasodilation or vasoconstriction based on warm and cold phenotypes, respectively. This categorization has been demonstrated to be fraught with errors. Indeed, as many as $66 \%$ of children judged by experienced clinicians to be in "cold shock" were noted to be vasodilated on invasive monitoring. ${ }^{75}$ Blood flow (Q) varies directly with perfusion pressure $(\square \square \mathrm{P})$ and inversely with resistance (R). This is mathematically represented by $\mathrm{Q}=\square \square \mathrm{P} / \mathrm{R}$. For the systemic circulation this is represented by cardiac output $(\mathrm{CO})=\mathrm{MAP}-\mathrm{CVP} /$ systemic vascular resistance (SVR). This relationship is important for organ perfusion. In the kidney, for example, renal blood flow $(\mathrm{RBF})=$ mean renal arterial pressure $(\mathrm{mRAP})-$ mean renal venous pressure $(\mathrm{mRVP}) /$ renal vascular resistance. Some organs (including the kidney and brain) have vasomotor auto-regulation, which maintains blood flow in low blood pressure (MAP or RAP) states. At some critical point, perfusion pressure is reduced below the ability of the organ to maintain blood flow. 
One goal of shock treatment is to maintain perfusion pressure above the critical point below which blood flow can not be effectively maintained in individual organs. Kumar, et al. demonstrated in children with severe CNS infections that therapies targeted to preservation of a minimum cerebral perfusion pressure rather than titrating for a maximal intracranial pressure reduced mortality from $38.2 \%$ in the ICP control group to $18.2 \%$ in the CPP preservation group. ${ }^{76}$ The kidney receives the second highest blood flow relative to its mass of any organ in the body, and measurement of urine output (with the exception of patients with hyperosmolar states such as hyperglycemia which leads to osmotic diuresis) and creatinine clearance can be used as an indicator of adequate perfusion pressure. Maintenance of MAP with norepinephrine has been shown to improve urine output and creatinine clearance in hyperdynamic sepsis. ${ }^{77}$ Producing a supranormal MAP above this point is likely not of benefit ${ }^{78}$ and may actually decrease cardiac output by increasing afterload above the capacity of the myocardium to compensate.

Reduction in perfusion pressure below the critical point necessary for adequate splanchnic organ perfusion can also occur in disease states with increased intra-abdominal pressure (IAP) such as bowel wall edema, ascites, or abdominal compartment syndrome. If this increased IAP is not compensated for by an increase in MAP then splanchnic perfusion pressure is decreased. Therapeutic reduction of IAP (measured by intra-bladder pressure) using diuretics and/or peritoneal drainage for IAP > $12 \mathrm{mmHg}$, and surgical decompression for $>30 \mathrm{mmHg}$, results in restoration of perfusion pressure and has been shown to improve renal function in children with burn shock. ${ }^{79}$

Normative blood pressure values in the very low birth weight (VLBW) newborn have been reassessed. A MAP $<30 \mathrm{mmHg}$ is associated with poor neurologic outcome and survival, and is considered the absolute minimum tolerable blood pressure in the extremely premature infant. ${ }^{51}$ Since blood pressure does not necessarily reflect cardiac output, it is recommended that normal CO and/or superior vena cava (SVC) flow, measured by Doppler echocardiography, be a primary goal as well. ${ }^{80-90}$ 
Although perfusion pressure is used as a surrogate marker of adequate flow, the previous equation shows that organ blood flow (Q) correlates directly with perfusion pressure but indirectly with vascular resistance. If the ventricle is healthy, an elevation of SVR results in hypertension with maintenance of cardiac output. Conversely, if ventricular function is reduced, the presence of normal blood pressure with high vascular resistance means that cardiac output is reduced. If the elevation in vascular resistance is marked, the reduction in blood flow results in shock. A cardiac index between $3.3-6.0 \mathrm{~L} / \mathrm{min} / \mathrm{m}^{2}$ is associated with best outcomes in septic shock patients ${ }^{29}$ compared to patients without septic shock for whom a cardiac index above $2.0 \mathrm{~L} / \mathrm{min} / \mathrm{m}^{2}$ is sufficient. ${ }^{91}$ Attainment of this cardiac output goal is often dependent on attaining threshold heart rates. However, if the heart rate is too high, then there is not enough time to fill the coronary arteries during diastole, and contractility and cardiac output will decrease. Coronary perfusion may be further reduced when an unfavorable transmural coronary artery filling pressure is caused by low diastolic blood pressure and /or high end diastolic ventricular pressure. In this scenario, efforts should be made to improve coronary perfusion pressure and reverse the tachycardia by giving volume if the stroke volume is low, or an inotrope if contractility is low. Because $\mathrm{CO}=$ heart rate $(\mathrm{HR}) \mathrm{x}$ stroke volume $(\mathrm{SV})$, therapies directed to increasing SV will often reflexively reduce $\mathrm{HR}$ and improve $\mathrm{CO}$. This will be evident in improvement of the shock index (heart rate/systolic blood pressure, $\mathrm{HR} / \mathrm{SBP}),{ }^{92}$ as well as $\mathrm{CO}$. Children have limited heart rate reserve compared to adults because they are already starting with high basal heart rates. For example if SV is reduced due to endotoxin-induced cardiac dysfunction, an adult can compensate for the fall in SV by increasing HR two-fold from 70 to 140 b.p.m., but a baby cannot increase from 140 b.p.m to 280 b.p.m. Although tachycardia is an important method for maintaining cardiac output in infants and children, the younger the patient, the more likely this response will be inadequate and the cardiac output will fall. In this setting, the compensatory response to falling SV and contractility is to vasoconstrict to maintain blood pressure. Increased vascular resistance is clinically identified by absent or weak distal pulses, cool extremities, prolonged capillary refill and narrow pulse pressure with relatively increased diastolic blood pressure. The effective approach for these children is 
vasodilator therapy with additional volume loading as vascular capacity is expanded. Vasodilator therapy reduces afterload and increases vascular capacitance. This shifts the venous compliance curve so that more volume can exist in the right and left ventricle at a lower pressure. In this setting, giving volume to restore filling pressure results in a net increase in end-diastolic volume (ie, preload) and a higher $\mathrm{CO}$ at the same or lower filling pressures. Effective use of this approach results in a decreased HR and improved perfusion.

At the other end of the spectrum, a threshold minimum HR is also needed because if the HR is too low then $\mathrm{CO}$ will be too low $(\mathrm{CO}=\mathrm{HR} \times \mathrm{SV})$. This can be attained by using an inotrope that is also a chronotrope. In addition to threshold heart rates, attention must also be paid to diastolic blood pressure (DBP). If the DBPCVP is too low then addition of a intrope/vasopressor agent such as norepinephrine will be required to improve diastolic coronary blood flow. Conversely, if wall stress is too high due to an increased end-diastolic ventricular pressure secondary to fluid overload, then a diuretic may be required to improve stroke volume by moving leftward on the over-filled Starling function curve. The effectiveness of these maneuvers will similarly be evidenced by improvement in the HR/SBP shock index, CO, and SVR along with improved distal pulses, skin temperature and capillary refill.

Shock should also be assessed and treated according to oxygen utilization measures. Measurement of $\mathrm{CO}$ and $\mathrm{O}_{2}$ consumption were proposed as being of benefit in patients with persistent shock because a cardiac index between 3.3 and $6.0 \mathrm{~L} / \mathrm{min} / \mathrm{m}^{2}$ and $\mathrm{O}_{2}$ consumption $>200 \mathrm{~mL} / \mathrm{min} / \mathrm{m}^{2}$ are associated with improved survival. ${ }^{29}$ Low CO is associated with mortality in pediatric septic shock. ${ }^{29-38}$ In one study, children with fluidrefractory dopamine-resistant shock were treated with goal directed therapy (cardiac index $>3.3$ and $<6$ $\mathrm{L} / \mathrm{min} / \mathrm{m}^{2}$ ) and found to have improved outcomes compared to historical reports. ${ }^{38}$ Because low CO is associated with increased $\mathrm{O}_{2}$ extraction, ${ }^{30} \mathrm{ScvO}_{2}$ saturation can be used as an indirect indicator of whether $\mathrm{CO}$ is adequate to meet tissue metabolic demand. If tissue oxygen delivery is adequate, then assuming a normal arterial oxygen saturation of $100 \%$, mixed venous saturation is $>70 \%$. Assuming a hemoglobin concentration of $10 \mathrm{~g} / \mathrm{dL}$ and $100 \%$ arterial $\mathrm{O}_{2}$ saturation then a cardiac index $(\mathrm{CI})>3.3 \mathrm{~L} / \mathrm{min} / \mathrm{m}^{2}$ with a normal oxygen 
consumption of $150 \mathrm{~mL} / \mathrm{min} / \mathrm{m}^{2}\left(\mathrm{O}_{2}\right.$ consumption $=\mathrm{CI} \times\left(\right.$ arterial $\mathrm{O}_{2}$ content - venous $\mathrm{O}_{2}$ content $)$ results in a mixed venous saturation of $>70 \%: 150 \mathrm{~mL} / \mathrm{min} / \mathrm{m}^{2}=3.3 \mathrm{~L} / \mathrm{min} / \mathrm{m}^{2} \times[1.36 \times 10 \mathrm{~g} / \mathrm{dL}+\mathrm{PaO} 2 \times 0.003] \times 10 \times[1$ -0.7]. Since 2002, Oliveira and colleagues performed a randomized controlled trial in children with septic shock showing a reduction in mortality from $39 \%$ to $12 \%$ when directing therapy to the goal of $\mathrm{ScvO}_{2}$ saturation $>70 \%$ (NNT 3.6). ${ }^{15,93}$ Sankar and colleagues observed an association with reduced mortality from $54 \%$ to $33.3 \%$ (NNT 5) and lower organ dysfunction with a similar $\mathrm{ScvO}_{2}$ saturation goal of $>70 \%{ }^{16}$ In contrast, supranormal $\mathrm{ScvO} 2$ saturations $>80-85 \%$ that reflect a narrowed arterio-venous difference in $\mathrm{O} 2$ content $\left(\mathrm{AVDO}_{2}\right)$ may reflect either mitochondrial dysfunction, a high cardiac output state, or overly aggressive resuscitation. ${ }^{94}$ In this narrow $\mathrm{AVDO}_{2}$ shock state, practitioners should incorporate in their serial patient assessments other markers of adequate tissue oxygen delivery and utilization and organ perfusion such as serum lactate and urine output.

In isolation, any one of the above clinical or hemodynamic parameters may under- or over-estimate the true severity of illness, leading to either false reassurance and under- resuscitation or over-resuscitation. Multimodal monitoring refers to the use of multiple variables and their changes over time to better determine the underlying hemodynamic state. Shock index (heart rate / SBP) ${ }^{92}$ and heart rate variability analysis ${ }^{95}$ both leverage the added value of evaluating combinations of variables and their trends over time and have been suggested as being superior to any individual parameter alone for diagnosing septic shock and assessing response to therapy. By combining information from clinical signs, invasive arterial monitoring, and serial bedside echocardiograms, Ranjit and colleagues were able to titrate hemodynamic therapies more precisely and achieve equivalent mortality outcomes to PICUs using more invasive continuous cardiac output monitoring. ${ }^{75}$

Laboratory markers of cardiac function and oxygen delivery:utilization balance include troponin and lactate. Blood troponin concentrations correlate well with poor cardiac function and response to inotropic support in children with septic shock. ${ }^{96-98}$ Lactate is recommended in adult septic shock laboratory testing bundles for both diagnosis and subsequent monitoring of therapeutic responses. However, most adult literature 
continues to define shock by hypotension, and recommends using lactate concentration to identify shock in normotensive adults. In pediatric studies, initial elevated lactate levels have correlated with increased mortality and decreasing lactate trends over time appear to correlate with recovery. ${ }^{99-103}$ However, each of these studies has been limited by small numbers. Lactate elevation for reasons other than cellular hypoxia further clouds the utility of using lactate to either predict outcome or track response to therapy. ${ }^{104}$ For now the committee recommends early recognition of pediatric septic shock using clinical examination, not biochemical tests. Nevertheless, given the broad adoption of lactate in the adult guidelines and the suggestive data in small pediatric studies, lactate measurements if high on initial measurement may be useful to judge resolution of shock. Early elevated lactate (from a free flowing sample) may grab a clinician's attention, when clinical signs are difficult to decipher - it is inexpensive, readily available, and over time performed well as an indicator of shock and its resolution.

In very low birth weight infants, ultrasound derived superior vena cava (SVC) blood flow measurement was reportedly useful in assessing the effectiveness of shock therapies. The SVC flow approximates blood flow from the brain. A value $>40 \mathrm{~mL} / \mathrm{kg} / \mathrm{min}$ is associated with improved neurologic outcomes and survival. ${ }^{86-90}$ $\mathrm{ScvO}_{2}$ saturation can be used in low birth weight infants but may be misleading in the presence of left to right shunting through the patent ductus arteriosus.

Intravascular Access Vascular access for fluid resuscitation and inotrope/vasopressor infusion is more difficult to attain in newborns and children compared with adults. Portable near-infrared imaging devices may assist with placement of peripheral vascular access. ${ }^{105,106}$ To facilitate a rapid approach to vascular access in critically ill infants and children, the American Heart Association and the American Academy of Pediatrics developed neonatal resuscitation program (NRP) and pediatric advanced life support (PALS) guidelines for emergency establishment of intravascular support. ${ }^{107-110}$ Essential age-specific differences include use of umbilical artery (UAC) and umbilical venous (UVC) access in newborns, and rapid use of intraosseous (IO) 
access in children. ${ }^{108-1104}$ Ultrasound guidance facilitates placement of central lines in children, but is technologist dependent. Clinicians entering the field of pediatric critical care should consider training in this modality given the recent, dramatic increase in use of ultrasound technology for vascular access. ${ }^{113-119}$ Catheter selection may not have an immediate impact on resuscitation, however heparin-bonded and antibiotic-coated central venous catheters are associated with reduced catheter associated blood stream infections. ${ }^{120-125}$

Fluid Therapy $\quad$ Fuid resuscitation trials have been performed since 2002. Several randomized trials showed that when children with mostly Stage III (narrow pulse pressure/tachycardia) and some Stage IV (hypotension) WHO classification Dengue shock received fluid resuscitation in the emergency department there was near $100 \%$ survival regardless of the fluid composition used..$^{3,10,126,127}$ In a randomized controlled trial, Maitland and colleagues demonstrated a reduction in malaria septic shock mortality from $18 \%$ to $4 \%$ when albumin was used compared to crystalloid. ${ }^{128}$ In contrast, Maitland et al subsequently demonstrated harm in the FEAST trial when fluid boluses were given rather than intravenous fluid at a maintenance rate and blood transfusion contradicting this earlier study. ${ }^{11}$ The adult SAFE trial that compared crystalloid versus albumin fluid resuscitation reported a hypothesis generating trend towards improved outcome $(\mathrm{p}<0.1)$ in septic shock patients who received albumin. ${ }^{129}$ Preference for the exclusive use of colloid resuscitation was made based on a clinical practice position paper from a group who reported outstanding clinical results in resuscitation of meningococcal septic shock (5\% mortality) both using $4 \%$ albumin exclusively (20 mL/kg boluses over 5-10 minutes) and intubating patients who required greater than $40 \mathrm{~mL} / \mathrm{kg}^{4}$ In an Indian trial of fluid resuscitation of pediatric septic shock there was no difference in outcome with gelatin compared to crystalloid. ${ }^{130}$ In the initial clinical case series that popularized the use of aggressive volume resuscitation for reversal of pediatric septic shock, a combination of crystalloid and colloid therapies was used. ${ }^{131}$ Several new investigations examined both the feasibility of the 2002 guideline recommendation of rapid fluid resuscitation as well as the need for fluid removal in patients with subsequent oliguria following fluid resuscitation. The 2002 guideline recommended rapid $20 \mathrm{~mL} / \mathrm{kg}$ fluid boluses over five minutes followed by assessment for improved perfusion 
or fluid overload as evidenced by new onset rales, increased work of breathing and hypoxemia from pulmonary edema, hepatomegaly, or a diminishing MAP - CVP. Emergency medicine investigators reported that 20 $\mathrm{mL} / \mathrm{kg}$ of crystalloid or colloid can be pushed over 5 minutes, or administered via a pressure bag over 5 minutes through a peripheral and/or central intravenous line. ${ }^{132}$ Ranjit and colleagues reported improved outcome from Dengue and bacterial septic shock when they implemented a protocol of aggressive fluid resuscitation followed by fluid removal using diuretics and/or peritoneal dialysis if oliguria ensued. ${ }^{133}$ In this regard, Foland and colleagues similarly reported that patients with multiple organ failure who received CRRT when they were < $10 \%$ fluid overloaded had better outcomes than those who were $>10 \%$ fluid overloaded. ${ }^{134}$ Similarly, two best outcome practices reported routine use of CRRT to prevent fluid overload while correcting prolonged INR with plasma infusion in patients with purpura and septic shock. ${ }^{4,18}$

The use of blood as a volume expander was examined in two small pediatric studies, but no recommendations were given by the investigators. ${ }^{135,136}$ In the previously mentioned study by Oliveira reporting improved outcome with use of the $2002 \mathrm{ACCM}$ guidelines and continuous $\mathrm{ScvO}_{2}$ saturation monitoring, the treatment group received more blood transfusions directed to improvement of $\mathrm{ScvO}_{2}$ saturation to > $70 \%(40 \%$ vs 7\%). ${ }^{15}$ Although the members of the taskforce use conservative goals for blood transfusion in routine critical illness ( $\mathrm{Hgb}<7 \mathrm{~g} / \mathrm{dL}$ without cardiopulmonary compromise), the observation that patients who have septic shock with a ScvO2 $<70 \%$ and $\mathrm{Hgb}<10 \mathrm{~g} / \mathrm{dL}$ had better outcomes when transfused to a goal $\mathrm{Hgb}>10 \mathrm{~g} / \mathrm{dL}$ supports a higher hemoglobin goal in this population.

Fluid infusion is best initiated with boluses of $20 \mathrm{~mL} / \mathrm{kg}$, titrated to assuring an adequate blood pressure and clinical monitors of cardiac output including heart rate, quality of peripheral pulses, capillary refill, level of consciousness, and urine output. Initial volume resuscitation requirements may be $0 \mathrm{~mL} / \mathrm{kg}$ (if rales or hepatomegaly) are present, but commonly requires $40-60 \mathrm{~mL} / \mathrm{kg}^{37,}, 131,137-144$ Patients who do not respond rapidly to initial fluid boluses, or those with insufficient physiologic reserve, should be considered for invasive hemodynamic monitoring. Monitoring filling pressures can be helpful to optimize preload and thus cardiac 
output. Observation of little change in the CVP in response to a fluid bolus suggests that the venous capacitance system is not over-filled and that more fluid is indicated. Observation that an increasing CVP is met with reduced MAP-CVP suggests that too much fluid has been given. Large volumes of fluid for acute stabilization in children have not been shown to increase the incidence of the acute respiratory distress syndrome or cerebral edema. ${ }^{122,135}$ Increased fluid requirements may be evident for several days secondary to loss of fluid from the intravascular compartment when there is profound capillary leak. ${ }^{37}$ Routine fluid choices include crystalloids (normal saline or lactated Ringers solution) and colloids (dextran, gelatin, or 5\% albumin). ${ }^{3,108-117,145-153}$ Fresh frozen plasma may be infused to correct abnormal PT and PTT values, but should not be pushed because it may produce acute hypotensive effects likely caused by vasoactive kinins and high citrate concentration. Since oxygen delivery depends on hemoglobin concentration, hemoglobin should be maintained at a minimum of $10 \mathrm{~g}$ / dL during the initial resuscitation phase. ${ }^{15}$ Diuretics / peritoneal dialysis / CRRT are indicated for patients who develop signs and symptoms of fluid overload.

Sedation for Invasive Procedures or Intubation Supplemental oxygen and optimal airway positioning should be provided at presentation for all patients with shock, consistent with PALS guidelines. Although patients presenting with hypopnea or frank apnea may need immediate intubation, in most instances there is time for fluid resuscitation, ideally at least 40 to $60 \mathrm{~mL} / \mathrm{kg}$ of either isotonic crystalloid or $5 \%$ albumin given rapidly, certainly within the first hour of presentation. Children with persistent or worsening shock, as manifested by failure to approximate normal vital signs for age and inadequate perfusion should be considered to be at high risk for deterioration and should receive ventilatory support. High-flow nasal cannulae and other modes of non-invasive respiratory support may be appropriate for selected patients. ${ }^{154}$ Patients with shock of any etiology are particularly vulnerable to the hemodynamic effects of sedatives and analgesics, emphasizing the importance of prompt appropriate fluid resuscitation and inotrope infusion (peripheral or central) prior to airway instrumentation in spontaneously-breathing patients. 
Intubation for controlled ventilation plays an important role in the management of neonates and children with septic shock, and must be impeccably timed: sedation, analgesia and positive-pressure ventilation associated with premature instrumentation of the airway, prior to adequate volume resuscitation, may cause profound drops in preload and precipitate severe hemodynamic instability or an arrest. Conversely, severe diastolic and systolic ventricular dysfunction may predispose the child to pulmonary edema and rapid desaturation during intubation, making the procedure more treacherous. Expertly performed intubation and mechanical ventilation eliminate work of breathing and improve oxygenation and organ perfusion, all of which are typically compromised in the septic child. The procedure should therefore be carefully planned and performed by the most experienced clinician available. ${ }^{155-158}$

Atropine increases the heart rate and protects against the deleterious effects of bradycardia, particularly in babies. ${ }^{159}$ Atropine does not cause cardiac dysrhythmias, and is not contraindicated in children exhibiting tachycardia. Ketamine remains the agent of choice for intubation of pediatric patients with shock, ${ }^{160}$ given its pharmacologic effects of dissociation while maintaining or augmenting systemic vascular resistance. Side effects may be minimized by administering intravenous boluses over 30 to 60 seconds. The use of ketamine with atropine pre-treatment should be considered as the sedative/induction regimen of choice to promote cardiovascular integrity. ${ }^{161}$

The use of etomidate is generally discouraged at this time, given its known effects on adrenal function, ${ }^{162-164}$ despite some reports suggesting no direct effect on patient mortality. ${ }^{165-166}$ Etomidate can be considered in the presence of profound shock if ketamine is unavailable. The role of hydrocortisone supplementation in this setting is unclear. It is possible that etomidate analogues currently in development may have a role in urgent pediatric airway management.

Other options to consider for intubation of neonates and children include the opioids fentanyl and remifentanil. These agents should be used instead of morphine, when available, because they have fewer hemodynamic effects. Opioids such as fentanyl should be given in titrated aliquots of 1 to 2 micrograms per 
kilogram, administered over 60 seconds. Although chest wall rigidity is usually associated with larger doses given as a bolus, this complication and altered hemodynamics can also occur with smaller doses. Benzodiazepines, if used, should be likewise carefully titrated to effect, using small doses.

Pentobarbital and other barbiturates are direct myocardial depressants and decrease systemic vascular resistance, commonly causing hemodynamic instability. These drugs are also devoid of intrinsic analgesic effects, making them unsuitable for tracheal intubation of patients with shock. Inhalational agents are not appropriate for isolated airway instrumentation in shock. Propofol commonly causes hypotension, and should be avoided during intubation or sedation in the presence of shock, particularly during transport and before admission to the intensive care unit.

Neuromuscular blocking agents such as rocuronium, or succinylcholine (absent a contraindication) may facilitate intubation by qualified providers. Hypotension may occur even in children who have received appropriate volume resuscitation and pharmacotherapy for intubation. It is advisable, therefore, to have additional isotonic crystalloid and vasoactive infusions available for immediate use during or following the procedure. Additional vascular access should be obtained as soon as practical. Sedation and analgesia may be maintained in ventilated patients requiring transport using agents such as fentanyl and midazolam, supplemented by neuromuscular blockade. Ketamine infusions may be utilized as well, but there is concern regarding neuroapoptosis following exposure to ketamine in infants. ${ }^{167,168}$ Unplanned extubation may occur as the child recovers from shock. The endotracheal tube should be carefully secured once adequate placement is achieved. Appropriately titrated analgesia and sedation are essential for safe transport. Neuromuscular blockade and physical restraints may be appropriate under some circumstances, always in the presence of adequate analgesia and sedation.

\section{Intravascular Catheters and Non-Invasive or Minimally Invasive Monitoring $\quad$ Minimal invasive} monitoring is necessary in children with fluid-responsive shock; however, in children with fluid-refractory shock, physical signs of cold vs warm shock may be unreliable and central venous access and arterial pressure 
monitoring is recommended. Intensivists have long used the ultrasound for central venous catheter placement in children, but its role is now expanding to direct resuscitation goals and therapeutic end points in shock resuscitation. Echocardiography is considered an appropriate non-invasive tool to rule out the presence of pericardial effusion, evaluate myocardial contractility and intravascular volume. Ranjit et al. incorporated the use of echocardiography in their usual practice, to categorize the hemodynamics in 48 patients with fluid refractory septic shock. Based on their findings on the echocardiogram and invasive blood pressure monitoring, fluid and inotrope/vasopressor therapy was changed in almost $88 \%$ of the patients. Early placement of invasive arterial catheters helped in the identification and subsequent management of a cohort of patients who presented with cold-shock, but had wide pulse pressure with low diastolic pressure ${ }^{75}$ Similarly, Brierley et al, categorized the hemodynamic patterns of pediatric septic shock with the use of doppler ultrasonography and observed that the manifestation of hemodynamics was cause dependent i.e., CVC associated sepsis presented with high cardiac output and low systemic vascular resistance, whereas community acquired infections sepsis presented with low cardiac output. ${ }^{43}$ A cardiac output $>3.3 \mathrm{~L} / \mathrm{min} / \mathrm{m}^{2}<6.0 \mathrm{~L} / \mathrm{min} / \mathrm{m}^{2}$ is associated with improved survival and neurologic function. Other non-invasive monitors undergoing evaluation in newborns and children include percutaneous venous oxygen saturation, aortic ultrasound, perfusion index (pulse-oximetry), near infrared spectroscopy, sublingual $\mathrm{PCO}_{2}$, and sublingual microvascular orthogonal polarization spectroscopy scanning. All show promise however none has been tested in goal-directed therapy trials. ${ }^{169-177}$

Maintenance of perfusion pressure [MAP-CVP], or [MAP-IAP] if the abdomen is tense secondary to bowel edema or ascitic fluid, is considered necessary for organ perfusion. ${ }^{47}$ Goal-directed therapy to achieve an $\mathrm{ScvO}_{2}$ saturation $>70 \%$ is associated with improved outcome. ${ }^{15}$ To gain accurate measures of $\mathrm{ScvO}_{2}$, the tip of the catheter must be at the SVC-RA or IVC-RA junction. ${ }^{178}$ A pulmonary artery (PAC), PICCO, or femoral artery thermodilution (FATD) catheter can be used to measure $\mathrm{CO}$ in those who remain in shock despite therapies directed to clinical signs of perfusion, MAP-CVP, $\mathrm{ScvO}_{2}$, and echocardiographic analyses. ${ }^{179-183}$ The PAC measures the PAOP (pulmonary artery occlusion pressure) to help identify selective 
left ventricular dysfunction, and can be used to determine the relative contribution of right and left ventricle work. A less invasive PICCO catheter estimates global end-diastolic volume in the heart (both chambers) and extra vascular lung water and can be used to assess whether preload is adequate. ${ }^{184,185}$ This measure of intravascular volume by global end-diastolic volume has been demonstrated in both children and adults to be more predictive than either CVP or PAOP for changes in cardiac output associated with volume challenge. Cardiovascular Drug Therapy When considering the use of cardiovascular agents in the management of infants and children with septic shock, several important points need emphasis. The first is that septic shock represents a dynamic process so that the agents selected and their infusion dose may need to be changed over time based on the need to maintain adequate organ perfusion. It is also important to recognize that the vasoactive agents are characterized by varying effects on systemic vascular resistance and pulmonary vascular resistance (i.e., vasodilators or vasopressors), contractility (i.e., inotropy), heart rate (chronotropy) and lusotropy (ventricle relaxation). These pharmacologic effects are determined by the pharmacokinetics of the agent and the pharmacodynamics of the patient's response to the agent. In critically ill septic children, perfusion of the liver and kidney is often altered leading to changes in the pharmacokinetics of these drugs with higher concentrations observed than anticipated. Thus, the infusion doses quoted in many textbooks are approximations of starting rates and should be adjusted based on the patient's response. We recommend frequent reevaluation of hemodynamic parameters when a patient requires the use of vasopressors, especially in relation to CO, SVR and peripheral perfusion so as to choose the appropriate combination with inotropic or vasodilator drugs +/fluids.

The latter is also determined by the pharmacodynamic response to the agent, which is commonly altered in septic patients. For example, patients with sepsis have a well recognized reduced response to alphaadrenergic agonists that is mediated by excess nitric oxide production as well as alterations in the alphaadrenergic receptor system. Similarly, cardiac beta-adrenergic responsiveness may be reduced by the effect of nitric oxide and other inflammatory cytokines. 
Inotropes Dopamine $(5-9 \square \mathrm{g} / \mathrm{kg} / \mathrm{min})$, dobutamine, or epinephrine $(0.05-0.3 \square \mathrm{g} / \mathrm{kg} / \mathrm{min})$ can be used as first line inotropic support. Dobutamine may be used when there is a low cardiac output state with adequate or increased systemic vascular resistance. ${ }^{29,186-214}$ Dobutamine or mid-dosage dopamine can be used as the first line of inotropic support if supported by clinical and objective data (e.g., assessment of contractility by echocardiogram) when one of the initial goals is to increase cardiac contractility in patients with normal blood pressure. However, children $<12$ months may be less responsive. ${ }^{211}$

Dobutamine- or dopamine-refractory low cardiac output shock may be reversed with epinephrine infusion. ${ }^{29,186,187,189}$ Epinephrine is more commonly used in children than in adults. Some members of the committee recommended use of low-dose epinephrine as a first-line choice for cold hypodynamic shock. It is clear that epinephrine has potent inotropic and chronotropic effects, but its effects on peripheral vascular resistance and the endocrine stress response may result in additional problems. At lower infusion doses (less than $\sim 0.3 \square / \mathrm{kg} / \mathrm{min}$ ) epinephrine has greater beta-2 adrenergic effects in the peripheral vasculature with little $\alpha$ adrenergic effect so that systemic vascular resistance falls, particularly in the skeletal musculature and skin. This may redirect blood flow away from the splanchnic circulation even though blood pressure and cardiac output increases. This effect of epinephrine likely explains the observation that epinephrine transiently reduces gastric intramucosal $\mathrm{pH}$ in adults and animals with hyperdynamic sepsis, ${ }^{193}$ but there are no data available to evaluate whether gut injury does or does not occur with epinephrine use in children. Epinephrine stimulates gluconeogenesis and glycogenolysis, and inhibits the action of insulin, leading to increased blood glucose concentrations. In addition, as part of the stimulation of gluconeogenesis, epinephrine increases the shuttle of lactate to liver as a substrate for glucose production (the Cori cycle). Thus, patients on epinephrine infusion have increased plasma lactate concentrations independent of changes in organ perfusion, making this parameter somewhat more difficult to interpret in children with septic shock.

Ideally, epinephrine should be administered by a secure central venous route, but in an emergency it may be infused through a peripheral intravenous route or through an intraosseous needle while attaining central 
access. The AHA/PALS guidelines for children recommends the initial use of epinephrine by peripheral IV or IO for CPR or post CPR shock, and by the IM route for anaphylaxis. ${ }^{176}$ Even though a common perception, there is no data clarifying if the peripheral infiltration of epinephrine produces more local damage than observed with dopamine. The severity of local symptoms likely depends on the concentration of the vasoactive drug infusion and the duration of the peripheral infiltration before being discovered. If peripheral infiltration occurs with any catecholamine, its adverse effects may be antagonized by local infiltration with phentolamine, 1 to 5 $\mathrm{mg}$ diluted in $5 \mathrm{~mL}$ of normal saline.

\section{Vasodilators}

When pediatric patients are normotensive with a low cardiac output and high systemic vascular resistance, initial treatment of fluid-refractory patients consists of the use of an inotropic agent such as epinephrine or dobutamine that tends to lower systemic vascular resistance. In addition, a short-acting vasodilator may be added, such as sodium nitroprusside or nitroglycerin to recruit microcirculation. ${ }^{215-221}$ Orthogonal polarizing spectroscopy showed that addition of systemic IV nitroglycerin to dopamine/norpeinephrine infusion restored tongue microvascular blood flow during adult septic shock. ${ }^{221}$ Nitrovasodilators can be titrated to the desired effect, but use of nitroprusside is limited if there is reduced renal function secondary to the accumulation of sodium thiocyanate. Use of nitroglycerin may also have limited utility over time through the depletion of tissue thiols that are important for its vasodilating effect. Other vasodilators that have been used in children include prostacyclin, pentoxyfilline, dopexamine, and fenoldapam. ${ }^{222-227}$

An alternative approach to improve cardiac contractility and lower systemic vascular resistance is based on the use of type III phosphodiesterase inhibitors (PDEI). ${ }^{228-234}$ This class of agents, which includes milrinone and inamrinone [formerly amrinone, but the name was changed to avoid confusion with amiodarone], has a synergistic effect with beta-adrenergic agonists because the latter agents stimulate intracellular cAMP production while the PDE inhibitors increase intracellular cAMP by blocking its hydrolysis. Since the PDE 
inhibitors do not depend on a receptor mechanism, they maintain their action even when the beta-adrenergic receptors are down-regulated or have reduced functional responsiveness. The main limitation of these agents is their need for normal renal function (for milrinone clearance) and liver function (for inamrinone clearance). Inamrinone and milrinone are rarely used in adults with septic shock because catecholamine refractory low cardiac output and high vascular resistance is uncommon; however, this hemodynamic state represents a major proportion of children with fluid-refractory, dopamine-resistant shock. Fluid boluses are likely to be required if inamrinone or milrinone are administered with full loading doses. Because milrinone and inamrinone have long half-lifes (1 -10 hours depending on organ function) it can take 3 to 30 hours to reach $90 \%$ of steady state. Although recommended in the literature some individuals in the committee choose not to use boluses of inamrinone or milrinone. This group administers the drugs as a continuous infusion only. Other members divide the bolus in 5 equal aliquots administering each aliquot over 10 minutes if blood pressure remains within an acceptable range. If blood pressure falls, it is typically because of the desired vasodilation and can be reversed by titrated (e.g., $5 \mathrm{~mL} / \mathrm{kg}$ ) boluses of isotonic crystalloid or colloid. Because of the long elimination half-life, these drugs should be discontinued at the first sign of arrhythmia, or hypotension caused by excessively diminished systemic vascular resistance. Hypotension-related toxicity can also be potentially overcome by beginning norepinephrine. Norepinephrine counteracts the effects of increased cyclic adenosine monophosphate in vascular tissue by stimulating the alpha receptor resulting in vasoconstriction.

Norepinephrine has little effect at the vascular $\beta_{2}$ receptor.

Rescue from refractory shock has been described in case reports and series using two medications with Type III phosphodiesterase activity. Levosimendan is a promising new medication that increases $\mathrm{Ca}^{++} / \mathrm{actin} /$ tropomyosin complex binding sensitivity and also has some Type III PDEI and ATP-sensitive $\mathrm{K}^{+}$channel activity. Because one of the pathogenic mechanisms of endotoxin-induced heart dysfunction is desensitization of $\mathrm{Ca}^{++} /$actin / tropomyosin complex binding, ${ }^{235-240}$ this drug allows treatment at this fundamental level of signal transduction overcoming the loss of contractility that characterizes septic shock. Enoximone is a Type III 
PDEI with 10 times more $\square_{1}$ cAMP hydrolysis inhibition than $\square \square_{2}$ cAMP hydrolysis inhibition. ${ }^{241-243}$ Hence it can be used to increase cardiac performance with less risk of undesired hypotension.

Vasopressors Vasopressors may also be beneficial in the treatment of pediatric septic shock when applied according to the guideline algorithm. Vasopressors can be titrated to end points of perfusion pressure (mean arterial pressure $[\mathrm{MAP}]$-central venous pressure $[\mathrm{CVP}]$ ) or systemic vascular resistance (SVR) that promote optimum urine output and creatinine clearance, but excessive vasoconstriction compromising microcirculatory flow should be avoided. Vasopressor effect can be obtained with different sympathicomimetic drugs. There is no clear evidence that supports the use one specific vasoactive drug over another (dopamine $>15 \mathrm{ug} / \mathrm{kg} / \mathrm{min}$, epinephrine $>0.3 \mathrm{ug} / \mathrm{kg} / \mathrm{min}$ or norepinephrine). ${ }^{244-252}$

When epinephrine is administrated in doses greater than $0.3 \mathrm{ug} / \mathrm{kg} / \mathrm{min}$ or dopamine in doses greater than $10 \mathrm{ug} / \mathrm{kg} / \mathrm{min}$ there is a vasopressor effect additional to their inotropic action. However, if the patient has ongoing shock and/or shows findings consistent with warm shock (flash capillary refill, warm extremities, low diastolic pressure and bounding pulses) the additional use of norepinephrine is suggested. ${ }^{244}$ Dopamine has been used as the first-line vasopressor for fluid-refractory hypotensive shock in the setting of low systemic vascular resistance (SVR). ${ }^{248,249}$ Dopamine-resistant shock commonly responds to norepinephrine or high-dose epinephrine. $^{244,225,250}$

Some committee members advocate the use of low-dose norepinephrine as a first-line agent for fluidrefractory hypotensive hyperdynamic shock. Based on experimental and clinical data, norepinephrine is recommended as the first line agent in adults with fluid-refractory shock. If the patient's clinical state is characterized by low systemic vascular resistance (SVR) (e.g. wide pulse pressure with diastolic blood pressure that is less than one-half the systolic pressure), norepinephrine is recommended alone. Other experts have recommended combining norepinephrine with dobutamine, recognizing that dobutamine is a potent inotrope that has intrinsic vasodilating action that may be helpful to counteract excessive vasoconstriction from 
norepinephrine. Higher norepinephrine doses than those usually suggested in the literature have been described to reverse hypotension and hypoperfusion without inducing significant adverse effects. ${ }^{251,252}$

The infusion of norepinephrine is suggested as the initial vasoactive drug in patients with warm shock, with vasodilatation and low systemic vascular resistance (SVR). A study using a non-invasive ultrasound cardiac output monitor device (USCOM) to measure serial hemodynamics showed that patients could present with cold or warm shock and that both types evolved in a heterogeneous manner needing frequent revision of cardiovascular support therapy. Children with initial warm shock were commenced on norepinephrine. Despite an initial good response, four patients developed low CI and needed epinephrine. ${ }^{44}$

When the use of vasopressor drugs is needed, it must be started as soon as possible but within 60 minutes of resuscitation, using intraosseus access, while central venous access is obtained. Lampin et al, describe in a retrospective study the use of norepinephrine in 144 children over a 10 year period $;^{251}$ it was used as the first-choice drug in $22 \%$ of the patients and in $19 \%$ of the cases it was used either by peripheral or intraosseus route. Paul et al describe delay in the initiation of vasoactive drugs in $65 \%$ of the cases and associate this with an increase in length of stay in intensive care. ${ }^{21,22}$

Vasopressin has been shown to increase mean arterial pressure (MAP), systemic vascular resistance (SVR), and urine output in patients with vasodilatory septic shock and hyporesponsiveness to catecholamines .$^{253-267}$ Vasopressin's action is independent of catecholamine receptor stimulation, and therefore its efficacy is not affected by alpha-adrenergic receptor down-regulation often seen in septic shock. Low dose infusion of vasopressin should not be used as routine adjunctive therapy but may be considered as rescue therapy in patients with catecholamine and steroid resistant hypotension. The Vasopressin and Septic Shock Trial, a randomized controlled clinical trial that compared low-dose arginine vasopressin with norepinephrine in adults with septic shock, showed no difference between regimens in the 28-day mortality primary end point. ${ }^{268}$ The results of another randomized control trial evaluating the use of low doses of vasopressin as an adjunctive therapy in vasodilated pediatric septic shock also failed to show benefits. ${ }^{269}$ 
Vasopressin or terlipressin can be considered as rescue therapy in patients in vasodilatory shock who don't respond to high doses of norepinephrine or other sympathicomimetics. Terlipressin, a long acting form of vasopressin, has been reported to reverse vasodilated shock as well. ${ }^{264-270}$ Administered as a continuous infusion or in bolus, it increases BP and urine output in pediatric patients with refractory septic shock. Decreased CO or distal necrosis has been reported as possible adverse events. ${ }^{277,278}$ Yildizdas et al evaluated the effect of continuous infusion of terlipressin in a randomized control trial in pediatric patients with septic shock and high catecholamine requirement. Terlipressin infusion had no effect on mortality. ${ }^{279}$

Angiotensin can also be used to increase blood pressure in patients who are refractory to norepinephrine, however, its clinical role is not as well defined. ${ }^{280}$ Phenylephrine is another pure vasopressor with no beta adrenergic activity. ${ }^{281}$ Its clinical role is also limited. NO inhibitors and methylene blue are considered investigational therapies. ${ }^{282-285}$ Studies have shown an increased mortality with nonselective NO synthase inhibitors suggesting that increasing blood pressure through excessive vasoconstriction can have adverse effects. $^{283}$

Glucose, Calcium, Thyroid, and Hydrocortisone Replacement Hypoglycemia, hyperglycemia, and glycemic variability have been associated with worse short-term outcomes in critically ill children. ${ }^{286,287}$ Hypoglycemia must be rapidly diagnosed and promptly treated. Hyperglycemia in non-diabetic children with sepsis has been associated with worse outcomes. ${ }^{288,289}$ Branco et al. ${ }^{288}$ reported a greater risk of death with hyperglycemia $(\geq 178 \mathrm{mg} / \mathrm{dL})$ in 57 children with septic shock. Day et al. ${ }^{289}$ reported hyperglycemia $(>180 \mathrm{mg} / \mathrm{dL})$ negatively correlated with ventilator free days at 30 days in a retrospective review of 97 children with meningococcal sepsis. Hyperglycemia and hypoglycemia during critical illness may simply represent epiphenomena. In contrast, Mesotten et al. ${ }^{290}$ reported that brief hypoglycemia $(\leq 40 \mathrm{mg} / \mathrm{dL})$ caused by tight glycemic control in a pediatric randomized controlled trial was not associated with worse neurocognitive outcome approximately four years later. 
Randomized controlled trials of tight glycemic control have been conducted primarily in post-cardiac surgery children. ${ }^{291-294}$ Results are conflicting, with one study showing a reduction in PICU length of stay and inflammatory markers ${ }^{293}$ and the other three not showing an improvement in mortality or morbidity. ${ }^{291,292,294}$ Hyperglycemia in children with meningococcal sepsis has been partially attributed to the suppression of insulin production by proinflammatory mediators rather than insulin resistance as seen in other critical illnesses. ${ }^{295,296}$

Calcium replacement should be directed to normalize ionized calcium concentration, however it's safety and efficacy has not been established in septic shock. Replacement with thyroid and/or hydrocortisone can also be lifesaving in children with thyroid and/or adrenal insufficiency and catecholamine-resistant shock. ${ }^{297-314}$ Hypothyroidism is relatively common in children with Trisomy 21 and children with central nervous system pathology, (e.g. pituitary abnormality). Hypothyroidism may manifest clinically after the administration of corticosteroids for adrenal insufficiency and needs to be recognized and treated promptly. Infusion therapy with Tri-iodothyronine may be beneficial in postoperative congenital heart disease patients but has yet to be studied in children with septic shock.

Multiple studies suggest sepsis induced changes in the HPA axis ${ }^{315,316}$ glucocorticoid receptor changes, 317 and changes in cortisol metabolism during sepsis. ${ }^{318}$ Possible rationales for the use of corticosteroids in sepsis are beneficial pharmacologic effect on the cardiovascular system and anti-inflammatory properties. ${ }^{301,319-}$ ${ }^{321}$ A recent prospective study of critically ill children reported a prevalence of relative adrenal insufficiency in critically ill children of $30.2 \%$ on the first day of admission and $19.8 \%$ on the second day of admission as defined by an increase in cortisol of less than $9 \mathrm{mcg} / \mathrm{dL}$ after administration of low dose $(1 \mathrm{mcg})$ adrenocorticotropic hormone $(\mathrm{ACTH}){ }^{315}$ The prevalence of relative adrenal insufficiency reported in other studies is widely variable depending on the diagnostic criteria used and remains somewhat arbitrary. ${ }^{322}$ Low or high serum cortisol concentrations have been associated with increased sepsis mortality. ${ }^{323}$ A cutoff of $<25$ $\mathrm{mcg} / \mathrm{dL}$ in adults with septic shock has been described as useful to predict hemodynamic response to cortisol administration. In children, a serum cortisol concentration of $>36 \mathrm{mcg} / \mathrm{dL}$ and a lack in response to ACTH 
stimulation may predict a failure to respond to exogenous corticosteroid administration. ${ }^{324}$ Several factors contribute to the diagnostic controversy. In one study, patients with relative adrenal insufficiency had higher basal cortisol concentrations than those without relative adrenal insufficiency $(28.6 \mathrm{mcg} / \mathrm{dl}$ versus $16.7 \mathrm{mcg} / \mathrm{dl}$, $\mathrm{p}<0.001) .{ }^{315}$ A study of total and free cortisol concentrations among critically ill children found a high incidence of biochemical adrenal insufficiency utilizing various definitions, but no evidence of corresponding clinical adrenal insufficiency. ${ }^{325}$

Hypoproteinemia decreases total cortisol concentrations, but free cortisol concentrations have been observed to be high in patients with serum albumin concentrations less than $2.5 \mathrm{mg} / \mathrm{dl}$ despite a low total serum cortisol concentration in nearly $40 \%$ of adults tested. ${ }^{326}$ Reduced cortisol metabolism in critically ill adults suggests a $50 \%$ decrease in clearance of corticosteroids due to suppression of activity or expression of metabolizing enzymes. Furthermore, the authors observed a dissociation of cortisol concentrations after ACTH stimulation. In patients with elevated serum cortisol concentrations due to reduced clearance, ACTH concentrations were found to be lower suggesting negative feedback on the HPA axis. Mortality is correlated with a higher degree of suppression of corticosteroid metabolism in adults. ${ }^{318}$ The role of free cortisol in the diagnosis of adrenal insufficiency determination has not been sufficiently elucidated. Administration of etomidate $^{327}$, megestrol ${ }^{328}$, and ketoconazole ${ }^{329}$ have been identified as iatrogenic causes of adrenal insufficiency due to their interference with cortisol production.

Non-survivors have exceedingly high ACTH/cortisol ratios within the first eight hours of meningococcal shock. ${ }^{298-302,312,330}$ The lack of increase in serum cortisol concentration $(<9 \mathrm{mcg} / \mathrm{dL})$ in patients undergoing an ACTH stimulation test with baseline cortisol concentrations $>18 \mathrm{mcg} / \mathrm{dL}$ was associated with catecholamine refractory shock, but not mortality. ${ }^{306,322,324}$ The value of ACTH stimulation test in the diagnosis and treatment of relative adrenal insufficiency and CIRCI "critical illness-related corticosteroid insufficiency" in children and adults remains unclear. ${ }^{315}$ No gold standard has been established for the diagnosis of adrenal insufficiency in critical illness. Absolute adrenal insufficiency has been defined as a basal serum cortisol concentration of $<7$ 
$\mathrm{mcg} / \mathrm{dL}$ and peak serum cortisol of $<18 \mathrm{mcg} / \mathrm{dL}$ after stimulation. ${ }^{322}$ Others suggested a basal serum cortisol of $<5$ or $<9 \mathrm{mcg} / \mathrm{dL}$ and use the same peak cutoff after ACTH stimulation of $<18 \mathrm{mcg} / \mathrm{dL}$ for the definition of absolute adrenal insufficiency. ${ }^{315}$ Relative adrenal insufficiency has been proposed as a basal serum cortisol concentration of $<20 \mathrm{mcg} / \mathrm{dL}$ and delta $<9$ after ACTH stimulation, ${ }^{331}$ or a basal total cortisol $<10$, delta total cortisol $<9$ or free cortisol $<2 . .^{332,333}$

Patients at risk of inadequate cortisol/aldosterone production due to absolute adrenal insufficiency in the setting of shock include children with purpura fulminans and Waterhouse-Friedrichson syndrome, children who previously received steroid therapies for chronic illness, and children with pituitary or adrenal abnormalities. These patients may benefit from stress doses of hydrocortisone early in the course of their illness, in the presence of sepsis without shock. The need for separate mineralocorticoid replacement during critical illness is unclear. Serum aldosterone concentrations are markedly depressed in menigococcemia. ${ }^{334}$ The administration of fludrocortisone in addition to hydrocortisone has been suggested in septic shock ${ }^{335}$ with the benefit of shortening the duration of norepinephrine administration in the septic subgroup, over hydrocortisone administration alone. The mineralocorticoid activity of hydrocortisone alone however, may be sufficient and should not exceed $200 \mathrm{mg}$ per day (equivalent to about $100 \mathrm{mg} / \mathrm{m}^{2} /$ day) when given to adults. ${ }^{336}$

Hydrocortisone's mineralocorticoid activity is deemed to be equivalent to $150 \mathrm{mcg} / \mathrm{m}^{2} /$ day of $9 \alpha$-fludrocortisone when a total daily dose of $20-50 \mathrm{mg}$ of hydrocortisone is reached ${ }^{337,338}$.

Treatment with low dose hydrocortisone for relative adrenal insufficiency has gained interest since the first RCT in adults with septic shock was published in 2002, proving a mortality benefit. ${ }^{297}$ A subsequent RCT in adults did not confirm a mortality advantage for the treatment with stress doses of hydrocortisone, leaving us with conflicting results ${ }^{339}$. The pediatric literature lacks large RCTs evaluating the benefit of corticosteroids specifically in septic shock and refractory septic shock and a pediatric metanalysis evaluating the role of corticosteroids in shock did not demonstrate benefit. ${ }^{324}$ Trials in premature newborns, and other studies in 
children and adults have repeatedly shown a positive effect on the cardiovascular system by decreasing the duration and/or amount of catecholamines administered. ${ }^{297,335,339-342}$

Very high dose corticosteroid administration in septic shock has previously been associated with higher infection rates. Several studies published since 2006 point to the possibility of infectious complications as a result of corticosteroid administration in adults and children. ${ }^{339,343,344}$ Steroid use was linked to disseminated candidiasis in a case report, ${ }^{345}$ however infectious complications were not found to be increased by the administration of corticosteroids in children and adults with shock in other studies. ${ }^{319,324}$ Other side effects in patients receiving corticosteroids have been described, including hyperglycemia ${ }^{319,346}$ and bleeding ${ }^{324}$. Concerns regarding the development of myopathy in association with corticosteroid therapy have been raised, but not confirmed in either the adult ${ }^{319}$ or pediatric population with shock ${ }^{320}$. A rise in sodium during corticosteroid administration was observed in several studies and self-resolves after discontinuation. ${ }^{319}$ Pediatric septic shock is associated with suppression of all aspects of adaptive immunity. ${ }^{347}$

Analysis of data obtained during the RESOLVE Trial did not reveal treatment benefit associated with the administration of corticosteroids, ${ }^{348}$ but the concerns for higher mortality associated with corticosteroid administration raised by the analysis of the PHIS database were not corroborated. Studies in patients with serious infectious illnesses, i.e. meningococcal meningitis, have shown cortisol production rates between 4-15 times the normal daily production rate of $5.7 \mathrm{mg} / \mathrm{m}^{2298,349,350}$ to $12.5 \mathrm{mg} / \mathrm{m}^{2} 298,299,351,352$ of cortisol. Effects on the cardiovascular system in shock have been shown at the lower end of the stress dose range. Administration of stress doses as low as $0.18 \mathrm{mg} / \mathrm{kg} /$ hour of hydrocortisone (about $4 \mathrm{mg} / \mathrm{kg} /$ day) shorten the time to cessation of vasopressor support (median time 2 days vs 7 days in the placebo group) without improving mortality in adults. ${ }^{353}$ In a single center study of term neonates, the administration of $45 \mathrm{mg} / \mathrm{m}^{2} / \mathrm{day}$ of hydrocortisone resulted in similar complication rates compare to historical controls and resulted in a statistically significant increase in blood pressure at 2, 6, 12 and 24 hours after initiation. ${ }^{342}$ Cortisol levels in adults after intravenous boluses of $50 \mathrm{mg}$ of hydrocortisone given 6-hourly, showed peak plasma cortisol levels over $100 \mu \mathrm{g} / \mathrm{dL}$, and 
nadir levels remained elevated at 40-50 $\mu \mathrm{g} / \mathrm{Dl} .{ }^{336}$ Among children, only those with fluid refractory shock were found to have adrenal insufficiency. ${ }^{354}$

Persistent Pulmonary Artery Hypertension (PPHN) of the Newborn Therapy Inhaled nitric oxide therapy is the treatment of choice for uncomplicated PPHN. ${ }^{355,356}$ However, metabolic alkalinization remains an important initial resuscitative strategy during shock because PPHN can reverse when acidosis is corrected. ${ }^{357}$ For centers with access to inhaled nitric oxide, this is the only selective pulmonary vasodilator reported to be effective in reversal of PPHN. ${ }^{359-363}$ Milrinone may be added to improve heart function as tolerated. ${ }^{364-366}$ Investigations support use of inhaled iloprost (synthetic analog of prostacyclin) or adenosine infusion as modes of therapy for PPHN. ${ }^{367-372}$ ECMO remains the therapy of choice for patients with refractory PPHN and sepsis. ${ }^{373-376}$

Extracorporeal therapies Various extracorporeal therapies such as extracorporeal membrane oxygenation (ECMO), continuous renal replacement therapy (CRRT), and blood purification (hemofiltration, hemoperfusion, and therapeutic plasma exchange) have been reported with various successes in the management of pediatric sepsis and septic shock. ECMO is a viable therapy for refractory septic shock in neonates and children. ${ }^{373-382}$ Neonates have comparably good outcomes (80\%+ survival) whether the indication for ECMO is refractory respiratory failure or refractory shock from sepsis. Pediatric and adult patients with sepsis have lower survival (historically $\leq 50 \%$ ) than neonates, but experienced ECMO centers are now reporting survival rates approaching $75 \%{ }^{383-385}$ for refractory shock and $90 \%$ for refractory pneumonia ${ }^{386}$. Although ECMO survival is similar in pediatric patients with and without sepsis, thrombotic complications are common in sepsis. Efforts are warranted to reduce ECMO-induced hemolysis because free heme scavenges nitric oxide, adenosine, and ADAMTS-13 (a.k.a. von Willebrand factor-cleaving protease) leading to microvascular thrombosis, reversal of portal blood flow and multiple organ failure. ${ }^{387,388}$ Severe hemolysis (plasma $\mathrm{Hb}>1 \mathrm{~g} / \mathrm{L}$ ) is associated with longer ECMO runs, more blood product administration, and increased mortality. ${ }^{389}$ Independent risk factors for hemolysis on ECMO include very negative inlet pressures, higher pump speeds, kinked or narrowed cannulae, 
and non-pediatric oxygenators. ${ }^{389}$ The risk of hemolysis can be mitigated by using the proper sized cannulas for age, avoiding excessive pump speeds, and maintaining the negative inlet pressure close to the specified pressure drop given by the manufacturer for the flow rate and never greater than $-100 \mathrm{mmHg} .{ }^{390,391}$

Outcome benefits of CRRT, either alone or in tandem with ECMO, are uncertain in pediatric sepsis. Theoretical benefits of CRRT in sepsis could include prevention or management of fluid overload, management of acute kidney injury (AKI), clearance of lactate and organic acids, binding of inflammatory mediators, reversal of coagulopathy or some combination of these actions. ${ }^{392,393}$ Mortality in children receiving CRRT in sepsis ranges from 39-59\%, likely reflecting severity of illness of patient selection for CRRT use. The best documented association of CRRT and outcome is related to fluid overload. In general, use of CRRT earlier in the course of multiple organ dysfunction syndrome, including septic patients, has been associated with decreased mortality in children, even when adjusted for severity of illness. ${ }^{394-396}$ No specific randomized trials of CRRT use in pediatric sepsis have been performed. In adults, use of higher CRRT flux rates (greater than 35 $\mathrm{mL} / \mathrm{kg} / \mathrm{h}$ filtration-dialysis flux), while initially encouraging, has not shown overall mortality benefit in subsequent randomized trials and meta-analysis. ${ }^{397,398}$ Investigators in pediatric settings have reported that the use of high flux flow rate CRRT, with concomitant FFP, anti-thrombotic protein C infusion, or in combination with plasma exchange on ECMO have been associated with reduced inotrope/vasopressor requirements in children with refractory septic shock and purpura. ${ }^{399-405}$

Investigators have reported more experiences with blood purification for pediatric sepsis since the last update. In 2010, guided by the evidence-based adult and pediatric literature, the American Society of Apheresis gives a category III recommendation, which is "Optimum role of apheresis therapy is not established. Decision making should be individualized", for the use of therapeutic plasma exchange (TPE) for sepsis with multiorgan failure. ${ }^{406}$ Meta-analysis of adult randomized trials reports survival benefit with the use of blood purification for sepsis by hemoperfusion or TPE but not by hemofiltration. ${ }^{407}$ In this regard, pediatric case series and small trials have reported survival benefits with the use of TPE for sepsis-induced multiple organ 
dysfunction syndrome (MODS), and in particular, patients with significant coagulopathy. ${ }^{405,408-416}$ These studies use TPE as a strategy to reverse MODS and not for shock resuscitation. As for other blood purification techniques for pediatric sepsis, a large RCT testing plasma filtration was stopped due to poor recruitment, ${ }^{417}$ and hemoperfusion experience had been very limited. ${ }^{418-420}$

\section{RECOMMENDATIONS}

\section{PEDIATRIC SEPTIC SHOCK (FIGURE 3)}

Diagnosis The inflammatory triad of fever, tachycardia, and vasodilation is common in children with benign infections. Septic shock is suspected when children with this triad have a change in mental status manifested as irritability, inappropriate crying, drowsiness, confusion, poor interaction with parents, lethargy or becoming unarousable. The clinical diagnosis of septic shock is made in children who 1) have a suspected infection manifested by hypothermia or hyperthermia, and 2) have clinical signs of inadequate tissue perfusion including any of the following: decreased or altered mental status, prolonged capillary refill $>2$ seconds, diminished pulses, mottled cool extremities, or flash capillary refill, bounding peripheral pulses and wide pulse pressure or decreased urine output $<1 \mathrm{~mL} / \mathrm{kg} / \mathrm{h}$. Hypotension is not necessary for the clinical diagnosis of septic shock; however, its presence in a child with clinical suspicion of infection is confirmatory.

We recommend that each institution develop a Recognition Bundle (see Figure 1) to optimize identification of patients at risk for septic shock that is based on vital sign abnormalities and high-risk criteria (1C)

The Recognition Bundle should contain:

1) A trigger tool. Elements that are recommended for use in a trigger tool include vital signs, physical exam, and at-risk populations. (An example trigger tool is located in Figure 2)

2) Rapid clinician assessment within 15 minutes for any patient that is identified by the trigger tool.

3) Activation of a sepsis Resuscitation Bundle within 15 minutes for patients with suspected septic shock. 
We recommend that each institution also develop or adopt a first hour Resuscitation and Stabilization Bundle (see Figure 1) to optimize time to completion of First Hour and Stabilization tasks when a patient with suspected septic shock is identified (1C)

The Resuscitation Bundle may contain:

1) IO or IV access within 5 minutes

2) Appropriate fluid resuscitation initiated within 30 minutes

3) Initiation of broad spectrum antibiotics within 60 minutes

4) Blood culture if it does not delay antibiotic administration

5) Appropriate use of peripheral or central inotrope within 60 minutes

The Stabilization Bundle may contain:

1) Multimodal monitoring to guide fluid, hormonal, and cardiovascular therapies to attain a normal MAP CVP for age $(55+1.5 \mathrm{x}$ age in years $)$, and SCVO2 $>70 \%$ and/or Cardiac Index 3.3-6.0 L/min $/ \mathrm{m}^{2}$

2) Administration of appropriate antibiotic therapy and source control

We recommend that each institution develop or adopt a Performance Bundle (see Figure 1) to identify barriers to attaining the Recognition, Resuscitation, and Stabilization Bundle Goals (1C)

The Performance Bundle should contain:

1) Measurement of adherence as well as achievement of goals and individual components.

\section{ABCs: The first hour of Resuscitation (Emergency Room Resuscitation)}

Goals: (Level 1C)

Maintain or restore airway, oxygenation, and ventilation

Maintain or restore circulation, defined as normal perfusion and blood pressure

Maintain or restore threshold heart rate 


\section{Therapeutic Endpoints (Level 1C)}

Capillary refill $\leq 2$ seconds, normal pulses with no differential between the quality of peripheral and central pulses, warm extremities, urine output $>1 \mathrm{ml} / \mathrm{kg} / \mathrm{h}$, normal mental status, normal blood pressure for age (only reliable when pulses palpable), normal glucose concentration, normal ionized calcium concentration.

\section{Monitoring (Level 1C)}

Pulse oximeter

Continuous EKG

Blood pressure and pulse pressure

Temperature

Urine Output

Glucose, Ionized Calcium

\section{Airway and Breathing (Level 1C)}

Airway and breathing should be rigorously monitored and maintained. High flow nasal cannula oxygen is recommended as initial therapy. Lung compliance and work of breathing may change precipitously. In early sepsis, patients often have a respiratory alkalosis from centrally-mediated hyperventilation. As sepsis progresses, patients may have hypoxemia as well as metabolic acidosis and are at high risk to develop respiratory acidosis secondary to a combination of parenchymal lung disease and/or inadequate respiratory effort due to altered mental status. The decision to intubate and ventilate is based on clinical assessment of increased work of breathing, hypoventilation, or impaired mental status. Waiting for confirmatory laboratory tests is discouraged. If possible, volume loading and peripheral or central inotropic/vasoactive drug support is recommended before and during intubation because of relative or absolute hypovolemia, cardiac dysfunction, and the risk of suppressing endogenous stress hormone response with agents that facilitate intubation. Etomidate is not recommended. Ketamine with atropine pre-treatment should be considered the induction combination of choice during intubation, to promote cardiovascular integrity during the procedure. A short- 
acting neuromuscular blocking agent can facilitate intubation if the provider is confident and skilled.

\section{Circulation (Level 1C)}

Vascular access should be rapidly attained. In addition to direct visualization and/or palpation, portable nearinfrared imaging devices may assist in peripheral vascular access. Establish IO access if reliable PIV access cannot be attained in minutes. Powered IO devices (i.e. "IO drill”) can facilitate successful IO placement but should be reserved for use in children $>3 \mathrm{~kg}$. Fluid resuscitation should commence immediately unless hepatomegaly, rales, or a cardiac gallop are present. In the fluid-refractory patient, begin a peripheral inotrope (epinephrine) if a second PIV / IO is in place, while establishing a central venous line. When administered through a PIV / IO, the inotrope should be infused either as a dilute solution or with a second carrier solution running at a flow rate to assure that it reaches the heart in a timely fashion. Care must be taken to reduce dosage if evidence of peripheral infiltration / ischemia occurs as alpha adrenergic receptor mediated effects occur at higher concentrations for epinephrine and dopamine. Central dopamine, epinephrine, or norepinephrine can be administered as a first line drug as indicated by hemodynamic state when a central line is in place. It is generally appropriate to begin central venous infusion and wait until a pharmacologic effect is observed before stopping the peripheral infusion. Establishing a central venous line during the initial resuscitation may be dependent upon the availability of skilled personnel and appropriate equipment and should not delay or compromise ongoing resuscitation efforts. Utilization of bedside vascular imaging modalities such as ultrasound guidance can facilitate successful central venous access for skilled personnel familiar with such technologies. High frequency (7.5-13 MHz) probes should be used for infants and children, with higher frequencies yielding better resolution for the smallest patients $(<15 \mathrm{~kg})$. When transitioning from peripheral inotrope to central inotrope infusion it is generally appropriate to begin the vasoactive infusion(s) centrally and wait until a pharmacologic effect is observed before stopping the peripheral infusion. Although not an immediate concern when trying to establish emergency central venous access, heparin-bonded central venous catheters (CVCs) 
have been associated with reduced catheter-associated blood stream infections (CA-BSIs), and the operator may consider preferential insertion of these modified CVCs, if available.

\section{Fluid Resuscitation (Level 1C)}

Rapid fluid boluses of $20 \mathrm{ml} / \mathrm{kg}$ (isotonic crystalloid or $5 \%$ albumin) can be administered by push or rapid infusion device (pressure bag) while observing for signs of fluid overload (ie, the development of increased work of breathing, rales, cardiac gallop rhythm, or hepatomegaly). In the absence of these clinical findings, children can require $40-60 \mathrm{ml} / \mathrm{kg}$ in the first hour. Fluid can be pushed with the goal of attaining normal perfusion and blood pressure. Hypoglycemia and hypocalcemia should be corrected. A $10 \%$ dextrose containing isotonic IV solution can be run at maintenance intravenous fluid rates to provide age appropriate glucose delivery and to prevent hypoglycemia.

\section{Hemodynamic Support (Level IC)}

Central dopamine can be titrated to a maximum of $10 \mathrm{mcg} / \mathrm{kg} / \mathrm{min}$ through central access however epinephrine or norepinephrine are more likely to be beneficial. Central epinephrine can be started for cold shock $(0.05-0.3$ $\mathrm{mcg} / \mathrm{kg} / \mathrm{min}$ ) or norepinephrine can be titrated for warm shock to restore normal perfusion and blood pressure.

\section{Hydrocortisone Therapy (Level IC)}

If a child is at risk of absolute adrenal insufficiency or adrenal pituitary axis failure ( eg purpura fulminans, congenital adrenal hyperplasia, prior steroid exposure, hypothalamic/pituitary abnormality, intubation with etomidate induction) and remains in shock despite epinephrine or norepinephrine infusion then hydrocortisone can be administered ideally after attaining a blood sample for subsequent determination of baseline cortisol concentration. Hydrocortisone may be administered as an intermittent or continuous infusion at a dosage which may range from 1-2 mg/kg/day for stress coverage to $50 \mathrm{mg} / \mathrm{kg} /$ day titrated to reversal of shock.

\section{STABILIZATION: Beyond the first hour (PICU hemodynamic support).}

\section{Goals: $\quad$ (Level 1C)}

Normal perfusion, capillary refill $\leq 2$ secs, threshold heart rates

Perfusion pressure (MAP - CVP, or MAP - IAP) appropriate for age. 
$\mathrm{ScvO}_{2}>70 \%$

Cardiac index $>3.3 \mathrm{~L} / \mathrm{min} / \mathrm{m}^{2}$ and $<6.0 \mathrm{~L} / \mathrm{min} / \mathrm{m}^{2}$

\section{Therapeutic Endpoints: (Level 1C)}

Capillary refill $\leq 2$ seconds, threshold heart rates, normal pulses with no differential between the quality of the peripheral and central pulses, warm extremities, urine output $>1 \mathrm{ml} / \mathrm{kg} / \mathrm{h}$, normal mental status, CI $>3.3$ and $<$ 6.0 L/min $/ \mathrm{m}^{2}$ with normal perfusion pressure (MAP-CVP, or MAP-IAP) for age (Table 1), $\mathrm{ScvO}_{2}>70 \%$. Maximize preload in order to maximize CI, MAP - CVP. Normal INR, anion gap and lactate.

\section{Monitoring (Level 1C)}

Pulse oximetry

Continuous ECG

Continuous Intra-arterial Blood Pressure

Temperature (core)

Urine Output

Central Venous Pressure/ $\mathrm{O}_{2}$ saturation and/or

Pulmonary Artery Pressure/ $\mathrm{O}_{2}$ saturation

Cardiac Output

Serial limited echocardiogram

Glucose and Calcium

INR

Lactate, anion gap

\section{Fluid Resuscitation (Level 1C)}

Fluid losses and persistent hypovolemia secondary to diffuse capillary leak can continue for days. Ongoing fluid replacement should be directed at clinical endpoints including perfusion, pulmonary capillary wedge pressure/global end diastolic volume (when available), and cardiac output. Crystalloid is the fluid of choice in 
patients with $\mathrm{Hgb}>10 \mathrm{~g} / \mathrm{dL}$. Red blood cell transfusion can be given to children with $\mathrm{Hgb}<10 \mathrm{~g} / \mathrm{dL}$. FFP is recommended for patients with prolonged INR but as an infusion, not a bolus. Following shock resuscitation, diuretics / peritoneal dialysis / high flux continuous renal replacement therapy (CRRT) can be used to remove fluid in patients who are $10 \%$ fluid overloaded and unable to maintain fluid balance with native urine output / extra-renal losses.

Elevated lactate concentration and anion gap measurements can be treated by assuring both adequate oxygen delivery and glucose utilization. Adequate oxygen delivery (indicated by a $\mathrm{ScvO}_{2}>70 \%$ ) can be achieved by attaining $\mathrm{Hgb} \geq 10 \mathrm{~g} / \mathrm{dL}$ and cardiac output $>3.3 \mathrm{~L} / \mathrm{min} / \mathrm{m}^{2}$ using adequate volume loading and inotrope / vasodilator support when needed (as described below). Appropriate glucose delivery can be attained by giving a D10\% containing isotonic IV solution at fluid maintenance rate. Appropriate glucose uptake can be attained in subsequently hyperglycemic patients by titrating a glucose / insulin infusion to prevent hyperglycemia (keep glucose concentration $\leq 150 \mathrm{mg} / \mathrm{dL}$ ) and hypoglycemia (keep glucose concentration $\leq 80$ $\mathrm{mg} / \mathrm{dL}$ ). The use of lesser glucose infusion rates (eg D5\% or lower volumes of D10\%) will not provide glucose delivery requirements.

\section{Hemodynamic support (Level 1C)}

Hemodynamic support can be required for days. Children with catecholamine resistant shock can present with low cardiac output/high systemic vascular resistance, high cardiac output /low systemic vascular resistance, or low cardiac output/low systemic vascular resistance shock. Although children with persistent shock commonly have worsening cardiac failure, hemodynamic states may completely change with time. Titration of vasoactive infusion(s) may be guided by clinical examination (blood pressure, heart rate, and capillary refill/skin perfusion analysis) and laboratory data (arterial blood gas and $\mathrm{ScvO}_{2}$ analysis). For patients with persistent shock (reduced urine output, poor perfusion, metabolic/lactic acidosis, or hypotension), a more accurate assessment of cardiac output may be warranted. Many modalities for cardiac output assessment currently exist and include, pulmonary artery, PICCO, femoral artery or thermodilution catheters, and/or cardiac 
output estimated by Doppler ultrasound. These additional data may justify further changes in the vasoactive regimen with resolution of shock. Therapies should be directed to maintain mixed venous $/ \mathrm{ScvO}_{2}>70 \%, \mathrm{CI}>$ 3.3 L/min $/ \mathrm{m}^{2}<6.0 \mathrm{~L} / \mathrm{min} / \mathrm{m}^{2}$, and a normal perfusion pressure for age (MAP-CVP).

Shock with Low Cardiac Index, Normal Blood Pressure and High Systemic Vascular Resistance (Level 1D) Milrinone is considered by the authors to be the first line inodilator in patients with epinephrine-resistant shock and normal blood pressure. As noted above, the long elimination half-life of these drugs can lead to slowly reversible toxicities (hypotension, tachyarrhythmias or both) particularly if abnormal renal or liver function exists. Such toxicities can be reversed in part with norepinephrine infusion. Additional volume loading may be necessary to prevent hypotension when loading doses are used. Nitroprusside or nitroglycerin maybe considered as second line vasodilators. Monitoring is needed to avoid cyanide or isothiocyanate toxicity. Levosimendan and enoximone may have a role in recalcitrant low cardiac output syndrome. Thyroid replacement with triiodothyronine is warranted for thyroid insufficiency, and hydrocortisone replacement can be warranted for adrenal or HPA axis insufficiency

Shock with Low Cardiac Index, Low Blood Pressure, and Low Systemic Vascular Resistance (Level 1D) Norepinephrine can be added to/or substituted for epinephrine to increase diastolic blood pressure and systemic vascular resistance. Once an adequate blood pressure is achieved, dobutamine, type III PDE inhibitors such as milrinone or enoximone, (which is more cardio-selective than milrinone), or levosimendan can be added to norepinephrine to improve cardiac index and $\mathrm{ScvO}_{2}$. Thyroid replacement with tri-iodothyronine is warranted for thyroid insufficiency, and hydrocortisone replacement is warranted for adrenal or HPA axis insufficiency.

\section{Shock with High Cardiac Index and Low Systemic Vascular Resistance (Level 1D)}

When titration of norepinephrine and fluid does not resolve hypotension, then low dose vasopressin, angiotensin, or terlipressin can be helpful in restoring blood pressure; however, these potent vasoconstrictors can reduce cardiac output, therefore it is recommended that these drugs are used with $\mathrm{CO} / \mathrm{ScvO} \mathrm{O}_{2}$ monitoring. In this situation, additional inotropic therapies will be required such as low dose epinephrine or dobutamine. 
Terlipressin is a longer acting drug than angiotensin or vasopressin so toxicities are more long-acting. As with other forms of severe shock, thyroid hormone or adrenocortical replacement therapy may be added for appropriate indications. We recommend frequent reevaluation of hemodynamic parameters when a patient requires the use of vasopressors, especially in relation to $\mathrm{CO}, \mathrm{SVR}$ and peripheral perfusion so as to choose the appropriate combination with inotropic or vasodilator drugs + /- fluids.

\section{Refractory Shock (Level 2C)}

Children with refractory shock must be suspected to have unrecognized morbidities (treatment in parenthesis), including pericardial effusion (pericardiocentesis), pneumothorax (thoracentesis), hypoadrenalism (adrenal hormone replacement), hypothyroidism (thyroid hormone replacement), ongoing blood loss (blood replacement/hemostasis), increased intra-abdominal pressure (peritoneal catheter, or abdominal release), necrotic tissue (nidus removal), inappropriate source control of infection (remove nidus and use antibiotics with the lowest MIC possible, preferably < 1, use IVIG for toxic shock), excessive immunosuppression (wean immunosuppressants), or immune compromise (restore immune function; eg, white cell growth factors/transfusion for neutropenic sepsis). When these potentially reversible causes are addressed, ECMO becomes an important alternative to consider. The expected survival with ECMO for septic shock is no greater than $50 \%$ in children, although some centers have recently reported survival rates as high as $75 \%$ by using high flow, goal-directed central ECMO where the right atrium and ascending aorta are cannulated directly. This approach mitigates any differential cyanosis and allows the highest possible flow rates, which may facilitate faster resolution of shock. If high flow rates are necessary to resolve shock, it is important to monitor for, and prevent, hemolysis. Maintaining plasma free hemoglobin concentration $<0.05 \mathrm{~g} / \mathrm{L}$ by using adequate catheter, circuit and oxygenator sizes for age. Monitor the inlet pressure as close to the patient as possible (at the connection between the venous cannula and the tubing) and maintain this pressure between zero and the expected pressure drop for the cannula size and the pump flow that is employed. At pressures below these points, there is an increased risk for creating negative pressure in the vessel leading to vessel damage. The 
absolute number that is measured should never be more than $-100 \mathrm{mmHg}$ because of the increased hemolysis that occurs at these levels. Thus the cannula size should be chosen to stay below this limit at the peak expected flow. If these limits are approached, the pump speed should be temporarily reduced while the cause is urgently sought out and corrected. Aside from unnecessarily high circuit flow targets, causes of extremely negative inlet pressures include hypovolemia, inadequate cannula size, partial cannula obstruction or kinking, or high intrathoracic pressure (eg. cardiac tamponade, excessive PEEP, pneumothorax, abdominal compartment syndrome). Adequate cannula placement can be confirmed using both chest x-ray and ultrasound guidance. Use of CRRT should be considered for management of potential or actual fluid overload and in patients with purpura. CRRT dosing of 20-25 ml/kg/hr is adequate. High flux CRRT dosing (> $35 \mathrm{ml} / \mathrm{kg} / \mathrm{hr}$ ) can be utilized, but benefits are theoretical. Consideration should be given to use of CRRT on ECMO primarily for improvement of fluid balance. TPE should not be used during the initial septic shock resuscitation. Once shock resuscitation is addressed, TPE could be considered as a strategy to reverse MODS, especially in patients with significant coagulopathy. Titration of medications will be needed during the procedure to prevent hemodynamic changes because TPE will also remove inotropes, vasopressors and sedatives,. Citrate, a calcium chelator, is used as an anticoagulant for the TPE circuit, therefore calcium levels will need to be monitored and replenished during the procedure.

\section{NEWBORN SEPTIC SHOCK (FIGURE 4)}

Diagnosis Septic shock should be suspected in any newborn with tachycardia, respiratory distress, poor feeding, poor tone, poor color, tachypnea, diarrhea, or reduced perfusion, particularly in the presence of a maternal history of chorioamnionitis or prolonged rupture of membranes. It is important to distinguish newborn septic shock from cardiogenic shock caused by closure of the patent ductus arteriosus in newborns with ductaldependent complex congenital heart disease. Any newborn with shock and hepatomegaly, cyanosis, a cardiac murmur, or differential upper and lower extremity blood pressures or pulses should be started on prostaglandin 
infusion until complex congenital heart disease is ruled out by echocardiographic analysis. Inborn errors of metabolism resulting in hyperammonemia or hypoglycemia may simulate septic shock and appropriate laboratory tests should be obtained to rule out these conditions. Newborn septic shock is typically accompanied by increased pulmonary vascular resistance and artery pressures. Persistent pulmonary hypertension (PPHN) can cause right ventricle failure with right to left shunting at the atrial/ductal levels causing cyanosis.

\section{ABCs: The first hour of Resuscitation (Delivery Room Resuscitation)}

\section{Goals: (Level 1C)}

Maintain airway, oxygenation, and ventilation

Restore and maintain circulation, defined as normal perfusion and blood pressure

Maintain neonatal circulation

Maintain threshold heart rates

\section{Therapeutic Endpoints: (Level 1C)}

Capillary refill $\leq 2$ seconds, normal pulses with no differential in quality between peripheral and central pulses, warm extremities, urine output $>1 \mathrm{ml} / \mathrm{kg} / \mathrm{h}$, normal mental status, normal blood pressure for age, normal glucose and calcium concentrations.

Difference in pre- and post-ductal $\mathrm{O}_{2}$ saturation $<5 \%$

$95 \%$ arterial oxygen saturation

\section{Monitoring: (Level 1C)}

Temperature

Pre- and Post-Ductal Pulse oximetry

Intra-arterial (umbilical or peripheral) blood pressure

Continuous ECG

Blood pressure

Arterial pH 
Urine Output

Glucose, Ionized Calcium concentration

\section{Airway and Breathing (Level ID)}

Airway patency and adequate oxygenation and ventilation should be rigorously monitored and maintained.

High flow nasal cannula oxygen is the first choice for respiratory support. The decision to intubate and ventilate is based on clinical diagnosis of increased work of breathing or inadequate respiratory effort or marked hypoxemia. Volume loading and inotrope infusion is often necessary prior to intubation and ventilation because analgesia, sedation and positive pressure ventilation can reduce preload, precipitating severe hemodynamic instability or arrest. Critically ill neonates may have rapid decline in systolic and diastolic ventricular function, which implies the need for close reassessment as resuscitation progresses. Expertly timed and performed intubation and mechanical ventilation will enhance physiologic performance at all levels by obviating work of breathing and ensuring the best possible oxygenation and perfusion. Pharmacologic management of intubation includes, in addition to adequate fluid resuscitation, the use of atropine to prevent hemodynamically-significant bradycardia, and judicious analgesia, which can be accomplished in many cases with small doses of fentanyl, given slowly as $1-2$ microgram/kg aliquots. The use of NMDA-receptor antagonists such as ketamine is discouraged by many experts, given concerns regarding neurotoxicity. Etomidate is associated with adrenal suppression, and is generally discouraged, although the agent has been used successfully by some experts in this setting. Morphine, propofol, barbiturates, high-dose benzodiazepines and dexmedetomidine are likely to cause hemodynamic instability in the septic neonate and should not be used as first-line agents to secure the airway in this setting.

\section{Circulation (Level 1D)}

Vascular access can be rapidly attained according to NRP guidelines. Placement of an umbilical arterial and venous line is preferred. Intraosseous access, particularly in preterm newborns, is not the preferred route of drug administration. 


\section{Fluid Resuscitation (Level 1C)}

Fluid boluses of $10 \mathrm{ml} / \mathrm{kg}$ can be administered, observing for the development of hepatomegaly and increased work of breathing. Up to $60 \mathrm{ml} / \mathrm{kg}$ may be required in the first hour. Fluid should be infused with a goal of attaining normal perfusion and blood pressure. A D10 containing isotonic IV solution run at maintenance rate will provide age appropriate glucose delivery to prevent hypoglycemia.

\section{Hemodynamic Support (Level 1C)}

Patients with severe shock uniformly require cardiovascular support during fluid resuscitation. Although dopamine can be used as the first-line agent, its effect on pulmonary vascular resistance should be considered. A combination of dopamine at low dosage $(<8 \mathrm{mcg} / \mathrm{kg} / \mathrm{min})$ and dobutamine (up to10 $\mathrm{mcg} / \mathrm{kg} / \mathrm{min}$ ) is initially recommended. If the patient does not adequately respond to these interventions, then epinephrine $(0.05$ to 0.3 $\mathrm{mcg} / \mathrm{kg} / \mathrm{min}$ ) can be infused to restore normal blood pressure and perfusion.

\section{PPHN Therapy (Level 1B)}

Hyperoxygenate initially with $100 \%$ oxygen and institute metabolic alkalinization (up to $\mathrm{pH} 7.50$ ) with $\mathrm{NaHCO}_{3}$ or tromethamine unless and until iNO is available. Mild hyperventilation to produce a respiratory alkalosis can also be instituted until $100 \% \mathrm{O}_{2}$ saturation and $<5 \%$ difference in pre- and post-ductal saturations are obtained. Inhaled nitric oxide should be administered as the first treatment when available. Back-up therapies include milrinone and inhaled iloprost.

\section{STABILIZATION: Beyond the first hour (NICU hemodynamic support)}

\section{Goals: (Level 1C)}

Restore and maintain threshold heart rate.

Maintain normal perfusion and blood pressure.

Maintain neonatal circulation.

$\mathrm{ScvO}_{2}>70 \%$

$\mathrm{CI}>3.3 \mathrm{~L} / \mathrm{min} / \mathrm{m}^{2}$

SVC flow $>40 \mathrm{~mL} / \mathrm{kg} / \mathrm{min}$ 


\section{Therapeutic Endpoints (Level 1C)}

Capillary refill $\leq 2$ seconds, normal pulses with no differential between peripheral and central pulses, warm extremities, urine output $>1 \mathrm{ml} / \mathrm{kg} / \mathrm{h}$, normal mental status, normal blood pressure for age

$>95 \%$ arterial oxygen saturation

$<5 \%$ difference in pre- and post- ductal arterial oxygen saturation

$\mathrm{ScvO}_{2}>70 \%$

Absence of right-to-left shunting, tricuspid regurgitation, or right ventricular failure on echocardiographic analysis.

Normal glucose and ionized calcium concentrations

SVC flow $>40 \mathrm{~mL} / \mathrm{kg} / \mathrm{min}$

$\mathrm{CI}>3.3 \mathrm{~L} / \mathrm{min} / \mathrm{m}^{2}$

Normal INR

Normal anion gap, and lactate

Fluid overload $<10 \%$

Monitoring (Level 1C)

Pulse oximetry

Arterial pH

Continuous ECG

Continuous Intra-arterial Blood Pressure

Temperature

Glucose and Calcium concentration

Ins and Outs, Urine Output

Central Venous Pressure/ $\mathrm{O}_{2}$ saturation

Cardiac Output 
SVC flow

INR

Anion gap and lactate

\section{Fluid Resuscitation (Level 1C)}

Fluid losses and persistent hypovolemia secondary to diffuse capillary leak can continue for days. Ongoing fluid replacement should be directed at clinical endpoints, including perfusion and central venous pressure. Crystalloid is the fluid of choice in patients with $\mathrm{Hgb}>12 \mathrm{~g} / \mathrm{dL}$. Packed red blood cells can be transfused in newborns with $\mathrm{Hgb}<12 \mathrm{~g} / \mathrm{dL}$. Diuretics or CRRT are recommended in newborns who are $10 \%$ fluid overloaded and unable to attain fluid balance with native urine output/extra-renal losses. A D10\% containing isotonic IV solution run at maintenance rate can provide age appropriate glucose delivery to prevent hypoglycemia. Insulin infusion can be used to correct hyperglycemia. Diuretics are indicated in hypervolemic patients to prevent fluid overload.

\section{Hemodynamic support (Level 1C)}

A 5-day, six- hour per day course of IV pentoxifylline can be used to reverse septic shock in VLBW babies. In term newborns with PPHN, inhaled nitric oxide is often effective. Its greatest effect is usually observed at 20 PPM. In newborns with poor left ventricle function and normal blood pressure, the addition of nitrosovasodilators or type III phosphodiesterase inhibitors to epinephrine $(0.05-0.3 \mathrm{mcg} / \mathrm{kg} / \mathrm{min}) \mathrm{can}$ be effective but must be monitored for toxicities. It is important to volume load based on clinical exam and blood pressure changes when using these systemic vasodilators. Tri-iodothyronine is an effective inotrope in newborns with thyroid insufficiency. Norepinephrine can be effective for refractory hypotension but $\mathrm{ScvO}_{2}$ should be maintained $>70 \%$. An additional inotrope therapy should be added if warranted. Hydrocortisone therapy can be added if the newborn has adrenal insufficiency (defined by a peak cortisol after ACTH $<18$ $\mathrm{mcg} / \mathrm{dL}$, or basal cortisol $<4 \mathrm{mg} / \mathrm{dL}$, or basal cortisol $<18$ with the need for intropic support). An additional inotrope therapy should be added if warranted. 
The total duration of umbilical catheterization should not exceed 5 days for an umbilical artery catheter or 14 days for an umbilical vein catheter. Low-doses of heparin $(0.25-1.0 \mathrm{U} / \mathrm{ml})$ should be added to the fluid infused through umbilical arterial catheters. Prophylactic use of heparin for peripherally inserted silastic percutaneous central venous catheters increases the likelihood that they will complete their intended use (complete therapy) and reduces catheter occlusion.

\section{Refractory Shock (Level 1C)}

Newborns with refractory shock must be suspected to have unrecognized morbidities (requiring specific treatment) including cyanotic or obstructive heart disease (responsive to PGE1), a critically large PDA (PDA closure), inborn errors of metabolism (responsive to glucose \& insulin infusion or ammonia scavengers), pericardial effusion (pericardiocentesis), pneumothorax (thoracentesis), ongoing blood loss (blood replacement/hemostasis), hypoadrenalism (hydrocortisone), and/or hypothyroidism (tri-iodothyronine). When these causes have been excluded, ECMO becomes an important therapy to consider in term newborns. The current ECMO survival rate for newborn sepsis is $80 \%$. Most centers accept refractory shock or a $\mathrm{PaO}_{2}<40$ mm Hg after maximal therapy to be sufficient indication for ECMO support. When on venovenous ECMO, persistent hypotension and/or shock should be treated with inotropic and/or vasopressor therapy, or conversion to veno-arterial support. Inotrope requirements can diminish when veno-arterial ECMO is used, but may persist. Calcium concentration should be normalized in the red blood cell pump prime (usually requires $300 \mathrm{mg}$ $\mathrm{CaCl}_{2}$ per unit of $\mathrm{pRBCs}$ ). In newborns with inadequate urine output and $10 \%$ fluid overload despite diuretics, CRRT is best performed while on the ECMO circuit. No specific recommendations for CRRT can be made in neonatal sepsis. Venous access for CRRT in neonates can be problematic, but in patients on ECMO, CRRT can be provided in tandem. It is a technical challenge to perform TPE in a neonate weighing less than $5 \mathrm{~kg}$. TPE should not be used during the initial septic shock resuscitation. Once the shock resuscitation is addressed, TPE could be considered as a strategy to reverse MODS, especially in patients with significant coagulopathy. 
Titration of medications and calcium replenishment will be needed during the procedure to prevent hemodynamic changes. 
Table 1. Threshold heart rates and perfusion pressure MAP-CVP or MAP-IAP for age. ' ${ }^{\text {a }}$ The 'Good Risk' heart rates are as defined in the Pediatric Risk of Mortality Scoring System. ${ }^{73}$ b The MAP goal is based on the estimated formula for $50^{\text {th }} \%$ MAP for a child with $50^{\text {th }} \%$ height in the healthy population with an expected $\mathrm{CVP}=0 \mathrm{~mm} \mathrm{Hg} .{ }^{421}$ When the CVP is greater than 0 then the goal MAP should be adjusted accordingly to achieve adequate perfusion pressure.

Heart Rate (b.p.m.) ${ }^{\mathrm{a}}$

Perfusion Pressure

MAP - CVP (mm Hg) $)^{\mathrm{b}}$
Newborn
110-160 b.p.m.
$(55+$ age $x 1.5)=55$
Infant (2 y.o)
90-160 b.pm
$(55+$ age $x 1.5)=58$
Child (7 y.o)
70-150 b.p.m.
$(55+$ age $x 1.5)=65$ 
Figure 1 Recognition, Resuscitation, Stabilization and Performance Bundles

\section{Recognition Bundle (see AAP Trigger tool example Figure 2)}

- Screen patient for septic shock using an institution trigger tool.

- Clinician assessment within 15 minutes for any patient who screens positive in the trigger tool.

- Initiate Resuscitation Bundle within 15 minutes for patient identified by the trigger tool whom the assessing clinician confirms suspicion of septic shock.

\section{Resuscitation Bundle ${ }^{22}$ (see Algorithm Figure 3 and 4)}

- Attain IV/IO access within 5 minutes.

- Appropriate fluid resuscitation begun within 30 minutes.

- Initiation of broad-spectrum empiric antibiotics within 60 minutes.

- Begin peripheral or central inotrope infusion therapy for fluid-refractory shock within 60 minutes.

\section{Stabilization Bundle (see Algorithm Figure 3 and 4)}

- Use multimodal monitoring to optimize fluid, hormonal, and cardiovascular therapies to attain hemodynamic goals

- Confirm administration of appropriate antimicrobial therapy and source control

\section{Performance Bundle}

- Measure adherence to Trigger, Resuscitation, and Stabilization Bundles

- Perform root cause analysis to identify barriers to adherence

- Provide an action plan to address identified barriers 
Figure 2 AAP trigger tool for Early Septic Shock Recognition

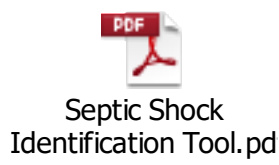


Figure 3

\section{0 min}

$5 \mathrm{~min}$

Recognize decreased mental status and perfusion.

Begin high flow nasal cannula $\mathrm{O}_{2}$ and establish IO/IV access according to PALS

If no hepatomegaly or rales/crackles then push $20 \mathrm{~mL} / \mathrm{kg}$ isotonic saline boluses and reassess after each bolus up to $60 \mathrm{~mL} / \mathrm{kg}$ until improved perfusion. Stop for rales, crackles or hepatomegaly. Correct hypoglycemia and hypocalcemia. Begin Antibiotics.

\section{$15 \mathrm{~min}$}

\section{Fluid refractory shock?}

Begin PIV/IO Inotrope infusion preferably epinephrine $0.05-0.3 \mathrm{mcg} / \mathrm{kg} / \mathrm{min}$ Use Atropine/Ketamine PIV/IO/IM if needed for Central Vein or Airway Access

If central access available titrate central Epinephrine $0.03-0.3 \mu \mathrm{g} / \mathrm{kg} / \mathrm{min}$ to reverse Cold Shock (Titrate central Dopamine 5-10 $\mu \mathrm{g} / \mathrm{kg} / \mathrm{min}$ if Epinephrine not available) Titrate central Norepinephrine from $0.05 \mu \mathrm{g} / \mathrm{kg} / \mathrm{min}$ and upward to reverse Warm Shock (Titrate Central Dopamine $>10 \mu \mathrm{g} / \mathrm{kg} / \mathrm{min}$ if Norepinephrine is not available)

\section{$60 \mathrm{~min}$}

\section{Catecholamine- resistant shock?}

If at risk for Absolute Adrenal Insufficiency begin Hydrocortisone Infusion Use Doppler US, PICCO, FATD, or PAC to Direct Fluid, Inotrope, Vasopressor, Vasodilators Goal is normal MAP- CVP, $\mathrm{ScvO}_{2}>70 \%$ and $\mathrm{Cl} 3.3-6.0 \mathrm{~L} / \mathrm{min} / \mathrm{m}^{2}$

Normal Blood Pressure

Cold Shock

$\mathrm{ScvO}_{2}<70 \% / \mathrm{Hgb}>10 \mathrm{~g} / \mathrm{dl}$ on Epinephrine?

Begin Milrinone infusion Add Nitroso-vasodilator if $\mathrm{Cl}$ index $<3.3 \mathrm{~L} / \mathrm{min} / \mathrm{m}^{2}$ with High SVRI and /or poor skin perfusion. Consider Levosimendan if unsuccessful
Low Blood Pressure

Cold Shock $\mathrm{ScvO}_{2}<70 \% / \mathrm{Hgb}>10 \mathrm{~g} / \mathrm{dL}$ on Epinephrine?

Add Norepinephrine to Epinephrine to attain normal diastolic blood pressure. If $\mathrm{Cl}$

$<3.3 \mathrm{~L} / \mathrm{min} / \mathrm{m}^{2}$ add

Dobutamine, Enoximone, Levosimendan, or Milrinone
Low Blood Pressure

Warm Shock

$\mathrm{SevO}_{2}>70 \%$

on Norepinephrine?

If euvolemic, add Vasopressin, Terlipressin or Angiotensin but if $\mathrm{Cl}$ decreases below 3.3 add Epinephrine, Dobutamine, Enoximone, Levosimendan

\section{Persistent Catecholamine- resistant shock?}

Evacuate Pericardial Effusion or Pneumothorax, Maintain IAP $<12 \mathrm{~mm} / \mathrm{Hg}$.

Refractory Shock?

ECMO

CRRT $35 \mathrm{~mL} / \mathrm{kg} / \mathrm{hr}$

When Stable 
Figure 4

\section{0 min $5 \mathrm{~min}$}

Recognize decreased perfusion, cyanosis, RDS.

Maintain airway and establish access according to NRP guidelines.

Push $10 \mathrm{~mL} / \mathrm{kg}$ isotonic crystalloid or colloid boluses an dreasses up to $60 \mathrm{~mL} / \mathrm{kg}$ until improved perfusion but stop if hepatomegaly develops.

Correct hypoglycemia and hypocalcemia. Begin antibiotics.

Begin prostaglandin infusion until echocardiogram r/o ductal - dependent lesion.

Fluid-refractory shock?

Infuse Dopamine $(<10 \mu \mathrm{g} / \mathrm{kg} / \mathrm{min})$

+ - Dobutamine

\section{Fluid refractory-dopamine resistant shock?}

Titrate Epinephrine $0.05-0.3 \mu \mathrm{g} / \mathrm{kg} / \mathrm{min}$

$60 \mathrm{~min}$

Catecholamine-resistant shock?

Goals

Normal MAP-CVP.ScvO $>2>70 \%$, SVC flow $>40 \mathrm{~mL} / \mathrm{kg} / \mathrm{min}$ or $\mathrm{CI}>3.3 \mathrm{~L} / \mathrm{m}^{2} / \mathrm{min}$

Cold Shock

Normal Blood Pressure

Poor LV function

$\mathrm{ScvO}_{2}<70, \mathrm{Hgb} \geq 12 \mathrm{~g} / \mathrm{dL}$

SVC flow $<40 \mathrm{~mL} / \mathrm{kg} / \mathrm{min}$

or $\mathrm{Cl}<3.3 \mathrm{~L} / \mathrm{m}^{2} / \mathrm{min}$ ?

Add Nitrosovasodilator, Milrinone

with volume loading
Cold Shock

Poor RV function PPHN $\mathrm{ScvO}_{2}<70 \%$

SVC flow $<40 \mathrm{~mL} / \mathrm{min}$ or $\mathrm{Cl}<3.3 \mathrm{~L} / \mathrm{m}^{2} / \mathrm{min}$ ?

Inhaled Nitric Oxide Inhaled Iloprost/ IV Adenosine

IV Milrinone, ? Levosimendan
Warm Shock Low Blood Pressure?

Titrate Volume Add Norepinephrine

? Vaso/Terlipressin/ Angiotensin

Keep $\mathrm{ScvO}_{2}>70 \%$, SVC flow $>40 \mathrm{~mL} / \mathrm{kg} / \mathrm{min}$, or $\mathrm{CI}>3.3 \mathrm{~L} / \mathrm{m}^{2} / \mathrm{min}$ with Inotropic Support

\section{Refractory Shock?}

Evacuate pneumothoraces and pericardial effusion. Give Hydrocortisone if Absolute Adrenal Insufficiency and $\mathrm{T}_{3}$ if Hypothyroid. Begin Pentoxifylline if VLBW newborn. Consider Closing PDA if hemodynamically significant.

ECMO

$(110 \mathrm{~mL} / \mathrm{kg} / \mathrm{min})$ 


\section{FIGURE LEGENDS}

Figure 1 Examples of Recognition, Resuscitation, Stabilization, and Performance Bundles

Figure 2 American Academy of Pediatrics trigger tool for Early Septic Shock Recognition

Figure 3 ACCM Algorithm for time sensitive, goal-directed stepwise management of hemodynamic support in infants and children. Proceed to next step if shock persists.

1) First hour goals - restore and maintain heart rate thresholds, capillary refill $\leq 2$ seconds, and normal blood pressure in the first hour/emergency department.

2) Subsequent ICU goals - if shock not reversed proceed to restore and maintain normal perfusion pressure (MAP-CVP) for age, $\mathrm{ScvO}_{2}>70 \%$, and $\mathrm{CI}>3.3<6.0 \mathrm{~L} / \mathrm{min} / \mathrm{m}^{2}$ in PICU.

Figure 4 ACCM Algorithm for time sensitive, goal-directed stepwise management of hemodynamic support in newborns. Proceed to next step if shock persists.

1) First hour goals - restore and maintain heart rate thresholds, capillary refill $\leq 2$ seconds, and normal blood pressure in the (first hour), and

2) Subsequent ICU goals - restore normal perfusion pressure (MAP-CVP), pre and post-ductal $\mathrm{O}_{2}$ saturation difference $<5 \%$, and either $\mathrm{ScvO}_{2}>70 \%$, SVC flow $>40 \mathrm{ml} / \mathrm{kg} / \mathrm{min}$ or CI $>3.3 \mathrm{~L} / \mathrm{min} / \mathrm{m}^{2}$ in NICU.

Abbreviations - MAP $-\mathrm{CVP}=$ mean arterial pressure - central venous pressure; $\mathrm{ScvO} 2=$ central venous oxygen saturation at right atrial / vena cava junction level; IAP = intra-abdominal pressure; US = Doppler ultra sound; PICCO = pulse index contour cardiac output catheter; FATD = femoral artery thermodilution catheter; $\mathrm{PAC}=$ pulmonary artery catheter ECMO = extracorporeal membrane oxygenator CRRT $=$ continuous renal replacement therapy; $\mathrm{CI}=$ cardiac index; $\mathrm{SVC}=$ superior vena cava flow; $\mathrm{T} 3=$ tri-idothyronine; $\mathrm{VLBW}=$ very low birth weight; PDA = patent ductus arteriosus 


\section{LITERATURE}

1)Carcillo JA, Fields AI; American College of Critical Care Medicine Task Force Committee members Clinical practice parameters for hemodynamic support of pediatric and neonatal patients in septic shock Crit Care Med 2002 30(6):1365-1378

2) Brierley J, Carcillo JA, Choong K, et al Crit Care Med. Clinical practice parameters for hemodynamic support of pediatric and neonatal septic shock: 2007 update from the American College of Critical Care Medicine. Crit Care Med 2009 Feb;37(2):666-88. doi: 10.1097/CCM.0b013e31819323c6.

3)Nhan NT, Phuong CXT, Kneen R, et al. Acute management of dengue shock syndrome: a randomized double-blind comparison of 4 intravenous fluid regimens in the first hour Clin Infect Dis 2001:32: 204-212.

4)Booy R, Habibi P, Nadel S, de Munter C, Britto J, Morrison A, Levin M; Meningococcal Research Group. Reduction in case fatality rate from meningococcal disease associated with improved healthcare delivery Arch Dis Child. 2001;85(5):386-390

5)Kutko MC, Calarco MP, Flaherty MB, Helmrich RF, Ushay HM, Pon S, Greenwald BM Mortality rates in pediatric septic shock with and without multiple organ failure Pediatr Crit Care Med 2003;4(3):333-337

6) DuPont HL, Spink WW: Infections due to gram negative organisms: an analysis of 860 patients with bacteremia at University of Minnesota Medical Center. 1958-1966. Medicine 1968; 48(4):307.

7) Stoll BJ, Holman RC, Shuchat A. Decline in Sepsis-Associated Neonatal and Infant Deaths 1974-1994. Pediatrics 1998; 102 : E 18 8)Angus DC, Linde Zwirble WT, Liddicker J et al. Epidemiology of severe sepsis in the U.S.: Analysis of incidence, outcome, and associated costs of care Crit Care Med 2001; 29(7):1303-10.

9)Watson RS, Carcillo JA, Linde-Zwirble WT, Clermont G, Lidicker J, Angus DC The epidemiology of severe sepsis in the United States Am J Respir Crit Care Med 2003; 167(5):695-701.

10)Wills BA, Nguyen MD, Ha TL, Dong TH, Tran TN, Le TT. Tran VD, Nguyen TH, Nguyen VC, Stepniewski K, White NJ, Farrar JJ Comparison of the three fluid solutions for resuscitation in dengue shock N Engl J Med 2005;353(9):877-889.

11) Maitland K, Kiguli S, Opoka RO, et al Maitland K, Kiguli S, Opoka RO, et al Mortality after fluid bolus in African children with severe infection. N Engl J Med. 2011 Jun 30;364(26):2483-95.

12)Han YY, Carcillo JA, Dragotta MA, Bills DM, Watson RS, Westerman ME, Orr RA Early reversal of pediatric-neonatal septic shock by community physicians is associated with improved outcome Pediatrics 2003;112(4):793-799.

13)Ninis N, Phillips C, Bailey L, Pollock JI, Nadel S, Britto J, Maconochie I, Winrow A, Coen PG, Booy R, Levin M The role of healthcare delivery on outcome of meningococcal disease in children:case-control study of fatal and non-fatal cases BMJ 2005 330(7505): 1475

\section{4)Codreiro et al}

15) de Oliveira CF, de Oliveira DS, Gottschald AF, et al ACCM/PALS haemodynamic support guidelines for paediatric septic shock: an outcomes comparison with and without monitoring central venous oxygen saturation. Intensive Care Med. 2008 Jun;34(6):1065-75. doi: 10.1007/s00134-008-1085-9.

16) Sankar J, Sankar MJ, Suresh CP, Dubey NK, Singh A: Early goal-directed therapy in pediatric septic shock: comparison Of outcomes "with" and "without" intermittent superior venacaval oxygen saturation monitoring: a prospective cohort study*. Pediatric critical care medicine : a journal of the Society of Critical Care Medicine and the World Federation of Pediatric Intensive and Critical Care Societies 2014, 15(4):e157-167.

17)Karapinar B, Lin JC, Carcillo JA ACCM guidelines use, correct antibiotic therapy, and immune suppressant withdrawal are associated with improved survival in pediatric sepsis, severe sepsis, and septic shock Crit Care Med 2004 32(12) suppl 573 A161 18) Maat M, Buysse CM, Emonts M,et al. Improved survival of children with sepsis and purpura: effects of age, gender, and era. Crit Care. 2007;11(5):R112. 
19) Cruz AT, Perry AM, Williams EA, Graf JM, Wuestner ER, Patel B. Implementation of goal-directed therapy for children with suspected sepsis in the emergency department. Pediatrics. 2011 Mar;127(3):e758-66.

20) Larsen GY, Mecham N, Greenberg R. An emergency department septic shock protocol and care guideline for children initiated at triage. Pediatrics. 2011 Jun;127(6):e1585-92.

21) Paul R, Neuman MI, Monuteaux MC, Melendez E. Adherence to PALS Sepsis Guidelines and Hospital Length of Stay.Pediatrics. 2012 Aug;130(2):e273-80. doi: 10.1542/peds.2012-0094. Epub 2012 Jul

22) Paul R, Melendez E, Stack A, Capraro A, Monuteaux M, Neuman MI. Improving adherence to PALS septic shock guidelines. Pediatrics. 2014 May;133(5):e1358-66. doi: 10.1542/peds.2013-3871. Epub 2014 Apr 7

23) Cruz AT ${ }^{1}$, Williams EA, Graf JM et al. Test characteristics of an automated age- and temperature-adjusted tachycardia alert in pediatric septic shock. Pediatr Emerg Care 2012 Sep;28(9):889-94. doi: 10.1097/PEC.0b013e318267a78a.

24) Sepanski RJ ${ }^{1}$, Godambe $\mathrm{SA}^{2}$, Mangum $\mathrm{CD}^{1}$, Bovat $\mathrm{CS}^{1}$, Zaritsky $\mathrm{AL}^{3}$, Shah $\mathrm{SH}^{4}$. Designing a pediatric severe sepsis screening tool. Front Pediatr. 2014 Jun 16;2:56. doi: 10.3389/fped.2014.00056. eCollection 2014.

25) Han YY, Kissoon N, and Carcillo JA et al The Global Pediatric Sepsis Initiative, 2014 Pediatr Crit Care Med

26)Anonymous. Practice parameters for hemodynamic support of sepsis in adults with sepsis. Task force of the American College of Critical Care Medicine, Society of Critical Care Medicine Crit Care Med 1999;27(3):695-7.

27)Parker MM, Shelhamer JH, Natanson C et al. Serial cardiovascular variables in survivors and nonsurvivors of human septic shock: heart rate as an early predictor of prognosis Crit Care Med 1987;15(10):923-9

28)Parker MM, Shelhamer JH, Bacharach SL et al. Profound but reversible myocardial depression in patients with septic shock. Ann Intern Med 1984;100(4):483-90

29)Pollack MM, Fields AI, Ruttimann UE et al Sequential cardiopulmonary variables of infants and children in septic shock Crit Care Med 1984;12(7):554-9

30)Pollack MM, Fields AI, Ruttimann UE Distributions of cardiopulmonary variables in pediatric survivors and nonsurvivors of septic shock. Crit Care Med 1985;13(6):454-9

31)Carcillo JA, Pollack MM, Ruttimann UE, et al. Sequential physiologic interactions in cardiogenic and septic shock. Crit Care Med 1989;17(1):12-6

32)Monsalve F, Rucabado L, Salvador A. et al. Myocardial depression in septic shock caused by meningococcal infection. Crit Care Med 1984;12(12):1021-3

33)Mercier JC, Beaufils F, Hartmann JF et al. Hemodynamic patterns of meningococcal shock in children Crit Care Med $1988 ; 16(1): 27$

34)Simma B, Fritz MG, Trawoger R et al. Changes in left ventricular function in shocked newborns. Intensive Care Med 1997;23(9):982-6

35)Walther FJ, Siassi B, Ramadan NA. Cardiac output in newborn infants with transient myocardial dysfunction. J Pediatr 1985; 107(5):781-5.

36)Ferdman B, Jureidini SB, Mink RB. Severe left ventricular dysfunction and arrhythmias as complication of gram positive sepsis: rapid recovery in children. Pediatr Cardiol 1998;19:482-86

37)Feltes TF, Pignatelli R, Kleinert S et al. Quantitated left ventricular systolic mechanics in children with septic shock utilizing noninvasive wall stress analysis. Crit Care Med 1994;22:1647-59

38)Ceneviva G, Paschall JA, Maffei F. et al. Hemodynamic support in fluid refractory pediatric septic shock. Pediatrics $1998 ; 102$ (2):e19 (1-6) 
39)Hoban LD, Paschal JA, Eckstein J, et al. Awake porcine model of intraperitoneal sepsis and altered oxygen utilization. Circ Shock $1991 ; 34: 252-62$

40)Green EM, Adams HR. New perspectives in circulatory shock: pathophysiologic mediators of the mammalian response to endotoxemia and sepsis J Am Vet Med Assoc. 1992;200:1834-41

41)McDonough $\mathrm{KH}$, Brumfield BA, Lang $\mathrm{CH}$. In vitro myocardial performance after lethal and nonlethal doses of endotoxin. Am $J$ Physiol 1986; 250:H240-46

42)Natanson C, Fink MP, Ballantyne HK et al. Gram-negative bacteremia produces both severe systolic and diastolic cardiac dysfunction in a canine model that simulates human septic shock. J Clin Invest. 1986; 78:259-70

43)Brierly J, Thiruchelvan T, Peters MJ. Hemodynamics of early pediatric fluid resistant septic shock using non-invasive cardiac output (USCOM) distinct profiles of CVC infection and community acquired sepsis Crit Care Medicine 2006 33(12);171-I

44) Deep A, Goonasekera CD, Wang Y, Brierley J. Evolution of haemodynamics and outcome of fluid-refractory septic shock in children. Intensive Care Med. 2013 Sep;39(9):1602-9

45)Dobkin ED, Lobe TE, Bhatia J et al The study of fecal E coli peritonitis-induced septic shock in a neonatal pig model. Circ Shock $1985 ; 16(4): 325-36$

46) Peevy KJ, Chartrand SA, Wiseman HJ et al. Myocardial dysfunction in group B streptococcal shock Pediatr Res 1994;19(6):511-3

47) Meadow WL, Meus PJ. Unsuspected mesenteric hypoperfusion despite apparent hemodynamic recovery in the early phase of septic shock in piglets. Circ Shock. 1985; 15(2):123-9.

48) Meadow WL, Meus PJ. Early and late hemodynamic consequences of Group B beta streptococcal sepsis in piglets: effects on systemic, pulmonary, and mesenteric circulations. Circ Shock 1986; 19(4):347-56

49) Gill AB, Wendling AM Echocardiographic assessment of cardiac function in shocked very low birthweight infants. Arch Dis Child 1993; 68(1 Spec No):17-21

50) Kluckow M Low systemic blood flow and pathophysiology of the preterm transitional circulation Early Hum Dev 2005 81(5):429437

51) Munro MJ, Walker AM, Barfield CP Hypotensive extremely low birth weight infants have reduced cerebral blood flow Pediatrics 2004 114(6):1591-1596

52) Jayasinghe D, Gill AB, Levene MI CBF reactivity in hypotensive and normotensive preterm infants Pediatr Res 2003 54(6):848853

53)Vavilala MS, Lam AM CBF reactivitiy to changes in MAP (cerebral autoregulation) or $\mathrm{CO} 2$ (CO2 reactivity) is lost in hypotensive, ventilated, preterm infants Pediatr Res 2004 55(5):898-899

54)Al-Aweel I, Pursley DM, Rubin LP, Shah B, Weisberger S, Richardson DK Variations in prevalence of hypotension, hypertension, and vasopressor use in NICUs $J$ Perinat 2001 21(5):272-278

55) Martens SE, Rijken M, Stoelhorst GN, van Zwieten PH, Zwinderman AH, Wit JM, Hadders-Algra M et al Is hypotension a risk factor for neurological morbidity at term in very preterm infants? Early Hum Dev 2003 75(1-2):79-89

56) Subhedar NV Treatment of hypotension in newborns Semin Neonatol 2003 8(6):413-423

57) Seri I, Noori S Diagnosis and treatment of neonatal hypotension outside the transitional period Early Hum Dev 2005 81(5):405411

58) Noori S, Seri I Pathophysiology of newborn hypotension outside the transitional period Early Hum Dev 81(5):399-404

59) Evans JR, Lou Short B, Van Meurs K, Cheryl Sachs Cardiovascular support of preterm infants Clin Ther 2006 28(9):1366-1384

60)Evans N Which inotrope for which baby? Arch Dis Child Fetal Neonatal Ed 2006 91(3):F213-220 
61)Osborn DA Diagnosis and treatment of preterm transitional circulatory compromise Early Hum Dev 2005 81(5):413-422

62) Evans N Management of hypotension and circulatory assessment on NICU Early Hum Dev 2005 81(5):397-398

63) Seri I Inotrope, lusitrope, and pressor use in neonates J Perinatol 200525 Suppl 2:528-530

64) Schonberger W, Grimm W, Gemp W. et al. Transient hypothyroidism associated with prematurity, sepsis, and respiratory distress. Eur J Pediatr 1979; 132(2):85-92

65) Roberton NR, Smith MA Early neonatal hypocalcemia. Arch Dis Child. 1975; 50(8); 604-609

66) Efird MM, Heerens AT, Gordon PV, Bose CL, Young DA A randomized controlled trial of prophylactic hydrocortisone supplementation for the prevention of hypotension in extremely low birth weight infants J Perinatol 2005;25(2):119-124

67) Ng PC, Lee CH, Bnur FL. Chan IH, Lee AW, Wong E, Chan HB, Lam CW, Lee BS, Fok TF A double blind, randomized controlled study of a stress dose of hydrocortisone for rescue treatment of refractory hypotension in preterm infants Pediatrics 2006;117(2):367-375

68) Fernandez E, Schrader R, Wattenberg K Prevalence of low cortisol values in term and near term infants with vasopressor resistant hypotension J Perinatol 2005 25(2):114-118

69) Noori S, Siassi B, Durand M, Acherman R, Sardesai S, Ramanathan R Cardiovascular effects of low dose dexamethasone in very low birth weight neonates with refractory hypotension Biol Neonate 2006 89(2):82-87

70) Lauterbach R, Pawlik D, Kowalczyk D, et al. The effect of the immunomodulatory agent, pentoxyfilline in the treatment of sepsis in prematurely delivered infants; placebo controlled, double blinded trial. Crit Care Med 1999; 27(4): 807-14

71) Zimmerman JJ Appraising the potential of pentoxyfilline in septic premies. Crit Care Med 1999;27(4):695-7.

72) Haque K, Mohan P Pentoxifylline for neonatal sepsis Cochrane database Syst rev 2003;(4):CD004205

73) Pollack MM, Ruttiman UE, Getson PR Pediatric Risk of mortality (PRISM) score Crit Care Med 1988 16(11):1110-1116

74) Carcillo JA, Kuch BA, Han YY, et al. Mortality and functional morbidity after use of PALS/APLS by community physicians. Pediatrics. 2009 Aug;124(2):500-8.

75) Ranjit S, Aram G, Kissoon N, Ali MK, Natraj R, Shresti S, Jayakumar I, Gandhi D: Multimodal monitoring for hemodynamic categorization and management of pediatric septic shock: a pilot observational study*. Pediatric critical care medicine : a journal of the Society of Critical Care Medicine and the World Federation of Pediatric Intensive and Critical Care Societies 2014, 15(1):e17-26.

76) Kumar R, Singhi S, Singhi P, Jayashree M, Bansal A, Bhatti A: Randomized controlled trial comparing cerebral perfusionpressuretargeted therapy versus intracranial pressure-targeted therapy for raised intracranial pressure due to acute CNS infections in children. Critical care medicine 2014, 42(8):1775-1787

77) Redl-Wenzl EM, Armbruster C, Edelman G, et al. The effects of norepinephrine on hemodynamics and renal function in severe septic shock. Intens Care Med 1993; 19(3):151-4

78) LeDoux D, Astiz ME, Carpati CM et al. Effects of perfusion pressure on tissue perfusion in septic shock Crit Care Med 2000;28(8):2729-2732.

79) Greenhalgh DG. Warden GD. The importance of intra-abdominal pressure measurements in burned children. J Trauma 1994;36(5):685-90

80) Evans N, Osborn D, Kluckow M Preterm circulatory support is more complex than just blood pressure Pediatrics 2005 115(4):1114-1115

81) Osborn DA, Evan N, Kluckow M Clinical detection of low upper body blood flow in very premature infants using blood pressure, capillary refill time, and central - peripheral temperature difference Arch Dis Child Fetal Neonatal Ed 2004;69(2):F168-173 
82) Hunt RW, Evans N, Rieger I, Kluckow M Low superior vena cava flow and neurodevelopment at 3 years in very pre term infants $J$ Pediatr 2004 145(5):588-592

83) Evans N, Kluckow M, Simmons M, Osborn D Which to measure, systemic or organ blood flow? Middle cerebral artery and superior vena cava blood flow in very preterm infants Arch Dis Child Fetal Neonatal Ed 2002; 87(3):F181-184

84) Osborn DA, Evans N, Kluckow M Hemodynamic and antecedent risk factors of early and late periventricular/intraventricular hemorrhage in premature infants Pediatrics 2003 112(1 Pt 1):33-39

85) Osborn DA, Evans N, Kluckow M Effect of targeted indomethacin on the ductus arteriosus and blood flow to the upper body and brain in the preterm infant Arch Dis Child Fetal Neonatal Ed 2003 88(6):F477-482

86) Osborn D, Evans N, Kluckow M Randomized trial of dobutamine versus dopamine in preterm infants with low systemic blood flow J Pediatr 2002 140(2):183-191

87) Evans N, Osborn D, Kluckow M Mechanism of blood pressure increase induced by dopamine in hypotensive preterm neonates Arch Dis Child Fetal Neonatal Ed 2000 83(1):F75-76

88)Kluckow M Low systemic blood flow in the preterm infant Semin Neonatol 2001 6(1):75-84

89)Kluckow M, Evans N Ductal shunting, high pulmonary blood flow, and pulmonary hemorrhage J Pediatr 2000 137(1):68-72

90)Kluckow M, Evans N Low superior vena cava flow and intraventricular haemorrhage in preterm infants Arch Dis Child Fetal Neonatal Ed 2000;82(3):F188-194

91)Parr GV, Blackstone EH, Kirklin Cardiac performance and mortality early after intracardiac surgery in infants and young children Circulation 1975;51(5):867-874.

92) Yasaka Y, Khemani RG, Markovitz BP: Is shock index associated with outcome in children with sepsis/septic shock?*. Pediatric critical care medicine : a journal of the Society of Critical Care Medicine and the World Federation of Pediatric Intensive and Critical Care Societies 2013, 14(8):e372-379.

93) Rivers E, Nguyen B, Havstad et al, Early goal directed therapy in the treatment of Severe Sepsis and Septic Shock, New Engl J Med 2001;346(19):1368-1377

94) Textoris J, Fouche L, Wiramus S, Antonini F, Tho S, Martin C, Leone M: High central venous oxygen saturation in the latter stages of septic shock is associated with increased mortality. Crit Care 2011, 15(4):R176.

95) Ahmad S, Tejuja A, Newman KD, Zarychanski R, Seely AJ: Clinical review: a review and analysis of heart rate variability and the diagnosis and prognosis of infection. Crit Care 2009, 13(6):232.

96) Fenton KE, Sable CA, Bell MJ, Patel KM, Berger JT Increases in serum levels of troponin I are associated with cardiac dysfunction and disease severity in pediatric patients with septic shock Pediatr Crit Care Med 2004;5(6):533-536

97) Briassoulis G, Narlioglou, Zavras N, Hatzis T Myocardial injury in meningococcus-induced purpura fulminans in children Intensive Care Med 2001;27(6):1073-1082

98)Thiru Y, Pathan N, Bignall S, Habibi P, Levin M A myocardial cytotoxic process is involved in the cardiac dysfunction of meningococcal septic shock Crit Care Med 2000;28(8):2979-2983

99) Hatherill M, Waggie Z, Purves L, Reynolds L, Argent A: Mortality and the nature of metabolic acidosis in children with shock. Intensive care medicine 2003, 29(2):286-291.

100) Dugas MA, Proulx F, de Jaeger A, Lacroix J, Lambert M: Markers of tissue hypoperfusion in pediatric septic shock. Intensive care medicine 2000, 26(1):75-83.

101) Scott HF, Donoghue AJ, Gaieski DF, Marchese RF, Mistry RD: The utility of early lactate testing in undifferentiated pediatric systemic inflammatory response syndrome. Academic emergency medicine : official journal of the Society for Academic Emergency Medicine 2012, 19(11):1276-1280. 
102) Kim YA, Ha EJ, Jhang WK, Park SJ: Early blood lactate area as a prognostic marker in pediatric septic shock. Intensive care medicine 2013, 39(10):1818-1823.

103) Jat KR, Jhamb U, Gupta VK: Serum lactate levels as the predictor of outcome in pediatric septic shock. Indian journal of critical care medicine : peer-reviewed, official publication of Indian Society of Critical Care Medicine 2011, 15(2):102-107. 104) James JH, Luchette FA, McCarter FD, Fischer JE: Lactate is an unreliable indicator of tissue hypoxia in injury or sepsis. Lancet 1999, 354(9177):505-508.

105) Chapman L, Sullivan B, Pacheco A, Draleau C, Becker B. VeinViewer-assisted Intravenous Catheter Placement in a Pediatric Emergency Department. Acad Emerg Med 2011;18:966-971.

106) Kim MJ, Park JM, Rhee N, Je SM, Hong SH, Lee YM, Chung SP, Kim SH. Efficacy of VeinViewer in pediatric peripheral intravenous access: a randomized controlled trial. Eur J Pediatr 2012; published online Feb 28, 2012.

107) Aria DJ, Vatsky S, Kaye R, Schaefer C, Towbin R. Greater saphenous venous access as an alternative in children. Pediatr Radiol 2014;44:187-192.

108) Guilfoyle FJ, Milner R, Kissoon N. Resuscitation interventions in a tertiary level pediatric emergency department: implications for maintenance of skills. CJEM 2011;13:90-95.

109) Kanter RK, Zimmerman JJ, Strauss RH et al Pediatric emergency intravenous access. Evaluation of a protocol Am J Dis Child $1986 ; 140(2): 132-4$

110) Voigt J, Waltzman M, Lottenberg L. IO vascular access for in-hospital emergency use_A systematic clinical review; Pediatr Emerg Care 2012;28:185-199.

111) American Heart Association/American Academy of Pediatrics Pediatric Resuscitation Subcommittee. Pediatric Advanced Life Support Provider Manual. AHA/AAP 2010, p.110.

112) Fiorito BA, Mirza F, Doran TM, Oberle AN, Vince Cruz EC, Wendtland CL, Abd-Allah SA. Intraosseous access in the setting of pediatric critical care transport. Pediatr Crit Care Med 2005; 6:50 -53.

113) National Institute for Clinical Excellence. Guidance on the use of ultrasound locating devices for placing central venous catheters. Technology Appraisal Guidance No. 49, September 2002.

114) Verghese ST, McGill WA, Patel RI, Sell JE, Midgley FM, Ruttimann UE. Ultrasound-guided internal jugular venous cannulation in infants: a prospective comparison with the traditional palpation method. Anesthesiology 1999;91:71-7

115) Ultrasound guidance of central vein catheterization. In: Rothschild JM, editor. Evidence Report/Technology Assessment, No. 43. Making health care safer: a critical analysis of patient safety practices. Rockville, MD, Agency for Healthcare Research and Quality, 2001, Publication No. 01- E058, 245-53.

116)di Nardo M, Tomasello C, Pittiruti M, Perrotta D, Marano M, Cecchetti C, Pasotti E, Pirozzi N, Stoppa F. Ultrasound-guided central venous cannulation in infants weighing less than 5 kilograms. $J$ Vasc Access 2011;12:321-324.

117) Hind D, Calvert N, McWilliams R, Davidson A, Paisley S, Beverley C, Thomas S. Ultrasonic locating devices for central venous cannulation: meta-analysis. BMJ 2003;327-361-7.

118) Lamperti M, Caldiroli D, Cortellazzi P, Vailati D, Pedicelli A, Tosi F, Piastra M, Pietrini D. Safety and efficacy of ultrasound assistance during internal jugular vein cannulation in neurosurgical infants. Intensive Care Med 2008;34:2100-2105.

119)Sigaut S, Skhiri A, Stany I, Golmar J, Nivoche Y, Constant I, Murat I, Dahmani S. Ultrasound guided internal jugular vein access in children and infant: A meta-analysis of published studies. Pediatric Anesthesia 2009;19:1199-1206.

120) Chelliah A, Heydon KH, Zaoutis TE, Rettig SL, Dominguez TE, Lin R, Patil S, Feudtner C, St John KH, Bell LM, Coffin SE. Observational trial of antibiotic-coated central venous catheters in critically ill pediatric patients. Pediatr Infect Dis J 2007;26:816820 . 
121) Gilbert RE, Harden M. Effectiveness of impregnated central venous catheters for catheter related blood stream infection: a systematic review. Curr Opin Infect Dis 2008;21:235-245.

122)Sheridan RL, Weber JM. Mechanical and infectious complications of central venous cannulation in children: lessons learned from a 10-year experience placing more than 1000 catheters. J Burn Care Res 2006;27:713-718.

123)Centers for Disease Control Healthcare Infection Control Practices Advisory Committee. Guidelines for the Prevention of Intravascular Catheter-Related Infections, 2011. http://www.cdc.gov/hicpac/pdf/guidelines/bsi-guidelines-2011.pdf. CDC Guidelines 124)Shah PS, Shah N. Heparin-bonded catheters for prolonging the patency of central venous catheters in children. Cochrane Database Syst Rev 2007;4:CD005983. Update in: Cochrane Database Syst Rev 2014;2:CD005983.

125)Shah PS, Shah VS. Continuous heparin infusion to prevent thrombosis and catheter occlusion in neonates with peripherally placed percutaneous central venous catheters. Cochrane Database Syst Rev 2008;2:CD002772.

126) Ngo NT, Cao XT, Kneen R, Wills B, Nguyen VM, Nguyen TQ, Chu VT, Nguyen TT, Simpson JA, Solomon T, White NJ, Farrar J Acute management of dengue shock syndrome:a randomized double-blind comparison of 4 intravenous fluid regimens in the first hour Clin Infect Dis 2001;32(2):204-213

127) Dung NM, day NP, Tam DT, Loan HT, Chau HT, Minh LN,Diet TV, Bethell DB, Kneen R, Hien TT White NJ, Farrar JJ Fluid replacement in dengue shock syndrome: a randomized double blind comparison of four intravenous fluid regimens Clin Infect Dis 1999;29(4):787-794.

128)Maitland K, Pamba A, English M, Peshu N, Marsh K, Newton C, Levin M Randomized trial of volume expansion with albumin or saline in children with severe malaria:preliminary evidence of albumin benefit Clin Infect Dis 2005;40(4):538-545

129) Finfer S, Bellomo R, Boyce N, French J, Myburgh J, Norton R;SAFE Study Investigators A comparison of albumin and saline for fluid resuscitation in the intensive care unit N Engl J Med 2004;350(22):2247-2256

130) Upadhyay M, Singhi S, Murlidharan J, Kaur N, Majumdar S Randomized evaluation of fluid resuscitation with crystalloid (saline) and colloid (polymer from degraded gelatin in saline) in pediatric septic shock Indian Pediatr 2005;42(3):223-231.

131) Carcillo JA, Davis AI, Zaritsky A. Role of early fluid resuscitation in pediatric septic shock. JAMA 1991;266(9):1242-5

132) Stoner MJ, Goodman DG, Cohen DM, Hall MW Rapid fluid resuscitation in pediatrics; testing the ACCM guidelines Crit Care Med 2005;33(12):A68

133) Ranjit S, Kissoon N, Jayakumar I Aggressive management of dengue shock syndrome may decrease mortality rate: a suggested protocol Pediatr Crit Care Med 2005;6(4):412-419

134) Foland FA, Fortenberry JD, Warshaw BL, Pettignano R, Merrit RK, Heard ML, Rogers K, Reid C, Tanner AJ, Easley KA Fluid overload before continuous hemofiltration and survival in critically ill children; a retrospective analysis Crit Care Med 2004;32(8):1771-1776.

135) Lucking SE, Williams TM, Chaten FC. Dependence of oxygen consumption on oxygen delivery in children with hyperdynamic septic shock and low oxygen extraction. Crit Care Med 1990;18(12):1316-9

136) Mink RB, Pollack MM. Effect of blood transfusion on oxygen consumption in pediatric septic shock. Crit Care Med 1990; 18(10):1087-91

137) Carrol CG, Snyder JV Hyperdynamic severe intravascular sepsis depends on fluid administration in cynomolgous monkey $A m J$ Physiol 1982;243 (1):R131-41

138) Lee PK, Deringer JR, Kreiswirth BN et al. Fluid replacement protection of rabbits challenged subcutaneous with toxic shock syndrome toxins Infect Immun 1991;59

139) [a] Ottoson J, Dawidson I, Brandberg A et al. Cardiac output and organ blood flow in experimental septic shock and treatment with antibiotics, corticosteroids, and fluid infusion Circ Shock 1991;35 (1):14-24 
140) Hoban LD, Paschall JA, Eckstein J et al. Awake porcine model of intraperitoneal sepsis and altered oxygen utilization Circ Shock 1991;34 (2):252-62

141) Wilson MA, Choe MC, Spain DA Fluid resuscitation attenuates early cytokine mRNA expression after peritonitis. J Trauma 1996; 41(4):622-7

142) Boldt J, Muller M, Heesen M Influence of different volume therapies and pentoxifylline infusion on circulating adhesion molecules in critically ill patients. Crit Care Med 1998; 24 (3):385-91

143) Zadrobilek E, Hackl W, Sporn P et al. Effect of large volume replacement with balanced electrolyte solutions on extravascular lung water in surgical patients with sepsis syndrome Intens Care Med 1989;15(8):505-10

144) Powell KR, Sugarman LI, Eskenazi AE et al. Normalization of plasma arginine vasopressin concentrations when children with meningitis are given maintenance plus replacement fluid therapy. J Pediatr 1990; 117(4):515-22

145) Pladys P, Wodey E, Betremieux P. Effects of volume expansion on cardiac output in the preterm infant. Acta Paediatr. 1997; 86(11):1241-5

146) Lambert HJ, Baylis PH, Coulthard MG. Central-peripheral temperature difference, blood pressure, and arginine vasopressin in preterm neonates undergoing volume expansion Arch Dis Child Fetal Neonatal Ed. 1998;78(1):F43-5

147) Bressack MA, Morton NS, Hortop J. Group B streptococcal sepsis on the piglet: effects of fluid therapy on venous return, organ edema, and organ blood flow. Circ Res 1987; 61(5):659-69

148) Pollard AJ, Britto J, Nadel S, et al Emergency management of meningococcal disease Arch Dis of Child 1999;80(3):290-6

149) Boldt J, Heesen M, Welters I. Does the type of volume therapy influence endothelial-related coagulation in the critically ill? Brit $J$ Anaesth 1995; 75(6):740-6

150) Oca MJ, Nelson M, Donn SM Randomized trial of normal saline versus 5\% albumin for the treatment of neonatal hypotension $J$ Perinatol 2003 23(6):473-476

151) Pamba A, Maitland K Capillary refill:prognostic value in Kenyan children Arch Dis Child 2004 89(10):950-955

152) Maitland K, Pamba A, English M, Peshu N, Levin M, Marsh K Newton CR Pre-transfusion management of children with severe malarial anemia:a randomized controlled trial of intravascular expansion Br J Haematol 2005 128(3):393-400

153) Liet JM, Kuster A, Denizot S, Caillaux-varin G, Gras-leguen C, Roze JC Effects of hydroxyethyl starch on cardiac output in hypotensive neonates: a comparison with isotonic saline and 5\% albumin Acta Paediatr 2006 95(5):555-560

154) Cam BV, Tuan DT, Fonsmark L, Poulsen A, Tien NM, Tuan HM, Heegaard ED Randomized comparison of oxygen mask treatment vs nasal continuous positive airway pressure in dengue shock syndrome with acute respiratory failure J Trop Pediatr 2002 48(6):335-339

155) Yamamoto LG, Rapid sequence Intubation, in Textbook of Pediatric Emergency Care Eds Ludwig and Fleisher, Lippincott, Wilkins and Williams Philadelphia PA, 2000

156) Jabre P, Avenel A, Combes $X$ et al: Morbidity related to emergency endotracheal intubation - A substudy of the KETAmine SEDation trial. Resuscitation 82(2011)517-522

157) Haubner LY, Barry JS, Johnston LC: Neonatal intubation performance: room for improvement in tertiary neonatal intensive care units. Resuscitation 2013 Oct; 84(10): 1859-64 DOI: 10.1016/j.resuscitation.2013.03.014 Epub 2013 Apr 3

158) Li, S, Rehder K, Giuliano JS et al: Development of a Quality Improvement Bundle to Reduce Tracheal Intubation-Associated Events in PICUs. Am J Med Qual 2014 Aug 20.pli:1062860614547259.

159) Jones $P$, Dauger $S$, Denjoy I et al: The effect of atropine on rhythm and conduction disturbances during 322 critical care intubations. Pediatr Crit Care Med 2013 Jul; 14(6): e289-97. DOI 10.1097/PCC.0b013e31828a8624 
160) Jabre P, Combes $X$, Lapostolle F et al: Etomidate versus ketamine for rapid sequence intubation in acutely ill patients: a multicenter randomised control trial. Lancet 2009;374:293-300

161) Barois J, Tourneaux P: Ketamine and atropine decrease pain for preterm newborn tracheal intubation in the delivery room: an observational pilot study. Acta Paediatr 2103 Dec;102(12):e-534-8. DOI 10.1111/apa.12413

162) Cuthbertson BH, Sprung CL, Annane D et al: The effects of etomidate on adrenal responsiveness and mortality in patients with septic shock. Intensive Care Med (2009) 35:1868-1876. DOI 10.1007/s00134-009-1603-4 (II c)

163) den Brinker M, Hokken-Koelega AC, Hazelzet et al: One single dose of etomidate negatively influences adrenocortical performance for at least $24 \mathrm{~h}$ in children with meningococcal sepsis. Intensive Care Med 2008; 34(1):163-8 Epub 2007 Aug 21 164) Albert SG, Ariyan S, Rather A: The effect of etomidate on adrenal function in critical illness: a systematic review. Intens Care Med 2011 Jun;37 (6) 901-10. DOI 10.07/s00134-011-2160-1. Epub 2011 Mar 4

165) Dmello D, Taylor S, O’Brien J, Matuschak GM: Outcomes of Etomidate in Severe Sepsis and Septic Shock. Chest 2010; 138(6):1327-1332

166) McPhee LC, Badawi O, Fraser GL et al: Single-Dose Etomidate Is Not Associated With Increased Mortality in ICU Patients With Sepsis: Analysis of a Large Electronic ICU Database. Crit Care Med 2013 Mar 41(3):774-83. DOI 10.1097/CCM.0b013e18274190d

167) Nemergut M, Yaster B, Colby C: Sedation and Analgesia to Facilitate Mechanical Ventilation. Clin Perinatol 40(2013) 539-558

168) Hall RW: Anesthesia and analgesia in the NICU. Clin Perinatol 2012 Mar;39(1):239-54. DOI10.1016/j.clp.2011.12.013.

169) Morrow WR, Murphy DJ Jr, Fisher DJ et al Continuous wave Doppler cardiac output: use in pediatric patients receiving inotropic support. Pediatr Cardiol 1988;9(3):131-6

170) Gueugniaud PY, Muchada R, Moussa M et al Continuous esophageal aortic blood flow echo-Doppler measurement during general anesthesia in infants Can J Anesthes 1997;44:745-750

171) Bay Hansen R.B.et al Use of near infrared spectroscopy for estimation of peripheral venous saturation in newborns: comparison with co-oximetry of central venous blood 2002 Biol Neonate 82(1):1-8

172) Cechetti C, Stoppa F et al Monitoring of intrathoracic volemia and cardiac output in critically ill children 2003 Minerva Anesthesiol 69(12):907-918

173) Courand A, Marshall J et al Clinical applications of wall stress analysis in the pediatric intensive care unit 2001 Crit Care Med 29(3):526-533

174) Mahajan A, Shabanie A et al Pulse contour analysis for cardiac output monitoring in cardiac surgery for congenital heart disease 2003 Anesth Analg 97(5):1283-88

175) Martin M, Brown $\mathrm{C}$ et al Continuous noninvasive monitoring of cardiac performance and tissue perfusion in pediatric trauma patients 2005 J Pediatr Surg 40(12):1957-63

176) Mohan UR, Britto J, habibi P, de MC, Nadel S Noninvasive measurement of cardiac output in critically ill children 2002 Pediatr Cardiol 32(1):58-61

177) Sloth E, Pedersen J et al Transesophageal echocardiographic monitoring during pediatric cardiac surgery: obtainable information and feasibility in 532 children Paediatr Anaesth 11(6):657-662

178) Fernandez EG, Green TP, Sweenet M Low inferior vena caval catheters for hemodynamic and pulmonary function monitoring in pediatric critical care patients Pediatr Crit Care 2004 5(1) :14-18

179) Reynolds EM, Ryan DP, Sheridan RL et al. Left ventricular failure complicating severe pediatric burn injury J Pediatr Surg 1995; 30(2):264-9

180) Zaritsky A. Curr Concepts Ped Emergency and Crit Care 1998;November 
181) Duke T, Butt W, South M. Predictors of mortality and multiple organ failure in children with sepsis. Intensive Care Med 1997; 23:684-92

182) Tibby SM, Hatherill M, Marsh MJ et al. Clinical validation of cardiac output measurement using femoral artery thermodilution with direct Fick in ventilated children and adults Intens Care Med 1997 23(9):987-991

183) McLuckie A, Murdoch IA, Marsh MJ et al. Comparison of pulmonary artery and thermodilution cardiac indices in pediatric intensive care patients Acta Paediatr 1996;85:336-338

184) Pauli C, Fakle U et al Cardiac output determination in children: equivalence of the transpulmonary thermodilution method to the direct Fick principle 2002 Intens Care Med 28(7):947-952

185) Tirgay A, Pirat A et al Pulse contour cardiac output system use in pediatric orthotopic liver transplantation:preliminary report of nine patients 2005 Trans Proc 37(7):3168-3170

186) Bollaert PE, Bauer P. Audibert G et al. Effects of epinephrine on hemodynamics and oxygen metabolism in dopamine-resistant septic shock. Chest.1990; 98(4):949-53.

187) Heckmann M, Trotter A, Pohlandt F, Lindner W Epinephrine treatment of hypotension in very low birthweight infanst Acta Paediatr 2002 91(5):566-570

188) Pellicer A, Valverde E, Elorza MD, Madero R, Gaya F, Quero J, Cabanas F Cardiovascular support for low birth weight infants and cerebral hemodynamics: a randomized, blinded, clinical trial Pediatrics 2005115 (6):1501-1512

189) Valverde E, Pellicer A, Madero R, Elorza D, Quero J, Cabanas F Dopamine versus epinephrine for cardiovascular support in low birth weight infants: analysis of systemic effects and neonatal outcomes Pediatrics 2006 117(6):e1213-1222

190) Meier-Hellman A, Reinhart K, Bredle DC et al Epinephrine impairs splanchnic perfusion in septic shock Crit Care Med $1997 ; 25: 399-404$.

191) Subhedar NV, Shaw NJ Dopamine versus dobutamine for hypotensive preterm infants Cochrane Database Syst Rev 2003

(3):CD001242

192) Sakr Y, Reinhart K, Vincent JL, Sprung CL, Moreno R, Ranieri VM, De Backer D, Payen D. Does dopamine administration in shock influence outcome? Results of the Sepsis Occurrence in Acutely Ill Patients study Crit Care Med 2006 34(3)589-597

193) Padbury JF, Agata Y, Baylen BG, et al. Pharmacokinetics of dopamine in critically ill newborn infants. J Pediatr.1990;

$117(3): 472-6$

194) Bhatt-Mehta V, Nahata MC, McClead RE et al Dopamine pharmacokinetics in critically ill newborn infants. Eur J Clin Pharmacol.1991; 40(6):593-7

195) Allen E, Pettigrew a, Frank D, et al. Alterations in dopamine clearance and catechol-O-methyltransferase activity by dopamine infusions in children. Crit Care Med 1997; 25:181-89.

196) Outwater KM, Treves ST, Lang P. Renal and Hemodynamic effects of dopamine in infants following cardiac surgery. J Clin Anesth.1990;2(4):253-7

197) Lobe TE, Paone R, Dent SR. Benefits of high-dose dopamine in experimental neonatal septic shock. J Surg Res.1987;42(6):66574

198) Seri I, Tulassay T, Kiszel J, et al. Cardiovascular response to dopamine in hypotensive preterm neonates with severe hyaline membrane disease. Eur J Pediatr 1984; 142(1):3-9

199) Padbury JF, Agata Y, Baylen BG et al. Dopamine pharmacokinetics in critically ill newborn infants. J Pediatr 1987; 110(2):2938

200) Hentschel R, Hensel, Brune T et al. Impact on blood pressure and intestinal perfusion of dobutamine or dopamine in hypotensive preterm infants. Biol Neonate 1995; 68(5):318-24 
201) Klarr JM, Faix RG, Pryce CJ Randomized, blind trial of dopamine versus dobutamine for treatment of hypotension in preterm infants with respiratory distress syndrome. J Pediatr. 1994; 125(1):117-22

202) Liet JM, Boscher C, Gras-Leguen C, Gournay V, Debillon T, Roza JC Dopamine effects on pulmonary artery pressure in hypotensive preterm infants with patent ductus arteriosus J Pediatr 2002 149(3):373-375

203) Kim KK. Frankel LR The need for inotropic support in a subgroup of infants with severe life threatening respiratory syncytial viral infection. J Investig Med 1997;45(8):469-73

204) Jardin et al Venous admixture in human septic shock: comparative effects on blood volume expansion, dopamine infusion and isoproterenol infusion on mismatch of ventilation and pulmonary blood flow in peritonitis. Circulation 1979; 60:155-59.

205) Harada K, Tamura M, Ito T et al. Effects of low-dose dobutamine on left ventricular diastolic filling in children Pediatr Cardiol 1996; 17(4):220-5

206) Stopfkuchen H, Schranz D, Huth R, and Jungst BK. Effects of dobutamine on left ventricular performance in newborns as determined by systolic time intervals. Eur J Pediatr, 1987;146(2):135-9

207) Stopfkuchen H, Queisser-Luft A, Vogel K. Cardiovascular responses to dobutamine determined by systolic time intervals in preterm infants Crit Care Med 1990;18(7):722-4

208) Habib DM, Padbury JF, Anas NG et al. Dobutamine pharmacokinetics and pharmacodynamics in pediatric intensive care patients Crit Care Med 1992;20(5):601-8

209) Berg RA, Donnerstein RL, Padbury JF Dobutamine infusions in stable, critically ill children: pharmacokinetics and hemodynamic actions Crit Care Med 1993;21(5):678-86

210) Martinez AM, Padbury JF, Thio S. Dobutamine pharmacokinetics and pharmacodynamics and cardiovascular responses in critically ill neonates Pediatrics 1992;89(1):47-51

211) Perkin RM, Levin DL, Webb R et al. Dobutamine: a hemodynamic evaluation in children with shock. J Pediatr 1982; 100(6):977-83

212) Goto M, Griffin A Adjuvant effects of beta-adrenergic drugs on indomethacin treatment of newborn canine endotoxic shock $J$ Pediatr Surg.1991;26(10):1156-60

213) Clark SJ, Yoxall CW, Subhedar NV Right ventricular performance in hypotenisve preterm neonates treated with dopamine Pediatr Cardiol 2002 23(2):167-170

214) Lopez SL, Leighton JO, Walther FJ. Supranormal cardiac output in the dopamine- and dobutamine-dependent preterm infant. Pediatr Cardiol 1997; 18(4):292-6

215) Keeley SR, Bohn DJ The use of inotropic and afterload-reducing agents in neonates. Clin Perinatol 1988; 15(3):467-89

216) Butt W, Bohn D, Whyte H. Clinical experience with systemic vasodilator therapy in the newborn infant. Aust Pediatr J. 1986;22(2):117-20

217) Benitz WE, Rhine WD, Van Meurs KP et al. Nitrosovasodilator therapy for severe respiratory distress syndrome J Perinatol 1996;16(6):443-8

218) Wong AF, McCulloch LM, Sola A Treatment of peripheral tissue ischemia with topical nitroglycerin ointment in neonates. $J$ Pediatr.1992; 121(6):980-3

219) Bailey JM, Miller BE, Kanter KR et al. A comparison of the hemodynamic effects of amrinone and sodium nitroprusside in infants after cardiac surgery Anesth \& Analg 1997; 84(2):294-8.

220) Laitinen P, Happonen JM, Sairanae H et al. Amrinone vs dopamine-nitroglycerin after reconstructive surgery for complete atrioventricular septal defect. J Cardiothorac Vasc Anesth 1997; 11(7):870-4 
221) Spronk PE, Ince C, Gardien MJ, Mathura KR, Oudemans van Straaten HM, Zandstra DF Nitroglycerin in septic shock after intravascular volume resuscitation Lancet 2002 360(9343):1395-1396

222) Heyderman RS, Klein NJ, Shennan GI et al. Deficiency of prostacyclin production in meningococcal shock Arch Dis Child 1991; 66(11):1296-9

223) Lauterbach R, Zembala M. Pentoxifylline reduces plasma tumor necrosis factor-alpha concentration in premature infants with sepsis. Eur J Pediatr 1996; 155(5):404-9

224) Kawczynski P. Piotrowski A. Circulatory and diuretic effects of dopexamine infusion in low-birth-weight infants with respiratory failure Intens Care Med 1996; 22(1):65-70

225) Habre W, Beghetti M, Roduit C, et al Hemodynamic and renal effects of dopexamine after cardiac surgery in children. Anaesth Intens Care 1996; 24:435-39

226) Moffet BS, Orellana R Use of fenoldopam to increase urine output in a patient with renal insufficiency secondary to septic shock: a case report Pediatr Crit Care Med 2006 7(6):600-602

227)Morelli A, Rocco M, Conti G, Orecchini A, De Gaetano A, Coluzzi F, Vernaglione E, Pelaia P, Pietropaoli P Effects of short term fenoldopam infusion on gastric mucosal blood flow in septic shock Anesthesiology 2004 101(3):576-582

228) Barton P, Garcia J, Kouatli A et al. Hemodynamic effects of i.v. milrinone lactate in pediatric patients with septic shock. A prospective, double-blinded, randomized, placebo-controlled, interventional study.Chest 1996; 109(5):1302-12

229) Lindsay CA, Barton P, Lawless S. et al. Pharmacokinetics and pharmacodynamics of milrinone lactate in pediatric patients with septic shock. J Pediatr 1998; 132(2):329-34

230) Paradsis M, Evans N, Kluckow M, Osborn D, Maclachlan AJ Pilot study of milrinone for low sysyemic blood flow in very preterm infants J Pediatr 2006 148(3):306-313

231) Paradsis M, Jiang X, Mclachlan AJ, Evans N, Kluckow M, Osborn DA Population pharmacokinetics and dosing regimen design of milrinone in preterm infants Arch Dis Child Fetal Neonatal Ed 2006 May11 Epub

232) Irazuzta JE, Pretzlaff RK, Rowin ME Amrinone in pediatric refractory shock: An open label pharmacodynamic study Pediatr Crit Care Med 2001; 2:24-28

233) Sorenson GK, Ramamoorthy C, and Lynn AM et al. Hemodynamic effects of amrinone in children after Fontan surgery Anesth \& Analg. 1996; 82(2):241-6

234) Chang AC, Atz AM, Wernovsky G et al. Milrinone: systemic and pulmonary hemodynamics effects in neonates after cardiac surgery Crit Care Med 1995; 23(11):1907-14

235) Matejovic M, Krouzecky A, Radej J, Novak I Successful reversal of resistant hypodynamic septic shock with levosimendan Acta Anaesthesiol Scand 2005 49(1):127-128

236) Noto A, Giacomini M, Palandi A, Stabile L, Reali-Forster C, Iapichino G Levosimendan in septic cardiac failure Intensive Care Med 2005 31(1):164-165

237) Oldner A, Konrad D, Weitzberg E, Rudehill A, Rossi P, Wanecek M Effects of levosimendan, a novel inotropic calcium sensitizing drug in experimental septic shock Crit Care Med 29(11):2185-2193

238) Morelli A, Teboul JL, Maggiore SM, Viellard-Baron A, Rocco M, Conti G, De Gaetano A, et al Effects of levosimendan on right ventricular afterload in patients with acute respiratory distress syndrome: a pilot study Crit Care Med 2006 34(9):2287-2293

239) Muller K, Peters A, Zeus T, Hennersdorf M, Strauer BE Therapy of acute decompensated heart failure with levosimendan Med

Klin 2006 101Suppl 1:119-122

240) Namachivayam P, Crossland DS, Butt WW, Shekerdemian LS Early experience with Levosimendan in children with ventricular dysfunction Pediatr Crit Care 2006 7(5):445-448. 
241) Ringe HI, Varnholt V, Gaedicke G Cardiac rescue with enoximone in volume and catecholamine refractory septic shock Pediat Crit Care Med 2003 4(4):471-475

242) Kern H, Schroder T, Kaulfuss M, Martin M, Kox WJ, Spies CD Enoximone in contrast to dobutamine improves hepatosplanchnic function in fluid optimized septic shock patients Crit Care Med 2001 29(8):1519-1525

243) Hoang P, Fosse JP, Fournier JL, Souchot O, Cupa M Enoximone-noradrenaline combination in septic shock Presse Med 1991 20(36): 1785

244) Meadows D, Edwards JD, Wilkins RG et al Reversal of intractable septic shock with norepinephrine therapy. Crit Care Med $1988 ; 16: 663-66$

245) Desjars P, Pinaud M, Potel G et al A reappraisal of norepinephrine therapy in human septic shock Crit Care Med 1987;15:13437

246) Morimatsu H, Singh K, Uchino S, Bellomo R, Hart G. Early and exclusive use of norepinephrine in septic shock. Resuscitation. 2004 Aug; 62(2):249-54.

247) Redl-Wenzl EM, Armbruster C, Edelmann G, Fischl E, Kolacny M, Wechsler-Fördös A, Sporn P. The effects of norepinephrine on hemodynamics and renal function in severe septic shock states. Intensive Care Med. 1993;19(3):151-4

248) Sakr Y, Reinhart K, Vincent JL, Sprung CL, Moreno R, Ranieri VM, De Backer D, Payen D. Does dopamine administration in shock influence outcome? Results of the Sepsis Occurrence in Acutely Ill Patients (SOAP) Study. Crit Care Med. 2006 Mar;34(3):58997

249) Morimatsu H, Singh K, Uchino S, Bellomo R, Hart G. Early and exclusive use of norepinephrine in septic shock. Resuscitation. 2004 Aug;62(2):249-54

250) Hall LG, Oyen LJ, Taner CB, Cullinane DC, Baird TK, Cha SS, Sawyer MD. Fixed-dose vasopressin compared with titrated dopamine and norepinephrine as initial vasopressor therapy for septic shock. Pharmacotherapy. 2004 Aug;24(8):1002-12

251) Lampin ME, Rousseaux J, Botte A, Sadik A, Cremer R, Leclerc F. Noradrenaline use for septic shock in children: doses, routes of administration and complications. Acta Paediatr. 2012 Sep;101(9):e426-30

252) Tourneux P, Rakza T, Abazine A, Krim G, Storme L. Noradrenaline for management of septic shock refractory to fluid loading and dopamine or dobutamine in full-term newborn infants. Acta Paediatrica 2008 97: 177-180.

253) Klinzing S, Simon M, Reinhart K, Bredle DL, Meier-Hellmann A. High-dose vasopressin is not superior to norepinephrine in septic shock. Crit Care Med. 2003 Nov;31(11):2646-50.

254) Delmas A, Leone M, Rousseau S, Albanese J, Martin C. Clinical review: Vasopressin and terlipressin in septic shock patients. Critical Care 9(2):212-22, 2005 Apr.

255) Leibovitch L, Efrati O, Vardi A, Matok I, Barzilay Z, Paret G. Intractable hypotension in septic shock: successful treatment with vasopressin in an infant. Israel Medical Association Journal. 5(8):596-8, 2003 Aug.

256) Matok I, Vard A, Efrati O, Rubinshtein M, Vishne T, Leibovitch L, Adam M, Barzilay Z, Paret G. Terlipressin as rescue therapy for intractable hypotension due to septic shock in children. Shock. 2005 Apr;23(4):305-10

257) Tsuneyoshi I, Yamada H, Kakihana Y, Nakamura M, Nakano Y, Boyle WA 3rd. Hemodynamic and metabolic effects of lowdose vasopressin infusions in vasodilatory septic shock Critical Care Medicine. 29(3):487-93, 2001 Mar.

258) Peters MJ, Booth RA, Petros AJ. Terlipressin bolus induces systemic vasoconstriction in septic shock. Pediatr Crit Care Med. $2004 \operatorname{Mar} ; 5(2): 112-5$

259) Liedel JL, Meadow W, Nachman J, Koogler T, Kahana MD. Use of vasopressin in refractory hypotension in children with vasodilatory shock: five cases and a review of the literature. Pediatr Crit Care Med. 2002 Jan;3(1):15-8 
260) Vasudevan A, Lodha R, Kabra SK. Vasopressin infusion in children with catecholamine-resistant septic shock. Acta Paediatr. 2005 Mar;94(3):380-3

261) Rodriguez-Nunez A, Fernandez-Sanmartin M, Martinon-Torres F, Gonzalez-Alonso N, Martinon-Sanchez JM. Terlipressin for catecholamine-resistant septic shock in children Intens Care Med 30(3):477-80, 2004 Mar.

262) Matok I, Leibovitch L, Vardi A, Adam M, Rubinshtein M, Barzilay Z, Paret G. Terlipressin as rescue therapy for intractable hypotension during neonatal septic shock. Pediatr Crit Care Med 5(2):116-8, 2004 Mar.

263) Rosenzweig EB, Starc TJ, Chen JM et al. Intravenous arginine-vasopressin in children with vasodilatory shock after cardiac surgery Circulation 1999; 100 (19 Supp):11182-11186

264) Agrawal A, Singh V, Varma A, Sharma R. Intravenous arginine vasopressin infusion in refractory vasodilatory shock: a clinical study. Indian J Pediatr April 2012 79(4): 488-493.

265) Bidegain M, Greenberg R, Simmons C, Dang C, Cotton CM, Smith PB. Vasopressin for refractory hypotension in extremely low birth weight infants. J Pediatr 2010; 157:502-4.

266) Meyer S, Gottschling S, Baghai A, Wurn D, Gortner L. Arginine-vasopressin in catecholamine-refractory septic versus non-septic shock in extremely low birth weight infants with acute renal injury. Critical Care 2006; 10:R71

267) Meyer, S, Loffler G, Polcher T, Gottschling S, Gortner L. Vasopressin in catecholamine-resistant septic and cardiogenic shock in very-low-birthweight infants. Acta Paediatr 2005 1309-1312.

268) Russell JA, Walley KR, Singer J, Gordon AC, Hébert PC, Cooper DJ, Holmes CL, Mehta S, Granton JT, Storms MM, Cook DJ, Presneill JJ, Ayers D; VASST Investigators. Vasopressin versus norepinephrine infusion in patients with septic shock. N Engl J Med. 2008 Feb 28;358(9):877-87

269) Choong K, Bohn D, Fraser DD, Gaboury I, Hutchison JS, Joffe AR, Litalien C, Menon K, McNamara P, Ward RE; Canadian Critical Care Trials Group. Vasopressin in pediatric vasodilatory shock: a multicenter randomized controlled trial. Am J Respir Crit Care Med. 2009 Oct 1;180(7):632-9

270) Zeballos G, Lopez-Herce J, Fernandez C, Brandstrup KB, Rodriguez-Nunez A. Rescue therapy with terlipressin by continuous infusion in a child with catecholamine-resistant septic shock. Resuscitation. 2006. 68:151-153.

271) Radicioni M, Troiani S, Camerini PG.Effects of terlipressin on pulmonary artery pressure in a septic cooled infant: an echocardiographic assessment. J of Perinatology. 2012 32: 893-895.

272) Filippi L, Gozzini E, Daniotti M, Pagliai F, Catarzi S, Fiorini P. Rescue treatment with terlipressin in different scenarios of refractory hypotension in newborns and infants. Pediatr Crit Care Med 2011; 12:e237-e241).

273) Filippi L, Poggi C, Serafini L, Fiorini P. Terlipressin as rescue treatment of refractory shock in a neonate. Acta Paediatr 2008 97:500-502.

274) Leone M, Martin C. Role of terlipressin in the treatment of infants and neonates with catecholamine-resistant septic shock. Best Practice \& Research Clinical Anaesthesiology. 200822 (2): 323-333.

275) Michel F, Thomachot L, David M, Nicaise C, Vialet R, Marco JD, Lagier P. Continuous low-dose infusion of terlipressin as a rescue therapy in meningococcal septic shock. Am J Emerg Med 2007 25: 863.e1-e2.

276) Papoff P, Mancuso M, Barbara CS, Moretti C. The role of terlipressin in pediatric septic shock: a review of the literature and personal experience. International J Immunopathology Pharmacology. 2007. 20 (2): 213-221.

277) Rodríguez-Núñez A, Oulego-Erroz I, Gil-Antón J, Pérez-Caballero C, López-Herce J, Gaboli M, Milano G; Continuous terlipressin infusion as rescue treatment in a case series of children with refractory septic shock. Ann Pharmacother. 2010 Oct;44(10) 
278) Rodriguez-Nunez A, Lopez-Herce J, Gil-Anton J, Hernandez A, Rey C, RETSPED-II Working Group of the Spanish Society of Pediatric Intensive Care. Critical Care 2006, 10: R20

279) Yildizdas D, Yapicioglu H, Celik U, Sertdemir Y, Alhan E. Terlipressin as a rescue therapy for catecholamine-resistant septic shock in children. Intensive Care Med. 2008 Mar;34(3):511-7

280) Yunge M, Petros A. Angiotensin for septic shock unresponsive to noradrenaline. Arch Dis Child 2000: 82 (5): $388-9$.

281) Gregory JS, Binfiglio NF, Dasta JF, et al. Experience with phenylephrine as a component of pharmacologic support of septic shock. Crit Care Med 1991;19:1395-1340.

282) López A, Lorente JA, Steingrub J, Bakker J, McLuckie A, Willatts S, Brockway M, Anzueto A, Holzapfel L, Breen D, Silverman MS, Takala J, Donaldson J, Arneson C, Grove G, Grossman S, Grover R. Multiple-center, randomized, placebo-controlled, double-blind study of the nitric oxide synthase inhibitor 546C88: effect on survival in patients with septic shock. Crit Care Med. 2004 Jan;32(1):21-30

283) Grover R, Lopez A, Lorente J et al Multi-center, randomized, double blind, placebo-controlled, double bind study of nitric oxide inhibitor 546C88: effect on survival in patients with septic shock. Crit Care Med 1999; 27(1):A33

284) Driscoll W, Thurin S, Carrion V, Steinhorn RH, Morin FC 3rd. Effect of methylene blue on refractory neonatal hypotension. J Pediatr. 1996 Dec;129(6):904-8

285) Taylor K, Holtby H. Methylene blue revisited: management of hypotension in a pediatric patient with bacterial endocarditis. Journal of Thoracic \& Cardiovasc Surg. 130(2):566, 2005 Aug.

286)Faustino EVS, Bogue CW. Relationship between hypoglycemia and mortality in critically ill children. Pediatr Crit Care Med 2010; 11:690-698

287)Wintergerst KA, Buckingham B, Gandrud L et al. Association of hypoglycemia, hyperglycemia, and glucose variability with morbidity and death in the pediatric intensive care unit. Pediatrics 2006; 118:173-179

288)Branco RG, Garcia PCR, Piva JP, et al. Glucose level and risk of mortality in pediatric septic shock. Pediatr Crit Care Med 2005; 6:470-472

289)Day KM, Haub N, Betts H, Inwald DP. Hyperglycemia is associated with morbidity in critically ill children with meningococcal sepsis. Pediatr Crit Care Med 2008; 9:636-640

290)Mesotten D, Gielen M, Sterken C, et al. Neurocognitive development of children 4 years after critical illness and treatment with tight glucose control. A randomized controlled trial. JAMA 2012; 308:1641-1650

291)Macrae D, Grieve R, Allen E, et al. A randomized trial of hyperglycemic control pediatric intensive care. $N$ Engl J Med 2014; 370:107-118

292)Agus MSD, Stiel GM, Wypij D, et al. Tight glycemic control versus standard care after pediatric cardiac surgery. $N$ Engl J Med $2012 ; 367 ; 1208-1219$

293)Vlasselaers D, Milants I, Desmet L, et al. intensive insulin therapy for patients in paediatric intensive care: a prospective, randomized controlled study. Lancet 2009; 373:547-556

294)Rigby M, Maher K, Preissig C, et al. The Pedietrol trial: a 2-center trial of glycemic control in pediatric critical illness. Crit Care Med 2013; 41(12S):A993

295)Verhoeven JJ, den Brinker M, Hokken-Koelega ACS, Hazelzet JA, Joosten KFM. Pathophysiological aspects of hyperglycemia in children with meningococcal sepsis and septic shock: a prospective, observational cohort study. Crit Care 2011:15:R44 
296)van Waardenburg DA, Jansen TC, Vos GD, Buurman WA. Hyperglycemia in children with meningococcal sepsis and septic shock: the relation between plasma levels of insulin and inflammatory mediators. J Clin Endocrinol Metab 2006; 91:3916-3921

297)Annane D, Sebille V, Charpentier C et al. Effect of treatment with low doses of hydrocortisone and fludrocortisone on mortality in patients with septic shock. JAMA 2002;288(7):862-871.

298) Hodes HL. Care of the critically ill child: endotoxin shock. Pediatrics 1969;44(2):248-260.

299) Sonnenschein H, Joos HA. Use and dosage of hydrocortisone in endotoxic shock. Pediatrics 1970;45(4):720.

300) Migeon CJ, Kenny FM, Hung W, Voorhess ML. Study of adrenal function in children with meningitis. Pediatrics 1967;40(2):163-183.

301) Soni A, Pepper GM, Wyrwinski PM et al. Adrenal insufficiency occurring during septic shock: incidence, outcome, and relationship to peripheral cytokine levels. Am J Med 1995;98(3):266-271.

302) Riordan FA, Thomson AP, Ratcliffe JM, Sills JA, Diver MJ, Hart CA. Admission cortisol and adrenocorticotrophic hormone levels in children with meningococcal disease: evidence of adrenal insufficiency? Crit Care Med 1999;27(10):2257-2261.

303) Schonberger W, Grimm W, Gempp W, Dinkel E. Transient hypothyroidism associated with prematurity, sepsis, and respiratory distress. Eur J Pediatr 1979;132(2):85-92.

304) Sumarmo. The role of steroids in dengue shock syndrome. Southeast Asian J Trop Med Public Health 1987;18(3):383-389.

305) Min M, U T, Aye M, Shwe TN, Swe T. Hydrocortisone in the management of dengue shock syndrome. Southeast Asian J Trop Med Public Health 1975;6(4):573-579.

306) Hatherill M, Tibby SM, Hilliard T, Turner C, Murdoch IA. Adrenal insufficiency in septic shock. Arch Dis Child 1999;80(1):5155.

307) Ryan CA, Wenman W, Henningsen C, Tse S. Fatal Childhood Pneumococcal Waterhouse-Friderichsen Syndrome. Pediatric Infectious Disease Journal 1993;12(3):250-251.

308) Matot I, Sprung CL. Corticosteroids in septic shock: Resurrection of the last rites? Critical Care Medicine 1998;26(4):627-630.

309) Briegel J, Forst H, Kellermann W, Haller M, Peter K. Hemodynamic Improvement in Refractory Septic Shock with Cortisol Replacement Therapy. Intensive care medicine 1992;18(5):318.

310) Moran JL, Chapman MJ, Ofathartaigh MS, Peisach AR, Pannall PR, Leppard P. Hypocortisolaemia and Adrenocortical Responsiveness at Onset of Septic Shock. Intensive care medicine 1994;20(7):489-495.

311) Todd JK, Ressman M, Caston SA, Todd BH, Wiesenthal AM. Corticosteroid therapy for patients with toxic shock syndrome. JAMA 1984;252(24):3399-3402. 
312) Sonnenschein H, Joos HA. Hydrocortisone treatment of endotoxin shock. Another paradox in pediatrics. Clin Pediatr (Phila) 1970;9(5):251-252.

313) Bettendorf M, Schmidt KG, Grulich-Henn J, Ulmer HE, Heinrich UE. Tri-iodothyronine treatment in children after cardiac surgery: a double-blind, randomised, placebo-controlled study. Lancet 2000;356(9229):529-534.

314) Joosten KF, de Kleijn ED, Westerterp M et al. Endocrine and metabolic responses in children with meningoccocal sepsis: striking differences between survivors and nonsurvivors. J Clin Endocrinol Metab 2000;85(10):3746-3753.

315) Menon K, Ward RE, Lawson ML, Gaboury I, Hutchison JS, Hebert PC. A prospective multicenter study of adrenal function in critically ill children. Am J Respir Crit Care Med 2010;182(2):246-251.

316). Marquardt DJ, Knatz NL, Wetterau LA, Wewers MD, Hall MW. Failure to recover somatotropic axis function is associated with mortality from pediatric sepsis-induced multiple organ dysfunction syndrome*. Pediatric Critical Care Medicine 2010;11(1):18-25+164.

317). Indyk JA, Candido-Vitto C, Wolf IM et al. Reduced glucocorticoid receptor protein expression in children with critical illness. Hormone research in paediatrics 2013;79:169-178.

318) Boonen E, Vervenne H, Meersseman P et al. Reduced cortisol metabolism during critical illness. N Engl J Med 2013;368(16):1477-1488.

319) Annane D, Bellissant E, Bollaert PE et al. Corticosteroids in the treatment of severe sepsis and septic shock in adults: a systematic review. JAMA 2009;301(22):2362-2375.

320) Wheeler DS, Zingarelli B, Wheeler WJ, Wong HR. Novel pharmacologic approaches to the management of sepsis: targeting the host inflammatory response. Recent patents on inflammation \& allergy drug discovery 2009;3(2):96-112.

321) Oppert M, Schindler R, Husung C et al. Low-dose hydrocortisone improves shock reversal and reduces cytokine levels in early hyperdynamic septic shock. Crit Care Med 2005;33(11):2457-2464.

322) Sarthi M, Lodha R, Vivekanandhan S, Arora NK. Adrenal status in children with septic shock using low-dose stimulation test. Pediatric critical care medicine : a journal of the Society of Critical Care Medicine and the World Federation of Pediatric Intensive and Critical Care Societies 2007;8(1):23-28.

323) Sam S, Corbridge TC, Mokhlesi B, Comellas AP, Molitch ME. Cortisol levels and mortality in severe sepsis. Clin Endocrinol (Oxf) 2004;60(1):29-35.

324) Menon K, McNally D, Choong K, Sampson M. A systematic review and meta-analysis on the effect of steroids in pediatric shock. Pediatr Crit Care Med 2013;14(5):474-480.

325) Zimmerman, J. J., A. Donaldson, et al. (2011). "Real-time free cortisol quantification among critically ill children." Pediatr Crit Care Med 12(5): 525-531. 
326) Hamrahian AH, Oseni TS, Arafah BM. Measurements of serum free cortisol in critically ill patients. N Engl J Med 2004;350(16):1629-1638.

327) Cotton BA, Guillamondegui OD, Fleming SB et al. Increased risk of adrenal insufficiency following etomidate exposure in critically injured patients. Archives of surgery (Chicago, Ill : 1960 ) 2008;143(1):62-67.

328). Li J, Winkler M. Decompensated septic shock in the setting of megace-induced severe adrenal suppression in an otherwise healthy pediatric patient: a case report. Pediatric emergency care 2012;28(8):802-804.

329) Jeschke MG, Williams FN, Finnerty CC et al. The effect of ketoconazole on post-burn inflammation, hypermetabolism and clinical outcomes. PLoS One 2012;7(5):e35465.

330). Sakr Y, Reinhart K, Vincent JL et al. Does dopamine administration in shock influence outcome? Results of the Sepsis Occurrence in Acutely Ill Patients (SOAP) Study. Crit Care Med 2006;34(3):589-597.

331). Aneja R, Carcillo JA. What is the rationale for hydrocortisone treatment in children with infection-related adrenal insufficiency and septic shock? Archives of disease in childhood 2007;92(2):165-169.

332) Marik, P. E., S. M. Pastores, et al. (2008). "Recommendations for the diagnosis and management of corticosteroid insufficiency in critically ill adult patients: consensus statements from an international task force by the American College of Critical Care Medicine." Crit Care Med 36(6): 1937-1949.

333)Annane, D., V. Maxime, et al. (2006). "Diagnosis of adrenal insufficiency in severe sepsis and septic shock." Am J Respir Crit Care Med 174(12): 1319-1326.

334). Lichtarowicz-Krynska EJ, Cole TJ, Camacho-Hubner C et al. Circulating aldosterone levels are unexpectedly low in children with acute meningococcal disease. J Clin Endocrinol Metab 2004;89(3):1410-1414.

335) Hebbar KB, Stockwell JA, Fortenberry JD. Clinical effects of adding fludrocortisone to a hydrocortisone-based shock protocol in hypotensive critically ill children. Intensive care medicine 2011;37(3):518-524.

336) Arafah BM. Hypothalamic pituitary adrenal function during critical illness: limitations of current assessment methods. J Clin Endocrinol Metab 2006;91(10):3725-3745.

337) Jung C, Inder WJ. Management of adrenal insufficiency during the stress of medical illness and surgery. Med $\mathbf{J}$ Aust 2008;188(7):409-413.

338) Padidela R, Hindmarsh PC. Mineralocorticoid deficiency and treatment in congenital adrenal hyperplasia. Int J Pediatr Endocrinol 2010;2010:656925.

339) Sprung CL, Annane D, Keh D et al. Hydrocortisone therapy for patients with septic shock. N Engl J Med 2008;358(2):111-124. 
340) Ng PC, Lee CH, Bnur FL et al. A double-blind, randomized, controlled study of a "stress dose" of hydrocortisone for rescue treatment of refractory hypotension in preterm infants. Pediatrics 2006;117(2):367-375.

341) Lodygensky GA, Rademaker K, Zimine S et al. Structural and functional brain development after hydrocortisone treatment for neonatal chronic lung disease. Pediatrics 2005;116(1):1-7.

342) Baker CF, Barks JD, Engmann C et al. Hydrocortisone administration for the treatment of refractory hypotension in critically ill newborns. Journal of perinatology : official journal of the California Perinatal Association 2008;28(6):412-419.

343) Dix D, Cellot S, Price V et al. Association between corticosteroids and infection, sepsis, and infectious death in pediatric acute myeloid leukemia (AML): results from the Canadian infections in AML research group. Clinical infectious diseases : an official publication of the Infectious Diseases Society of America 2012;55(12):1608-1614.

344) Costello JM, Graham DA, Morrow DF, Potter-Bynoe G, Sandora TJ, Laussen PC. Risk factors for central line-associated bloodstream infection in a pediatric cardiac intensive care unit. Pediatric critical care medicine : a journal of the Society of Critical Care Medicine and the World Federation of Pediatric Intensive and Critical Care Societies 2009;10(4):453-459.

345) Burmester M, Pierce C, Petros A. Disseminated candidiasis after steroid treatment for early neonatal hypotension. Arch Dis Child Fetal Neonatal Ed 2001;85(3):F226.

346) Annane D, Cariou A, Maxime V et al. Corticosteroid treatment and intensive insulin therapy for septic shock in adults: a randomized controlled trial. JAMA 2010;303(4):341-348.

347) Wong, H. R., N. Z. Cvijanovich, et al. (2014). "Corticosteroids are associated with repression of adaptive immunity gene programs in pediatric septic shock." Am J Respir Crit Care Med 189(8): 940-946.

348) Zimmerman JJ, Williams MD. Adjunctive corticosteroid therapy in pediatric severe sepsis: observations from the RESOLVE study. Pediatric critical care medicine : a journal of the Society of Critical Care Medicine and the World Federation of Pediatric Intensive and Critical Care Societies 2011;12(1):2-8.

349) Esteban NV, Loughlin T, Yergey AL et al. Daily cortisol production rate in man determined by stable isotope dilution/mass spectrometry. J Clin Endocrinol Metab 1991;72(1):39-45.

350) Kerrigan JR, Veldhuis JD, Leyo SA, Iranmanesh A, Rogol AD. Estimation of daily cortisol production and clearance rates in normal pubertal males by deconvolution analysis. J Clin Endocrinol Metab 1993;76(6):1505-1510.

351) Kenny FM, Preeyasombat C, Migeon CJ. Cortisol production rate. II. Normal infants, children, and adults. Pediatrics $1966 ; 37(1): 34-42$.

352) Kenny FM, MALVAUX P, Migeon CJ. Cortisol production rate in newborn babies, older infants, and children. Pediatrics $1963 ; 31: 360-373$.

353) Briegel J, Forst H, Haller M et al. Stress doses of hydrocortisone reverse hyperdynamic septic shock: a prospective, randomized, double-blind, single-center study. Crit Care Med 1999;27(4):723-732. 
354) Pizarro CF, Troster EJ. Adrenal function in sepsis and septic shock. Jornal de pediatria 2007;83(5 Suppl):S155-S162.

355) Roberts JD Jr., Rinnai JR, Main FC 3rd et al. Inhaled nitric oxide and persistent pulmonary hypertension of the newborn. The Inhaled Nitric Oxide Study Group N Engl J Med 1997;336(9):605-10

356) Inhaled Nitric Oxide Study Group. Inhaled nitric oxide in full term and nearly full-term infants with hypoxic respiratory failure. $N$ Engl J Med 1997; 336;597-604.

357) Wung JT, James LS, Kilchevsky E. Management of infants with severe respiratory failure and persistence of the fetal circulation, without hyperventilation. Pediatrics 1985; 76(4):488-94

358) Drummond WH. Gregory GA, Heyman MA et al. The independent effects of hyperventilation, tolazoline, and dopamine on infants with persistent pulmonary hypertension need to be taken into consideration when using these drugs. J Pediatr 1981; 98(4):60311

359) Drummond WH. Use of cardiotonic therapy in the management of infants with PPHN. Clin Perinatol 1984; 11(3):715-28

360) Gouyon JB, Francoise M. Vasodilators in persistent pulmonary hypertension of the newborn: a need for optimal appraisal of efficacy. Dev Pharmacol Ther 1992; 19(2-3):62-8

361) Meadow WL, Meus PJ Hemodynamic consequences of tolazoline in neonatal group B streptococcal bacteremia: an animal model. Pediatr Res 1984; 18(10):960-5

362) Sandor GG, Macnab AJ, Akesode FA et al. Clinical and echocardiographic evidence suggesting afterload reduction as a mechanism of action of tolazoline in neonatal hypoxemia Pediatr Cardiol 1984; 5(2):93-9

363) Benitz WE, Malachowski N, Cohen RS et al. Use of sodium nitroprusside in neonates: efficacy and safety. J Pediatr 1985; 106(1):102-10

364) McNamara PJ, Laique F, Muang - In S, Whyte HE Milrinone improves oxygenation in neonates with severe persistent pulmonary hypertension of the newborn J Crit Care 2006 21(2):217-222

365) Bassler D, Choong K, McNamara P, Kirpalani H Neonatal persistent pulmonary hypertension treated with milrinone: four case reports Biol Neonate 2006 89(1):1-5

366) Rahis N, Morin FC $3^{\text {rd }}$, Swartz DD, Ryan RM, Wynn KA, Wang H, Lakshminrusimha S, kumar VH Effects of prostacyclin and milrinone on pulmonary hemodynamics in newborn lambs with persistent pulmonary hypertension induced by ductal ligation Pediatr Res 2006 60(5):624-629

367) Cincheiro Guisan A, Sousa Rouco C, Suarez Traba B, Paradela Carreira A, Ocampo Cardalda S, Antelo Cotizas J Inhaled Iloprost: a therapeutic alternative for persistent pulmonary hypertension of the newborn Ann Pediatr 2005;63(2):175-176.

368)Ehlen M, Wiebe B Iloprost in persistent pulmonary hypertension of the newborn Cardiol Young 2003;13(4):361-363

369) Patole S, Lee J, Buettner P, Whitehall J Improved oxygenation following adenosine infusions in persistent pulmonary hypertension of the newborn Biol Neonate 1998;74(5):345-350

370)Konduri GG, Garcia DC, Kazzi NJ, Shankaran S Adenosine infusion improves oxygenation in term infants with respiratory failure Pediatrics 1996;97(3):295-300

371)Motti A, Tissot C, Romensberger PC, Prina-Rousso A, Aggoun Y, Berner M, Beghetti M, da Cruz E Intravenous adenosine for refractory pulmonary hypertension in a low-birthweight premature newborn: a potential new drug for rescue therapy Pediatr Crit Care Med 2006;7(4):380-382.

372) Ng C, Franklin O, Vaidya M, Pierce C, Petros A Adenosine infusion for the management of persistent pulmonary hypertension of the newborn Pediatr Crit Care Med 2004;5(1):10-13

373) Bartlett RH, Roloff DW, Custer JR, et al. Extracorporeal life support: the University of Michigan experience JAMA 2000; 283(7):904-8 
374) Meyer DM, Jessen ME. Results of extracorporeal membrane oxygenation in neonates with sepsis. The Extracorporeal Life Support Organization experience. J Thorac Cardiovasc Surg. 1995; 109(3):419-425

375) Bernbaum J, Schwartz IP, Gerdes M. et al. Survivors of extracorporeal oxygenation at 1 year of age: the relationship of primary diagnosis with health and neurodevelopmental sequalae. Pediatrics 1995; 96(5 Pt 1):907-13

376) Anonymous. The collaborative UK ECMO (Extracorporeal Membrane Oxygenation) trial: follow-up to 1 year of age. Pediatrics 1998; 101(40):E1.

377) Meyer DM, Jessen ME, Results of extracorporeal membrane oxygenation in children with sepsis. The Extracorporeal Life Support Organization. Ann Thorac Surg 1997;63(3):756-61

378) Goldman AP, Kerr SJ, Butt W. Extracorporeal support for intractable cardiorespiratory failure due to meningococcal disease. Lancet 1997; 349 (9050): 466-9

379) Beca J. Butt W. Extracorporeal membrane oxygenation for refractory septic shock in children. Pediatrics 1994; 93(5):726-9

380) Dalton HJ, Siewers, Fuhrman BP et al. Extracorporeal membrane oxygenation for cardiac rescue in children with severe myocardial dysfunction. Crit Care Med 1997; 21(7):1020-1028

381) Hallin GW, Simpsom SQ, Crowell RE. Cardiopulmonary manifestations of Hantavirus pulmonary syndrome. Crit Care Med 1996; 24(2):252-8

382) Crowley MR, Katz RW, Kessler R et al. Successful treatment of adults with Hantavirus pulmonary syndrome with ECMO Crit Care Med 1998:26(2), 409-14.

383)MacLaren G, Butt W, Best D, Donath S: Central extracorporeal membrane oxygenation for refractory pediatric septic shock.

Pediatric critical care medicine : a journal of the Society of Critical Care Medicine and the World Federation of Pediatric Intensive and Critical Care Societies 2011, 12(2):133-136.

384)Maclaren G, Butt W, Best D, Donath S, Taylor A: Extracorporeal membrane oxygenation for refractory septic shock in children: one institution's experience. Pediatric critical care medicine : a journal of the Society of Critical Care Medicine and the World Federation of Pediatric Intensive and Critical Care Societies 2007, 8(5):447-451.

385)Brechot N, Luyt CE, Schmidt M, Leprince P, Trouillet JL, Leger P, Pavie A, Chastre J, Combes A: Venoarterial extracorporeal membrane oxygenation support for refractory cardiovascular dysfunction during severe bacterial septic shock. Critical care medicine 2013, 41(7):1616-1626.

386)Smalley N, MacLaren G, Best D, Paul E, Butt W: Outcomes in children with refractory pneumonia supported with extracorporeal membrane oxygenation. Intensive care medicine 2012, 38(6):1001-1007.

387) Jeffers A, Gladwin MT, Kim-Shapiro DB Computation of plasma hemoglobin nitric oxide scavenging in hemolytic anemias Free Radic Med 2006 41(10):1557-1565

388) Jackson EK, Koehler M, Mi Z, Dubey RK, Tofovic SP, Carcillo JA, Jones GS Possible role for adenosine deaminase in vasoocclusive disease J Hypertens 1996 14(1):19-29

389) Lou S, MacLaren G, Best D, Delzoppo C, Butt W: Hemolysis in pediatric patients receiving centrifugal-pump extracorporeal membrane oxygenation: prevalence, risk factors, and outcomes. Critical care medicine 2014, 42(5):1213-1220.

390) Pfaender M: Hemodynamics in the Extracorporeal Aortic Cannula: Review of Factors Affecting Choice of the Appropriate Size. The Journal of extra-corporeal technology 1981, 13(4):224-232.

391) Mulholland JW, Massey W, Shelton JC: Investigation and quantification of the blood trauma caused by the combined dynamic forces experienced during cardiopulmonary bypass. Perfusion 2000, 15(6):485-494. 

al: Surviving sepsis campaign: international guidelines for management of severe sepsis and septic shock: 2012. Critical care medicine 2013, 41(2):580-637.

393) Fortenberry JD, Paden ML, Goldstein SL: Acute kidney injury in children: an update on diagnosis and treatment. Pediatric clinics of North America 2013, 60(3):669-688.

394) Sutherland SM, Zappitelli M, Alexander SR, Chua AN, Brophy PD, Bunchman TE, Hackbarth R, Somers MJ, Baum M, Symons JM et al: Fluid overload and mortality in children receiving continuous renal replacement therapy: the prospective pediatric continuous renal replacement therapy registry. American journal of kidney diseases : the official journal of the National Kidney Foundation 2010, 55(2):316-325.

395) Goldstein SL, Somers MJ, Baum MA, Symons JM, Brophy PD, Blowey D, Bunchman TE, Baker C, Mottes T, McAfee N et al: Pediatric patients with multi-organ dysfunction syndrome receiving continuous renal replacement therapy. Kidney international 2005, 67(2):653-658.

396) Foland JA, Fortenberry JD, Warshaw BL, Pettignano R, Merritt RK, Heard ML, Rogers K, Reid C, Tanner AJ, Easley KA: Fluid overload before continuous hemofiltration and survival in critically ill children: a retrospective analysis. Critical care medicine 2004, 32(8):1771-1776.

397) Investigators RRTS, Bellomo R, Cass A, Cole L, Finfer S, Gallagher M, Lo S, McArthur C, McGuinness S, Myburgh J et al: Intensity of continuous renal-replacement therapy in critically ill patients. The New England journal of medicine 2009, 361(17):1627-1638.

398) Van Wert R, Friedrich JO, Scales DC, Wald R, Adhikari NK, University of Toronto Acute Kidney Injury Research G: Highdose renal replacement therapy for acute kidney injury: Systematic review and meta-analysis. Critical care medicine 2010, 38(5):1360-1369.

399) Booy R, Habibi P, Nadel S, de Munter C, Britto J, Morrison A, Levin M, Meningococcal Research G: Reduction in case fatality rate from meningococcal disease associated with improved healthcare delivery. Archives of disease in childhood 2001, 85(5):386-390.

400) Fortenberry JD, Paden ML: Extracorporeal therapies in the treatment of sepsis: experience and promise. Seminars in pediatric infectious diseases 2006, 17(2):72-79.

401) Smith OP, White B, Vaughan D, Rafferty M, Claffey L, Lyons B, Casey W: Use of protein-C concentrate, heparin, and haemodiafiltration in meningococcus-induced purpura fulminans. Lancet 1997, 350(9091):1590-1593.

402) Ratanarat R, Brendolan A, Ricci Z, Salvatori G, Nalesso F, de Cal M, Cazzavillan S, Petras D, Bonello M, Bordoni V et al: Pulse high-volume hemofiltration in critically ill patients: a new approach for patients with septic shock. Seminars in dialysis 2006, 19(1):69-74.

403) Piccinni P, Dan M, Barbacini S, Carraro R, Lieta E, Marafon S, Zamperetti N, Brendolan A, D'Intini V, Tetta C et al: Early isovolaemic haemofiltration in oliguric patients with septic shock. Intensive care medicine 2006, 32(1):80-86.

404) Bock KR: Renal replacement therapy in pediatric critical care medicine. Current opinion in pediatrics 2005, 17(3):368-371.

405) Bridges BC, Hardison D, Pietsch J: A case series of the successful use of ECMO, continuous renal replacement therapy, and plasma exchange for thrombocytopenia-associated multiple organ failure. Journal of pediatric surgery 2013, 48(5):1114-1117. 406) Szczepiorkowski ZM, Winters JL, Bandarenko N, Kim HC, Linenberger ML, Marques MB, Sarode R, Schwartz J, Weinstein R, Shaz BH: Guidelines on the use of therapeutic apheresis in clinical practice--evidence-based approach from the Apheresis Applications Committee of the American Society for Apheresis. Journal of clinical apheresis 2010, 25(3):83-177. 
Critical care medicine 2013, 41(9):2209-2220.

408) De Simone N, Racsa L, Bevan S, Matevosyan K, Valley T, Girod C, Sarode R: Therapeutic plasma exchange in the management of sepsis and multiple organ dysfunction syndrome: a report of three cases. Journal of clinical apheresis 2014, 29(2):127-131.

409) Demirkol D, Yildizdas D, Bayrakci B, Karapinar B, Kendirli T, Koroglu TF, Dursun O, Erkek N, Gedik H, Citak A et al: Hyperferritinemia in the critically ill child with secondary HLH/sepsis/MODS/MAS: what is the treatment? Critical Care 2012, 16(2):R52.

410) Qu L, Kiss JE, Dargo G, Carcillo JA: Outcomes of previously healthy pediatric patients with fulminant sepsis-induced multisystem organ failure receiving therapeutic plasma exchange. Journal of clinical apheresis 2011, 26(4):208-213.

411) Sevketoglu E, Yildizdas D, Horoz OO, Kihtir HS, Kendirli T, Bayraktar S, Carcillo JA: Use of therapeutic plasma exchange in children with thrombocytopenia-associated multiple organ failure in the Turkish thrombocytopenia-associated multiple organ failure network. Pediatric critical care medicine : a journal of the Society of Critical Care Medicine and the World Federation of Pediatric Intensive and Critical Care Societies 2014, 15(8):e354-359.

412) Churchwell KB, McManus ML, Kent P, Gorlin J, Galacki D, Humphreys D, Kevy SV: Intensive blood and plasma exchange for treatment of coagulopathy in meningococcemia. Journal of clinical apheresis 1995, 10(4):171-177.

413) van Deuren M, Frieling JT, van der Ven-Jongekrijg J, Neeleman C, Russel FG, van Lier HJ, Bartelink AK, van der Meer JW: Plasma patterns of tumor necrosis factor-alpha (TNF) and TNF soluble receptors during acute meningococcal infections and the effect of plasma exchange. Clinical infectious diseases : an official publication of the Infectious Diseases Society of America 1998, 26(4):918-923.

414) van Deuren M, Santman FW, van Dalen R, Sauerwein RW, Span LF, van der Meer JW: Plasma and whole blood exchange in meningococcal sepsis. Clinical infectious diseases : an official publication of the Infectious Diseases Society of America 1992, 15(3):424-430.

415) Yildirim I, Ceyhan M, Bayrakci B, Uysal M, Kuskonmaz B, Ozaltin F: A case report of thrombocytopenia-associated multiple organ failure secondary to Salmonella enterica serotype Typhi infection in a pediatric patient: successful treatment with plasma exchange. Therapeutic apheresis and dialysis : official peer-reviewed journal of the International Society for Apheresis, the Japanese Society for Apheresis, the Japanese Society for Dialysis Therapy 2010, 14(2):226-229.

416) Nguyen TC, Han YY, Kiss JE, Hall MW, Hassett AC, Jaffe R, Orr RA, Janosky J, Carcillo JA: Intensive plasma exchange increases a disintegrin and metalloprotease with thrombospondin motifs-13 activity and reverses organ dysfunction in children with thrombocytopenia-associated multiple organ failure*. Critical care medicine 2008, 36(10):2878-2887.

417) Long EJ, Shann F, Pearson G, Buckley D, Butt W: A randomised controlled trial of plasma filtration in severe paediatric sepsis. Critical care and resuscitation : journal of the Australasian Academy of Critical Care Medicine 2013, 15(3):198-204.

418) Hirabayashi K, Shiohara M, Saito S, Tanaka M, Yanagisawa R, Tsuruta G, Fukuyama T, Hidaka Y, Nakazawa Y, Shimizu T et al: Polymyxin-direct hemoperfusion for sepsis-induced multiple organ failure. Pediatric blood \& cancer 2010, 55(1):202-205.

419) Hirakawa E, Ibara S, Tokuhisa T, Hiwatashi S, Hayashida Y, Maede Y, Matsui T, Nakazawa Y, Inoue T, Kodaira Y: Septic neonate rescued by polymyxin B hemoperfusion. Pediatrics international : official journal of the Japan Pediatric Society 2013, 55(3):e70-72.

420) Nakamura T, Sato E, Fujiwara N, Kawagoe Y, Egawa Y, Ueda Y, Koide H: Polymyxin B-immobilized fiber hemoperfusion in a high school football player with septic shock caused by osteitis pubis. ASAIO journal 2011, 57(5):470-472. 
421) Haque IU, Zaritsky AL: Analysis of the evidence for the lower limit of systolic and mean arterial pressure in children. Pediatric critical care medicine : a journal of the Society of Critical Care Medicine and the World Federation of Pediatric Intensive and Critical Care Societies 2007, 8(2):138-144.Haque and Zaritsky 